\title{
Validating a Measure of Client Change
}

by

\author{
Taylor M. Carty
}

A thesis submitted to the Faculty of Graduate and Postdoctoral Affairs in partial fulfillment of the requirements for the degree of

\author{
Master of Arts \\ in \\ Psychology \\ Carleton University \\ Ottawa, Ontario \\ (C) 2019 \\ Taylor M. Carty
}




\begin{abstract}
While risk assessment has been most used as an evaluation of which offenders are most likely to re-offend, there are also various models explaining the process of client change which is thought to further describe who is at risk. While elements of change have been validated, there is no one assessment which assesses a client's position in the process of changing from an antisocial offender into a prosocial individual. The current research therefore attempted to validate the Client Change Scale (CCS), which is a theoretically and empirically supported measure for quantifying client change. Parole decision with offenders in the California parole system was used as a proxy measure of recidivism. Results indicated that while the CCS was reliable and correlated with risk, it didn't provide a good model and didn't predict decision independently. Further research is needed to assess the CCS' ability to predict recidivism directly for differing populations.
\end{abstract}




\section{Acknowledgements}

First and foremost, I would like to thank my supervisor, Dr. Ralph Serin, for providing me with the opportunity to complete this research and for his invaluable support and guidance, not only in completing my thesis but in various other professional aspects of my life. I am also thankful to Dr. Craig Bennell for his advice regarding my prospectus and for his assistance with data analysis for multiple research projects. Additionally, I owe thanks to Karen Jones for her assistance in rating parole portfolios.

I would also like to extend my gratitude to my friend and colleague, Gabrielle Lucente, who assisted me in editing, provided me with instrumental resources, and listened to me attempting to work through various statistical and theoretical problems. A thank you is also owed to my parents and family who, while they never had any idea what I was talking about or what I was doing, were always supportive. Finally, to my fiancé, Jeremy Shaw, who not only listened to me talk constantly about my thesis for the past two years but also purchased and read a book on statistics to try to understand what I was doing.

I would not have accomplished the same goals without each of your contributions. Thank you. 


\section{Table of Contents}

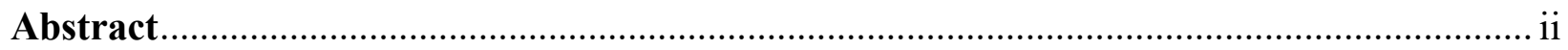

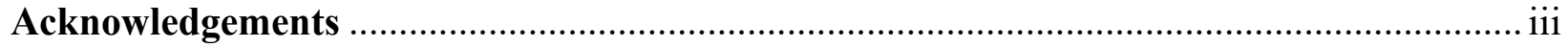

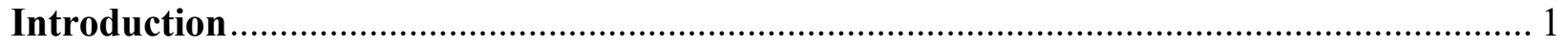

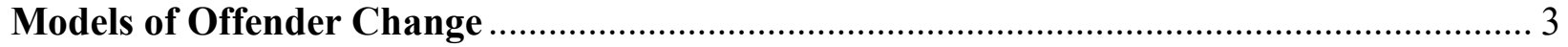

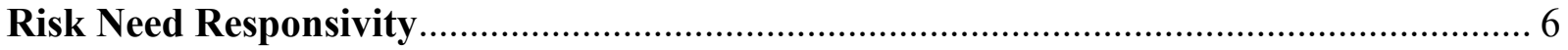

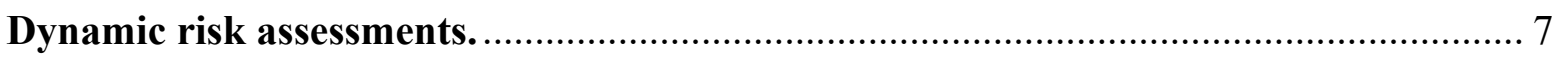

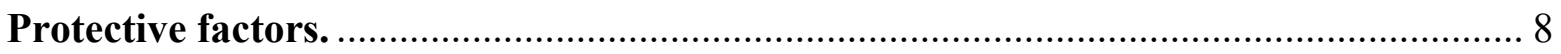

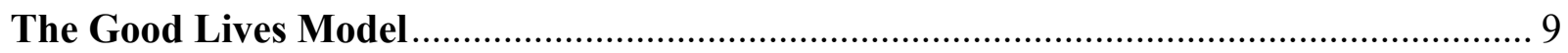

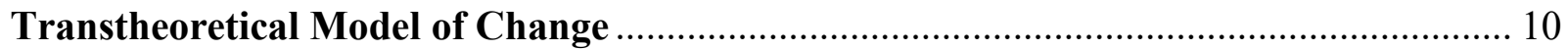

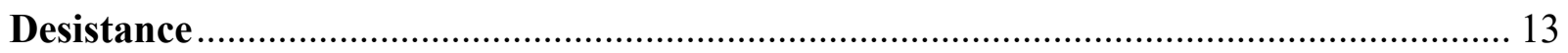

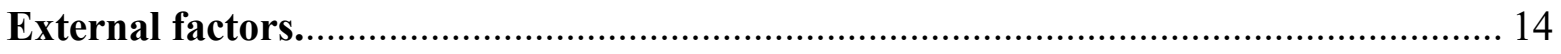

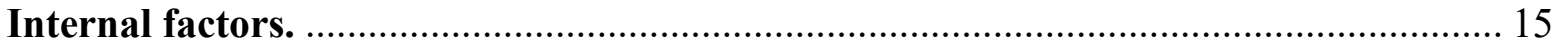

Transitional Model of Offender Change ............................................................... 16

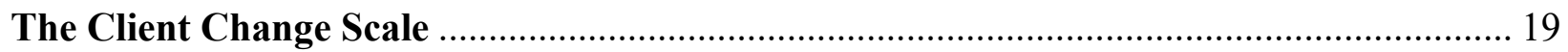

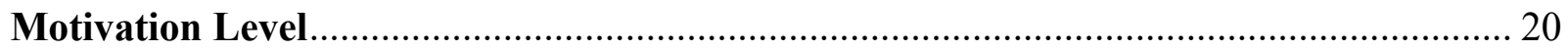

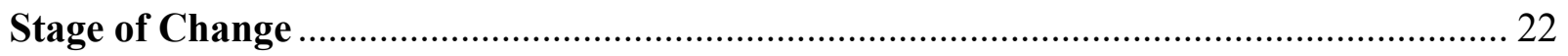

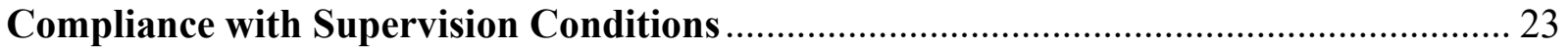

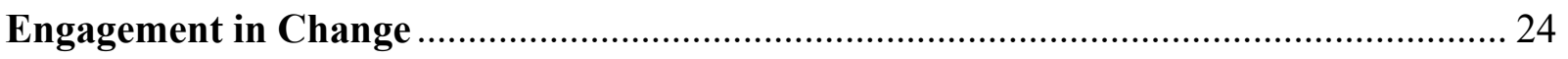

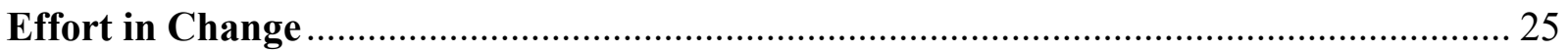

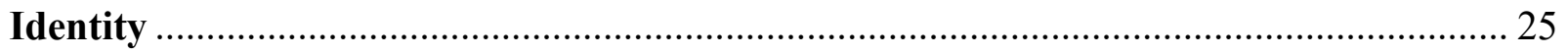

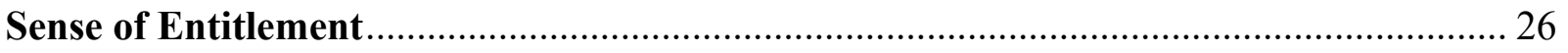

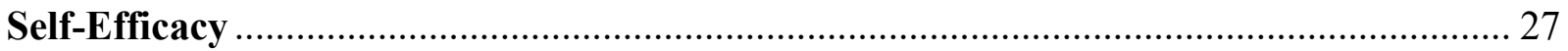

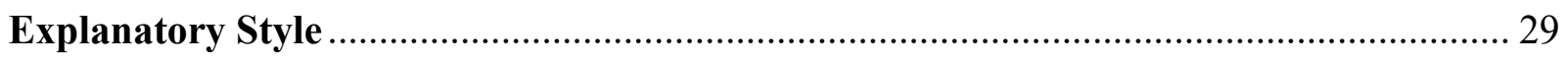

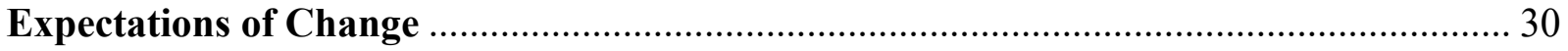

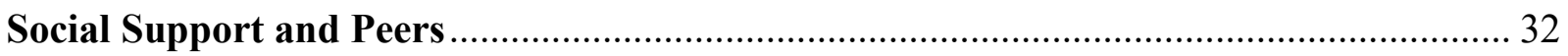

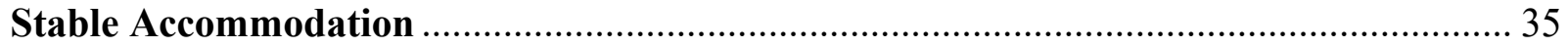




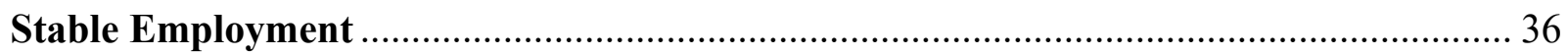

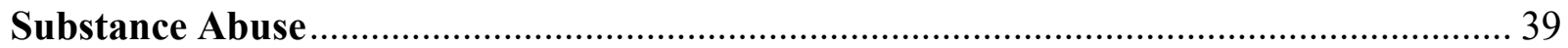

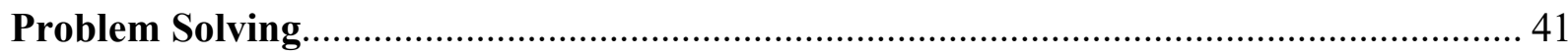

Self-Regulation/Affect Management ……………………............................................. 42

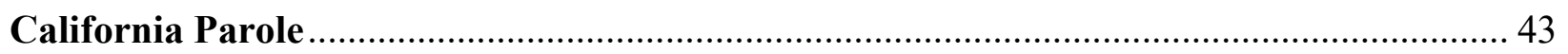

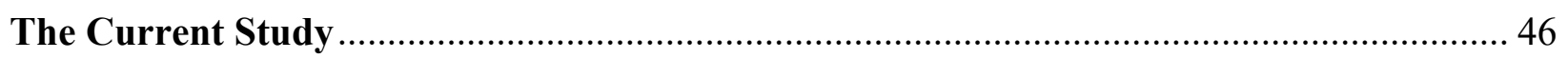

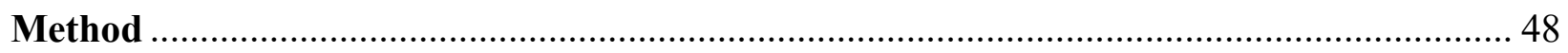

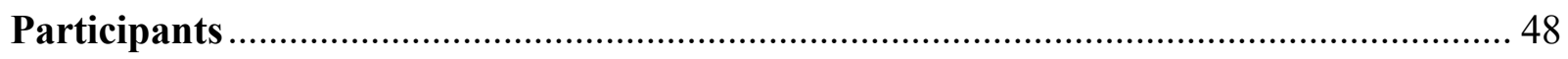

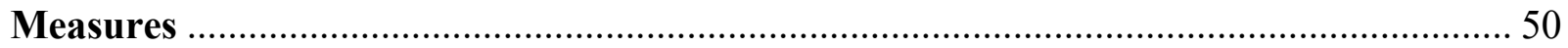

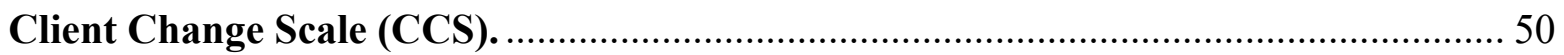

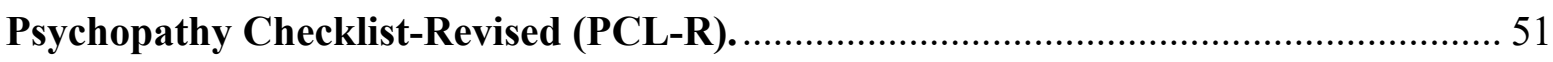

Historical Risk Management Version Three $\left(\right.$ HCR-20 $\left.{ }^{\mathrm{V} 3}\right)$. ........................................ 52

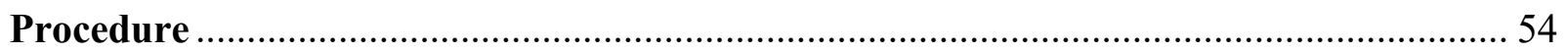

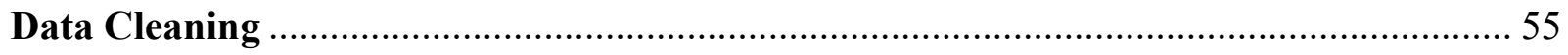

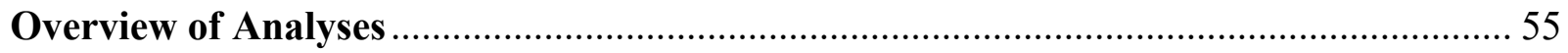

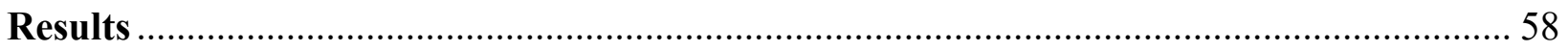

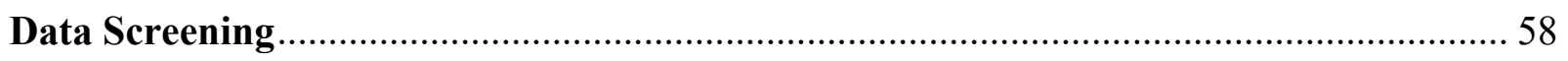

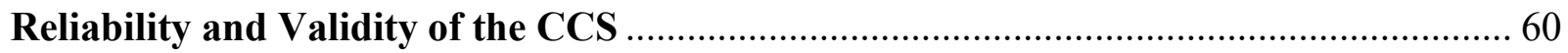

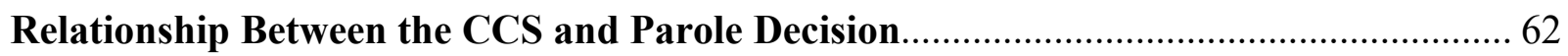

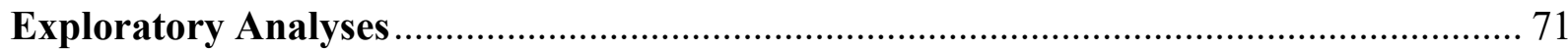

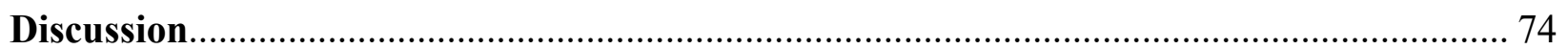

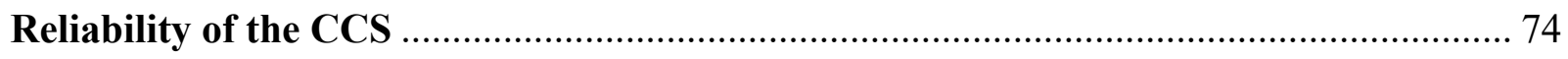

Relationship Between the CCS and Parole Decision........................................................ 75

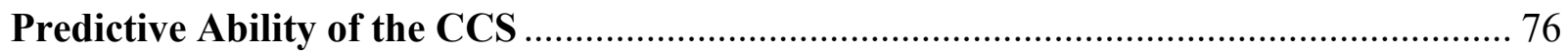

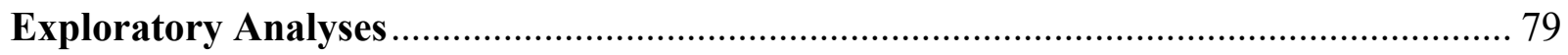

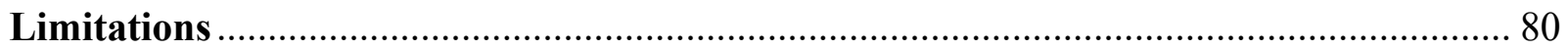




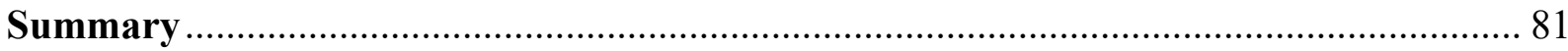

Conclusions and Directions for Future Research....................................................... 82

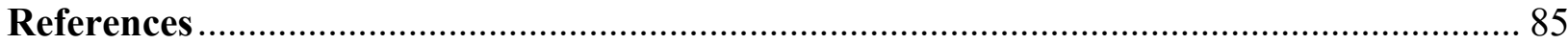

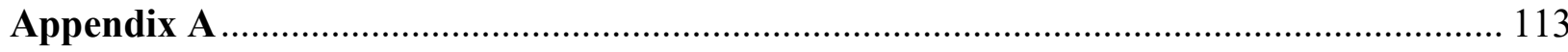

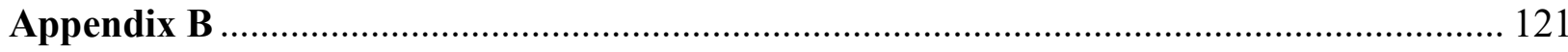

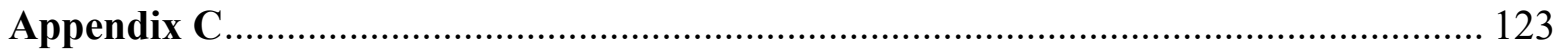




\section{List of Tables}

Table 1 Demogrpahic Characteristics ............................................................................... 49

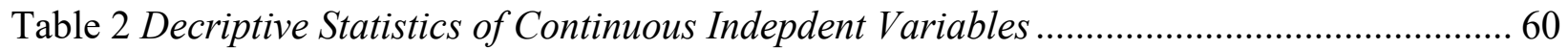

Table 3 CCS Item Total Correlations and Cronbach's Alphas if Item Deleted ........................ 60

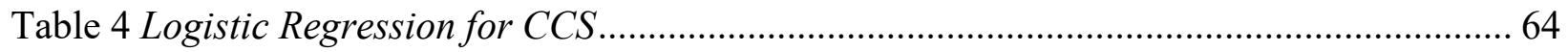

Table 5 Logistic Regression for CCS after Controlling for Age, Race, Sex, and Risk Level ....... 67

Table 6 AUC Statistics for Age, Race, Sex, PCL-R, and CCS Scores ..................................... 70

Table 7 Mean Comparisons and Kruskal Wallis Results Between Groups ............................... 73 


\section{List of Figures}

Figure 1 The transitional model of offender change from Serin et al., 2010 ........................ 18

Figure 2 Relationship Between Client Change Scale and PCL-R ........................................ 62

Figure 3. Relationship between Client Change Scores and Hearing Decision.......................... 63

Figure 4. ROC curve for CCS in predicting parole decision............................................... 68

Figure 5. ROC curves for individual variables of age, race, sex, PCL-R scores, and CCS in

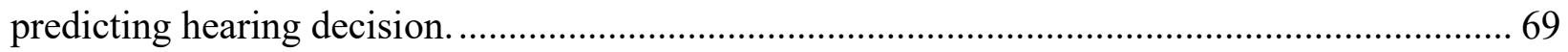

Figure 6. ROC curve for the additive predictive accuracy of age, sex, race, PCL-R scores, and

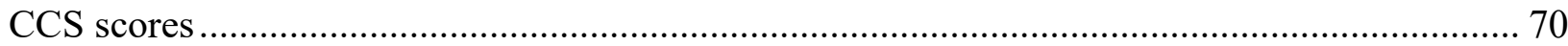




\section{List of Appendices}

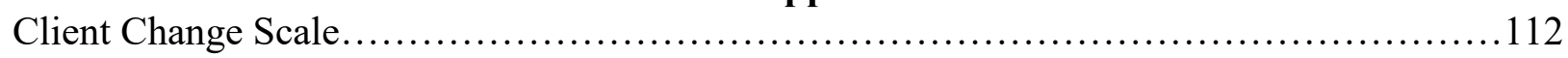

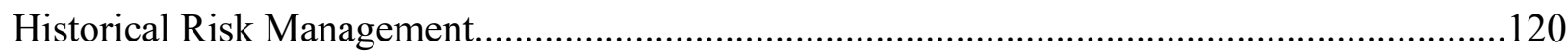

Psychopathy Checklist Revised...................................................... 122 


\section{Introduction}

Parole decision making is a difficult task that involves balancing the protection of society, the potential re-integration of an offender, and fiscal responsibility (Serin \& Gobeil, 2010). In an effort to reduce the influence of external factors and increase evidence-based practice surrounding parole decisions, Serin and Gobeil (2014) initiated the Parole Decision Making Framework in three states: Ohio, Connecticut, and Kansas. The framework was found to distinguish, above the ability of a risk assessment, whether an individual would receive parole or not (Wardrop, Serin \& Rentler, 2019). Moreover, the framework allowed for consistent and transparent parole decisions which would insulate parole boards if parolees were to re-offend. One of the seven factors involved in the framework was the analysis of offender change: whether an offender had benefitted from programming or otherwise changed during his sentencing period. However, initial research into 100 offenders in each of the above-mentioned states found that there was limited information from which to attain data about offender change (Serin \& Gobeil, 2014). An instrument designed to measure offender change which relates to decisions made by parole board members could therefore assist in fulfilling this aspect of parole decision making. The use of such an instrument could enhance the transparency and consistency of parole decision making further and assist decision makers to better identify offenders for whom incarceration has had a salutary impact.

The California Department of Corrections and Rehabilitation (2019ab) mandates that the purpose of the parole process is to both protect and preserve public safety while providing access to due process for offenders. There are various factors that are taken into consideration when determining parole suitability (Caplan, 2007). These include factors of the offense (such as the number of victims or the heinous nature of the offence), criminal history, age, institutional 
behaviour, and plans for the future (California office of administrative law, 2019). Moreover, upon finding an offender unsuitable for parole, the Board of Parole must provide evidence to support their findings. The limited evidence regarding the validity of measures of client change (Serin et al., 2013), potentially leads to less than optimal accuracy in these release decisions. Positive client change is viewed to reduce risk and as mentioned, is an important factor considered in early release decisions (Serin et al., 2016) and in determining conditions of parole release (California Office of Administrative Law, 2019). However, without a validated measure of client change there is no reliable and valid way of identifying and facilitating client success. Moreover, a generic measure of client change that focuses on general indicators of change not specific to any particular treatment will allow researchers and practitioners to measure change processes across various interventions that are relevant to the majority of justice-involved individuals.

This research will examine the relationship between client change constructs, risk, and parole decisions. A validated measure of client change would augment current parole decision making and provide empirically substantiated evidence for parole decisions as per the California Code of Regulations, title 15, section 2281 (California office of administrative law, 2019). Clients who are incarcerated for an extended period of time typically produce lower recidivism rates, specifically about $12.4 \%$ five years after release (Axford \& Young, 2014). In this way, a measure of client change which has been validated with parole decision as an outcome can potentially be extended to recidivism rates. The parole process instigated by the California Board of Parole Hearings (CBPH) provides detailed parole portfolios (also known as Comprehensive Risk Assessments), which supply needed information on various factors of client change that will be measured in this study. 
Underscoring a transitional model of offender change (Serin, Lloyd \& Hanby, 2010), this research will incorporate key aspects of client motivation, interpersonal style (agency and identity) and competency to better understand client change. These constructs reflect dynamic risk factors that have currently been demonstrated to be sensitive to change and to inform client outcome (Lowenkamp, Johnson, Trevino, \& Serin, 2016; Serin, Chadwick, \& Lloyd, 2016). Importantly, dynamic risk assessments provide incremental predictive validity relative to static measures (Campbell, French, \& Gendreau, 2009), which is germane to parole decision making. Moreover, the interpersonal style constructs have been successfully incorporated into a dynamic risk measure (Dynamic Risk Assessment for Offender Re-Entry; DRAOR, Serin, 2017) which has demonstrated validity in identifying client success in a community context (Serin et al., 2016; Lowenkamp et al., 2016; Yesberg \& Polaschek, 2014). The resultant measure of client change, titled the Client Change Scale (CCS) will be applied to comprehensive clinical risk assessments completed for offenders who were considered for parole suitability by the California Board of Parole. The resulting CCS scores will be related to client outcome in terms of the parole decision made.

\section{Models of Offender Change}

Risk assessment, traditionally driven by static risk factors, is the current standard by which researchers and practitioners assess the likelihood of an individual re-offending (Andrews \& Bonta, 2010; Hanson, 2009; Serin \& Lowenkamp, 2015). More recently, dynamic and protective factors have been assessed in their relation to re-offending (Serin, Chadwick \& Lloyd, 2016; Yesberg \& Polaschek, 2015). Dynamic factors are those that can change whereas static factors cannot (Andrews \& Bonta, 2007; Andrews \& Bonta, 2010). Protective factors are factors that putatively reduce the likelihood of re-offending (Fougere \& Daffern, 2011; Losel \& 
Farrington, 2012; Polaschek, 2016). Beyond risk assessment, there are various models proposed to explain the process of offender change and to more fully describe who is at risk. These models will be discussed in terms of providing context for the new Client Change Scale (CCS) being examined in this study.

Theories of behavioural change are generally divided into two categories: motivation theories and action theories (Casey, in press). The primary differentiation between motivation and action theories is that the former attempts to explain behaviour in an individual who is not motivated, while the latter attempts to explain behaviour for individuals who are already motivated (Casey, in press). An example of a motivation theory would be Social Cognitive Theory (SCT; Bandura, 2001) whereas an example of an action theory would be the Transtheoretical Model of Change (TTM: Prochaska \& Diclemente, 1983).

Motivation as a factor itself is hypothesized to encourage offenders in instigating, maintaining, and engaging in the behavioural change process which is required to decrease and ultimately eliminate offending (McMurran and Ward, 2010). This makes motivation central to many change theories. Research into motivation and treatment readiness also represent a shift in focus to offender strengths rather than detriments (McMurran \& Ward, 2010). Various models of treatment readiness with offenders theorize and illustrate the interplay between motivation for change, as well as effort and engagement in the change process (Mossière \& Serin, 2014; McMurran \& Ward, 2010).

Several of the primary concepts involved in the motivational theory of behavioural change; SCT are also highlighted as key concepts in Andrews and Bonta's (2010) General Personality and Cognitive Social Learning Perspective (GPCSL). In particular, these include the 
identification of the costs of criminality and the benefits of a pro-social lifestyle. Self-efficacy (i.e. an individual's belief in their ability to successfully complete behavioural change) is also relevant. Further, both theories highlight that outcome expectations effect the costs and benefits of criminal and non-criminal behaviour which influences change. Hence, outcome expectations are core elements in offender change programs. Moreover, proximal and distal goals provide directions for behaviour change. Similarly, broad prosocial goals which are valued by the person facilitate motivation, while personal goals provide incentives. Finally, perceived facilitators and impediments effect the personal and situational factors that, in combination with the Criminal Justice System, can potentially regulate behaviour (Casey, in press).

The GPCSL and the SCT both highlight the reciprocal relationship between the person, their environment, and their situation (Andrews \& Bonta, 2010; Bandura, 2001). These theories emphasize many factors that are purported to be involved with reductions in offending. [Selfefficacy, for example, has been illustrated to be predictively related to re-offending in various studies (e.g. (Bahr, Harris, Fisher \& Armstrong, 2010; Serin, Lloyd, \& Hanby, 2010; Serin \& Lloyd, 2009).] Moreover, central to offender change in GPCSL is the shift in contingencies whereby the benefits of prosocial behaviour outweigh the costs of crime (Bonta \& Andrews, 2007). The GPCSL was the theoretical basis of Andrews, Bonta, and Hoge's (1990) principles of effective treatment, Risk Need and Responsivity (RNR), which is one of the most widely accepted and empirically validated of correctional models for the assessment and treatment of offenders (Polaschek, 2012; Ward, Mesler, \& Yates, 2007). 


\section{Risk Need Responsivity}

There are three basic tenants of the RNR model; the first of these tenants has to do with "Risk." This factor of RNR states that the amount of intervention administered to an offender must be tailored to the individuals' risk of re-offending (measured through validated risk assessment). The second factor of the model, need, specifies that criminogenic needs must be analyzed and targeted in treatment (Andrews, Bonta, \& Hoge, 1990; Andrews \& Bonta, 2006, Bonta \& Andrews, 2007). Criminogenic needs refer to changeable risk factors that are moderately predictive of criminal activity, versus non-criminogenic needs which are changeable risk factors that are weakly predictive of criminal activity (Andrews \& Bonta, 2010; Ægisdóttir, , White, Spengler, Maugherman, Anderson, Cook, \& Rush, 2006; Grove, Zald, Lebow, Snitz, \& Nelson, 2000). Finally, responsivity refers to the idea that in order to maximize an individual's benefit from treatment the program needs to use a cognitive-behavioural intervention style and be personalized to the learning style, motivation, abilities and strengths of the offender (Andrews, Bonta, \& Hoge, 1990; Andrews, Bonta, \& Wormith, 2006; Bonta \& Andrews, 2007).

There is evidence that adhering to RNR principles yields the greatest reductions in reoffending (Bourgon, Bonta, Rugge, Scott \& Yessine, 2010; Smith, et al., 2009). Specifically, Smith and colleagues (2009) examined 21 reviews of quantitative analyses comparing treatment programs adhering to the need principle to those without and found that when treatments adhered to this principle the effect size ranged from an $r=.20$ to an $r=.30$ compared to $r$ 's ranging from -.01 to .04 when the need principle was not followed. Therefore, RNR programming has an empirically quantitative influence on offender recidivism. Of note, the CCS focuses on the need principle; that is, the identification of salient needs in terms of reduced propensity for criminal conduct. 


\section{Dynamic risk assessments.}

The GPCSL-based RNR principles lead to the introduction of risk assessments wherein clinical professionals would analyze who required further assessment and supervision (Bonta \& Anrews, 2007). The first generation of risk assessment utilized only clinical judgement with little external evidence to support decisions. Unsurprisingly, these risk assessments were found to have little utility, so evidence-based risk assessments were introduced (Bonta \& Andrews, 2007). It quickly became clear that these evidence-based assessments predicted criminal behaviour better than unstructured professional judgement (Bonta \& Andrews, 2007). More recently, these risk assessments have become dynamic so as to include changeable factors. These dynamic risk measurements analysed offenders' current and fluid situation with items probing such circumstances as emotional states, employment and relationships. Dynamic risk assessments allow correctional staff to reassess risk over time to inform changes in risk to re-offend. Ideally, such dynamic assessments could reflect offender change and could be used to examine the effectiveness of treatment (Andrews \& Bonta, 2007). Nonetheless, dynamic risk assessments fail to analyze general change factors based on the need principle (Serin \& Lloyd, 2009).

In terms of risk, studies have found that prediction of risk is best when both static and dynamic factors are measured (Brown, Amand, \& Zamble, 2009; Campbell et al., 2009; Lowenkamp et al., 2016). Additionally, some research has found that dynamic factors can outperform static factors in terms of prediction of recidivism (Yesberg \& Polaschek, 2015; Serin et al., 2016). Even when dynamic risk factors do not significantly outperform static risk factors, their function as targets for treatment demonstrate more clinical utility than stable risk factors (Campbell et al., 2009; Yang, Wong, \& Coid, 2010). In terms of change, more recently, these 
dynamic risk assessments have begun to incorporate protective factors (Serin, et al., 2016). It remains to be seen if client change factors can augment static risk assessment.

\section{Protective factors.}

As has been illustrated in the above review of risk assessment, research has primarily been focused on the deficits offenders may experience that lead them to crime (StouthamerLoeber, Loeber, Wei, \& Masten, 2004). However, until recently it has been unclear why some individuals who are exposed to many risk factors do not engage in criminal behaviour (Ullrich \& Coid, 2011). This observation has led to the identification and analysis of putative protective factors; factors that decrease an individual's risk of re-offending (Fougere \& Daffern, 2011; Losel \& Farrington, 2012; Polaschek, 2016; Serin, Chadwick, \&Lloyd, 2016). Losel and Farrington (2012) in their narrative analysis found that protective factors fell generally into five domains: individual factors such as self-efficacy or high self-control (Woldgabreal, Day, \& Ward, 2015), familial factors such as parent-child relationship (Losel \& Farrington, 2012), school/work factors such as school achievement (Losel \& Farrington, 2012), peer factors such as peer acceptance (Masten \& Coatsworth, 1998), and community factors. These factors are similar to those highlighted in SCT and GPCSL: self-efficacy, proximal and distal goals, and perceived facilitators to change. They also represent the same emphasis on a reciprocal relationship between the person, their environment and their situation (Andrews \& Bonta, 2010; Bandura, 2001).

A problem that has arisen from research with protective factors is whether protective factors are simply the inverse of risk factors (de vries Robbe, de Vogel, \& Douglas, 2013; Harris \& Rice, 2015; Stouthamer-Loeber et al., 2004; Ullrich \& Coid, 2011). For example, one risk factor for engaging in criminal behaviour is affiliation with deviant peers; conversely, a 
protective factor would be bonding with prosocial peers (Stouthamer-Loeber et al., 2004). This close association between risk and protective factors has instigated research to exemplify the differential impacts of each, providing evidentiary support for the idea that protective factors are more than just the inverse of risk factors (de vries Robbe, de Vogel, \& Douglas, 2013). For example, in three different risk assessments (DRAOR, the Structured Assessment of Protective Factors for Violence Risk; SAPROF, and the Youth Assessment and Screening Instrument; YASI) protective factors were found to have incremental predictive validity over the use of risk factors alone (Jones, Brown, Robinson, \& Frey, 2016; de Vries Robbe et al., 2013; Yesberg \& Polaschek, 2015). Such research supports the utility of protective factors in the prediction of risk.

\section{The Good Lives Model}

An alternative to the GPSCL based RNR model that offers a primarily strengths-based approach to criminal theory and that might inform offender change is the Good Lives Model (GLM). The primary goal of the GLM (Ward, Yates, \& Willis, 2012) is to supply offenders with the resources, both internal and external, to live a good life, 'good' meaning a pro-social and personally fulfilling one. In this model, criminogenic needs are conceptualized as being barriers to living a good life. According to the GLM, those who have a history of criminal offending are predisposed to seek primary human goods, which are characteristics, mind states, or experiences that have intrinsic value. These primary goods are thought to represent an individual's fundamental values and beliefs. Although all human beings seek these primary goods, the significance any particular good is given depends on the characteristics of the person. These primary goods are supplied through secondary goods, which are conceptualized as roles, goals, or actions which supply a way to attain a primary goal. In this framework, criminogenic needs exercise their influence through secondary goods, meaning that an offender may use antisocial 
primary goods, such as antisocial peers, to attain their primary goals. Polaschek (2016) observes that this may be more of a reflection of how RNR is implemented, as strengths are reflected in the GPCSL. Therefore, in addition to risk assessment, GLM proposes that offenders should map out their good lives plans as well as undertake validated assessments regarding personal goals. Once this plan is understood, treatment focuses on establishing pro-social secondary goals with the objective of attaining personally meaningful primary goals in a pro-social way (Ward, Yates, \& Willis, 2012). This is similar to the idea presented both in SCT and the GPCSL that the perception of the costs of criminal activity and benefits of pro-social behaviour must be changed, and that proximal and distal goals assist in motivating an offender (Andrews \& Bonta, 2010; Bandura, 2001).

The main differentiation between the GLM and RNR, according to its founders, is that while RNR focuses on reducing risk the GLM focuses on risk reduction as well as goods promotion. Importantly, Andrews, Bonta, and Wormith (2011) argue that the RNR framework incorporates a strengths-based approach; while Cullen (2012) argues the preponderance of evidence supports RNR being the dominant model for influencing offender change. As Cullen (2012) notes to date there has been no clear operationalization or validation of the GLM, raising legitimate concerns regarding its utility despite its popularity for understanding offender change. Recently there have been efforts to better situate RNR and desistance (e.g., GLM) work (Maruna \& Mann, 2019; Serin \& Lloyd, 2019).

\section{Transtheoretical Model of Change}

As mentioned, beyond risk assessment there are models of behaviour which attempt to explain change processes in offenders. An action theory of behavioural change is one that 
attempts to explain the behaviour of an individual who is already motivated to change (Casey, in press). The transtheoretical model (TTM) of change (Prochaska \& Diclemente, 1983) is an action model which has become one of the most influential models of behavioural change and has been applied frequently in offender rehabilitation (Day, Bryan, Davey, \& Casey, 2006). The TTM is conceptualized as a progressive stage model in which each stage is characterized by different values, beliefs, thoughts, and attitudes (Velicer, Prochaska, Fave, Norman, \& Redding, 1998). The stages of this model are: precontemplation, contemplation, preparation, action, and maintenance. The precontemplation stage is when an individual has no plans within the next six months to act in implementing change. This individual is not yet motivated to change and avoids thinking of their problematic offending behaviours. In essence, it is proposed that those in the precontemplation stage are not ready for treatment (Velicer, Prochaska, Fave, Norman, \& Redding, 1998). In the contemplation stage the person has an intention to change within the next six months and has become highly aware of both the pros and cons of changing their behaviour (Velicer, Prochaska, Fave, Norman, \& Redding, 1998). Again, this reflects the emphasis on changing the perceived outcome expectations of criminal activity and pro-social behaviour in the SCT and GPCSL perspectives, as well as perceived impediments and facilitators to success (Andrews \& Bonta, 2010; Bandura, 2001). However, this weighing of options can produce ambivalence such that the individual becomes fixated in this stage of the change process for long periods of time. This is often called chronic contemplation or behavioural procrastination; individuals experiencing this procrastination are also theorized as not being ready for actionoriented interventions (Velicer, Prochaska, Fave, Norman, \& Redding, 1998). Preparation is the stage in which individuals usually have some sort of plan to act within the next month. Typically, these individuals are those that should be recruited for action-oriented intervention programs. 
The action stage is one in which the person has completed specific, explicit behavioural changes within the past six months. This is the stage in which the person must be most wary of relapse (Velicer, Prochaska, Fave, Norman, \& Redding, 1998). The maintenance stage is where an individual is focusing on avoiding relapse, however, they are less tempted to relapse in this stage and become more confident as they continue through their change process (Velicer, Prochaska, Fave, Norman, \& Redding, 1998).

Behavioural change is thought to occur alongside cognitive change processes, decisional processes, and self-efficacy (Prochaska \& DiClemente, 1983; Velicer et al., 1998). Change processes such as stimulus control or self re-evaluation are used by an individual to modify the problematic behaviour (Prochaska \& DiClemente, 1983). Decisional balance is considered as the assessment of benefits and costs of the modification of behaviour (Velicer, DiClemente, Prochaska, \& Brandenburg, 1985), which are theorized to fluctuate in a predictable pattern as a person goes through the change process. For example, during the pre-contemplative stage, the pros of the problematic behaviour usually outweigh the cons (Velicer et al., 1998). As well, selfefficacy, or an individual's belief in their ability to accomplish a task, is central to the initiation of behavioural change (Bandura, 1977). For Velicer and colleagues (1998), self-efficacy is the ability of an individual not to relapse to a problematic behaviour throughout a variety of difficult situations. Self-efficacy tends to increase throughout the four stages of the TTM, or, with the process of change. These factors are comparable to those emphasized in both the SCT and the GPCSL perspective: the costs and benefits of a criminal versus a pro-social lifestyle, selfefficacy, outcome expectancies, proximal and distal goals, perceived impediments to change (Andrews \& Bonta, 2010; Bandura, 2001). 
The TTM has been widely used in various offender rehabilitation programs (Day, Bryan, Davey, \& Casey, 2006) including substance abuse (Assailly \& Cestac, 2014) domestic violence (Levesque, Driskell, Prochaska \& Prochaska, 2008), sex offenders (Tierney \& McCabe, 2005) and violent offenders (Williamson, Day, Howells, Bubner, \& Jauncey, 2003). There is some contention regarding the general stage models with offending behaviour. It is hypothesized that while the TTM is useful in high-occurring problematic behaviours such as smoking or overeating, offending behaviours are much less cyclical and do not occur regularly enough for the stage model to be effective (Day, Bryan, Davey, \& Casey, 2006). Encouragingly, the evidence suggests that matching treatment to a stage of change can maximize client-treatment congruence (Levesque et al., 2008).

Both the action model of the TTM (Prochaska \& DiClemente, 1998), the motivation model of the SCT (Bandura, 2001), and the GPCSL (Andrews \& Bonta, 2010) provide general factors which have been illustrated to reduce re-offending. These include: self-efficacy, outcome expectancies (Bandura, 2001; Andrews \& Bonta, 2010), motivation level, and stage of change (Prochaska \& DiClemente, 1998). Moreover, the RNR framework provides researchers with factors such as criminal associates, substance use, and self-efficacy which are shown to be some of the most significant factors involved in re-offending (Andrews \& Bonta, 2010). Furthermore, desistance theory provides further internal and external factors which are hypothesized to assist an offender in desisting from crime (Maruna, 2010; Serin, Lloyd, \& Hanby, 2010).

\section{Desistance}

Desistance is the process by which offenders eventually stop actively engaging in criminal behaviours (LeBel, Burnett, Maruna \& Bushway, 2008). For desistance to occur, there 
must be both a history of criminal activity and the subsequent termination of criminal behaviour (Serin \& Lloyd, 2009). As with any behaviour change, desistance is a process, it is not a spontaneous event (Maruna, 2001; Maruna \& Mann, 2019). Importantly, most individuals do cease criminal activity at some point in their lives in that the vast majority of offenders do not die in prison. Generally, there are three theories as to why this happens: natural desistance, cognitive transformation, and achievement of informal social controls (Youssef, Casey, \& Day, 2016). Natural desistance encompasses the age-crime curve, a staple in criminology and forensic psychology; it states that offending behaviour begins as a youth, increasing until the twenties after which most criminal behaviours begin to decline (Blumstein \& Cohen, 1987; Hirschi \& Gottfredson, 1983). The reasoning behind this trend is maturation; individuals may terminate offending behaviour simply because they no longer have the energy (Youssef, Casey, \& Day, 2016). However, while this age-crime curve is exemplified throughout research, it fails to take into account individual variations in offending behaviour as exemplified by differing crime careers (Kazemian, LeBlanc, Farrington, \& Pease, 2007). Maruna (2010) highlights correlates of desistance and these are better reflected in the cognitive transformation and social control theories of desistance.

\section{External factors.}

The social control theory posits that criminal behaviour is more likely in those with weakened or broken bonds to society (Laub \& Sampson, 1993). There are two somewhat different theories of social control, the first is the view of Gottfredson \& Hirschi (1990) who posited that those who participate in criminal behaviour are seeking pleasure through immediate gratification. As such, individuals who engage in criminal activity have poor self-control. This 
was thought to be a personal characteristic which began in the family. Therefore, bonding with social institutions such as marriage were viewed as important for desistance (as cited in Youssef, Casey, \& Day, 2016). More recently, Laub and Sampson (1993) posited an age graded theory of social control which emphasized ties to social institutions. This included participation in the labour force and marriage. However, unlike other life-course researchers, these authors believed that the quality of those ties was an important factor. These were considered "turning points" which could modify the path an individual would take either into conformity or criminality. Where Hirschi and Gottfredson emphasized the role of opportunity in criminogenic behaviour, Laub and Sampson (1993) emphasized personal agency.

\section{Internal factors.}

The cognitive transformation theory of desistance assumes personal choice and agency on the part of the offender. Desistance is theorized to be instigated by an awareness of the negative aspects of criminal behaviour, as well as the desire to terminate it (Maruna, 2001). Maruna researched this theory of criminal desistance in his Liverpool study and found two different types of offenders which he dubbed 'persisters' and 'desisters'. The desisters were categorized by an identity shift in which the person re-wrote their criminal past into a more positive, pro-social trajectory and maintained an internal locus of control.

Although each theory of behavioural change in offenders offers insight into the process, taken in isolation, no theory supplies a specific framework for implementing targeted programming for offenders. That is, they describe the end point but not the pathways necessary to achieve desistance. Cognitive transformation theory focuses specifically on internal factors, social control supplies the influence of external factors, and aging theory is a natural maturation 
process which should also be considered. Together, the three theories are complementary to each other and provide an overall model for desistance which has been captured through the Transitional Model of Offender Change.

\section{Transitional Model of Offender Change}

Serin and Lloyd (2009) propose a life course model (see Figure 1) following a similar trajectory of the age-crime curve to explain successful re-entry into the community and crime desistance. The Transitional Model of Offender Change incorporates aspects of each of the above noted change theories (GPCSL, RNR, desistance theory, and SCT). Essentially, risk factors, which are highlighted in both the GPCSL and RNR theory, heavily influence an individual becoming involved in crime (Andrews, Bonta \& Wormith, 2006). These risk factors also provide treatment targets that might instigate change, but these risk factors and their assessment are insufficient to identify which offenders will demonstrate reductions in criminogenic needs which will lead to sustained prosocial behaviour. Further, research shows that the extinction of risk factors that lead to initial involvement in crime are not sufficient to explain an individual's desistance from crime (Laub, Nagin, \& Sampson, 1998). At some point an individual will make a commitment to change. In order for this commitment to be followed by sustained behavioural change, internal and external change features interact to produce desistance correlates. Internal change features include those factors emphasized in the offender change theories discussed, GPCSL, SCT, desistance theory (Andrews \& Bonta, 2010; Bandura, 2001).These include agency or self-efficacy, attributions, outcome expectancies, identity and self concept and change beliefs, similar to those highlighted in both SCT and GPCSL perspectives. This model provides an outlook of an offender in transition from actively offending to desisting 
which is illustrated by the downward curve of the graph in Figure 1 (Serin, Lloyd, \& Hanby, 2010). The transitional model acknowledges that desistance is likely a reciprocal relationship between all of these factors, rather than a more additive, linear process.

The desistance correlates exemplify that the individual has initiated important commitments to prosocial living as well as learning how to avoid becoming involved in criminal activity (Serin \& Lloyd, 2009). As well, the model illustrates that offender change is theoretically related to desistance from crime. Research conducted on crime acquisition and crime desistance illustrate the potential advantage of their integration (Serin \& Lloyd, 2009). All models describe how change occurs and to a lesser extent, key constructs relating to such change. The Client Change Scale (CCS; Serin, 2018) is specifically derived from the transitional model; its purpose is to quantify where an offender is in this process in order to inform correctional and parole decisions. 


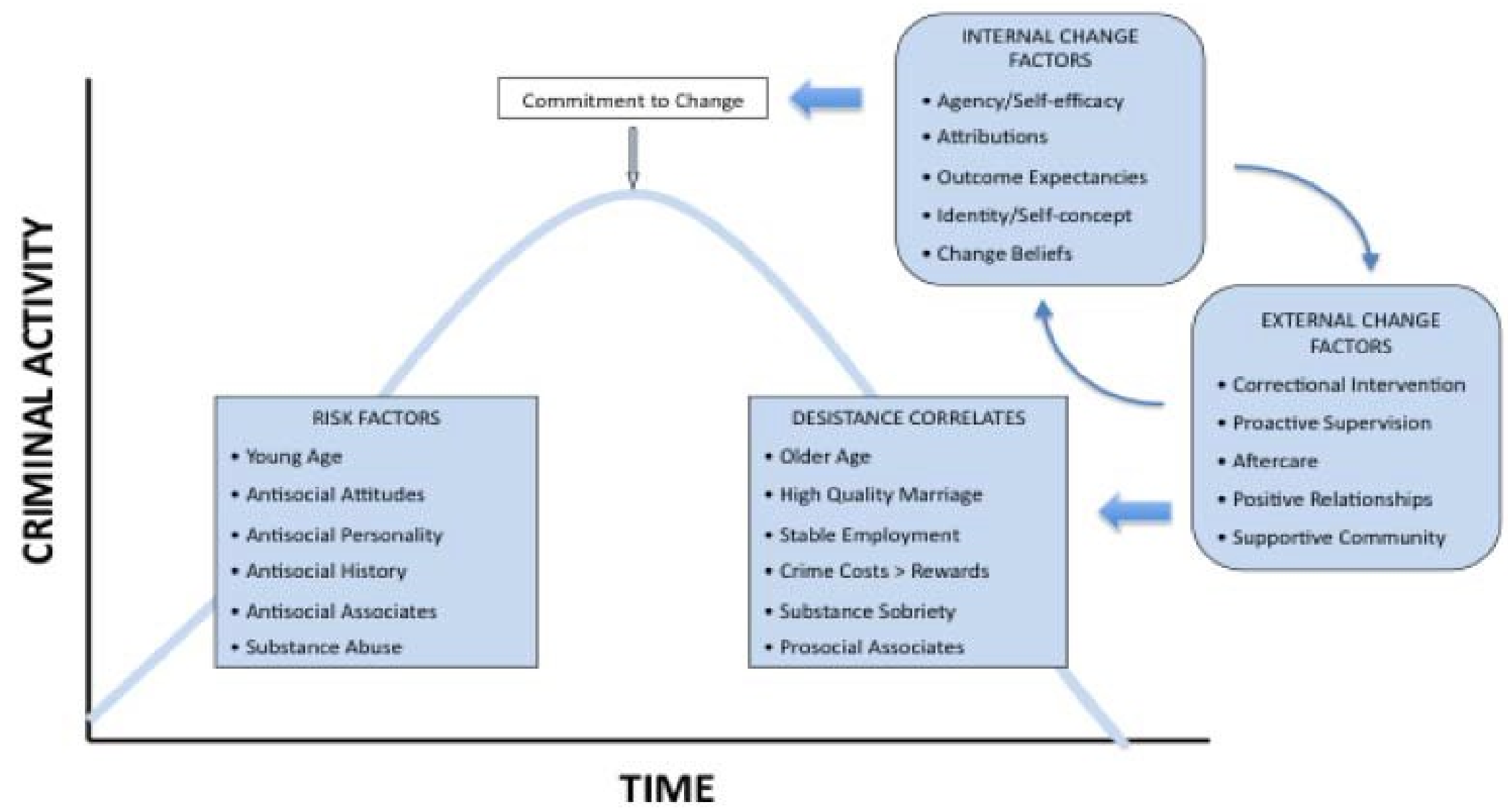

Figure 1 The transitional model of offender change from Serin et al., 2010. 


\section{The Client Change Scale}

The intended purpose of the Client Change Scale (CCS; Serin, 2018) is to systematically assess and re-assess concepts reflected in the above noted change theories (identity, change beliefs, self-efficacy, sense of entitlement). The items are designed to generalize across program types in order to tap into foundational change processes which can potentially be relevant to all justice involved individuals. It is expected that higher scores will be related to more successful client outcome, which, for the purposes of this research, will be a parole grant decision. This research will specifically seek to differentiate those further along in the change process (higher scores on the CCS) by a parole grant decision, from those in the beginning stages of the change process by a parole denial decision. However, more broadly, success can also be program engagement and program completion versus dropout and non-compliance. Therefore, the CCS is designed to be usable both to gauge progress for those who are incarcerated and on supervision. If validated, the CCS can provide a systematic explanation of client effort and change as well as potentially be used as a rationale for parole and correctional decision making (e.g., change in security classification). In this way, positive client change can be quantified to identify those who have made appropriate rehabilitative progress and potentially for outcome is improved. It is expected the CCS would be shared with clients to both challenge and encourage them regarding their progress.

Each of the 16 items of the CCS have been empirically demonstrated to predict recidivism: motivation level, stage of change, compliance with supervision conditions, engagement in change, effort in change, identity, agency for positive change, explanatory style, expectations about change, social support and peers, stability of employment, stability of accommodation, substance use, problem-solving, self-regulation /affect management, and sense 
of entitlement. Moreover, these items are built from validated change theory incorporated through the Transitional Model of offender Change including (Serin, 2017).

\section{Motivation Level}

Motivation to change is often treated as a selection criterion to identify those offenders that will benefit from treatment. However, treatment programs are also formulated to build and encourage motivation to change (McMurran, 2002). Hence, failure to achieve pro-social change as a result of treatment is often conceptualized as a lack of motivation within the offender. However, research has shown that motivation is a modifiable interpersonal phenomenon and that changing motivation can also change the probability that a person will initiate and/or maintain behavioural action. In this way, motivation is both a prerequisite to initiate behavioural change as well as necessary to continue to maintain positive behavioural change (Viets, Walker, \& Miller, 2002). Additionally, a person's belief regarding their ability to be successful concerning prosocial change (self-efficacy) is related to prosocial change as well. The possession of both the motivation for behavioural change as well as the belief that one can successfully achieve the behavioural change represent both the intention and capacity to undergo meaningful change (Viets, Walker, \& Miller, 2002).

The importance of motivation was exemplified in O'Brien and Daffern's (2017) research in which 115 violent male offenders were analysed on factors such as motivation for treatment, treatment engagement, and treatment completion. The results found that offenders with higher motivation prior to treatment had better behaviour in treatment, that higher motivation was related to enhanced engagement in treatment, and that engagement in treatment was related to 
treatment completion. Here, motivation is a catalyst for behavioural change in that it is associated with engagement which is related to treatment completion.

In terms of empirical illustration of the importance of motivation, motivational interviewing (MI) interventions have been designed where increasing motivation is the focal target (Heather \& Stockwell, 2004; Anstiss, Polaschek, \& Wilson, 2009). While evidence of the effectiveness of MI in increasing motivation, engagement in treatment, and reducing recidivism varies across studies, researchers propose that more information about who responds to what kind of MI in relation to reconviction as well as establishing an overall theory of change would stabilize these effects (McMurran, 2009). Research conducted by Anstiss, Polaschek, and Wilson (2011) illustrates the usefulness of MI. Here, 116 participants underwent either MI treatment or treatment as usual and were compared in post-release recidivism rates. Participants had been incarcerated for at least six months with varying offence types including violent, sexual, and driving offences. The MI group and the treatment as usual group were matched on age, sex, ethnicity, and recidivism risk - those factors that are most closely associated with criminality. The MI for this study was centralized upon increasing participants' willingness both to address their criminogenic needs and their participation in treatment programs. Reconviction rates for those undergoing MI were significantly lower compared to those undergoing treatment as per usual $\left(\chi^{2}(1)=4.7, p<.05\right)$. While this trend was significant for those offenders who were charged again once leaving prison, for those who were re-incarcerated the difference was not significant, though trending in the same direction $(p=.08)$. Survival analyses indicated that time between both reconviction and re-imprisonment was longer for MI offenders versus treatment as usual offenders. Additionally, those offenders who underwent MI also increased their readiness to change (Anstiss et al., 2011). 


\section{Stage of Change}

As mentioned, the TTM has been widely used in various offender rehabilitation programs (Day, Bryan, Davey, \& Casey, 2006). Examining the stage of change an offender is currently in is one of the items of the CCS. Although there is some contention regarding using the stage model with offenders (Day, Bryan, Davey, \& Casey, 2006; Williamson, et al., 2003), the majority of evidence suggests that matching treatment to a stage of change can maximize clienttreatment congruence (Levesque et al., 2008). Specifically, Olver and Wong (2009) empirically demonstrated its usefulness in examining recidivism with sex offenders. These researchers examined treatment attrition as well as 10-year recidivism after treatment in a group of psychopathic sex offenders. The researchers used the Violence Risk Scale-Sex Offender Version (VRS-SO) to examine risk in offenders. The importance of this risk instrument is that all 17 dynamic risk items in the assessment are conceptualized along the lines of the stages of change in the TTM. Therefore, a person scoring low on the dynamic item would be conceptualized as being in the early stages of the change process. This progression through the stages of change shows the commitment and acquisition of positive coping strategies. The ratings of these stages through the dynamic items showcase the extent to which an offender has acquired skills and knowledge that are relevant to reducing risk (Olver \& Wong, 2009). For this study, researchers analyzed offenders on dynamic items of the VRS-SO pre and post treatment. When psychopathy was controlled for, change scores using the VRS-SO dynamic items were inversely associated with decreased violent recidivism $(B=-.27, S E=.09)$ and when static items of the VRS-SO were used to control for risk, change scores were inversely related to sexual recidivism $(B=-.19$, $S E=.09)$. Meaning that higher levels in terms of stages of change predicted lower levels of recidivism (Olver \& Wong, 2009). 


\section{Compliance with Supervision Conditions}

Some of the items of the CCS were derived from the Dynamic Risk Assessment for Offender Re-Entry (DRAOR; Serin, 2007) and the STABLE 2007 for sex offenders (Hanson, Harris, Scott, \& Helmus, 2007) including compliance with supervision conditions and attitudes towards authority. The DRAOR and the STABLE 2007 are validated dynamic risk assessments which were developed to assist probation officers in real-time assessment and re-assessment of offender risk throughout their supervision and to inform case planning (Serin, 2007). It is currently being used on a national basis in New Zealand (Serin et al., 2016), for probation services in numerous US states and in community supervision by the Singapore Police Service (Wilson, 2014). The DRAOR is a rating scale which was designed to allow parole officers to assess risk throughout community supervision, therefore capturing change in these variables and enabling parole officers to respond to fluctuations in risk which could inform the likelihood of offending (Serin et al., 2016). This means that the DRAOR and the STABLE 2007 items may be ideally formulated to measure change in offenders.

The DRAOR (Serin, 2007) includes responsiveness to advice as a protective factor and attitudes towards authority as an acute risk factor. This is because anti-social cognitions are important risk factors for criminality indicated by their presence in the Big Four of the Central Eight risk factors (Andrews \& Bonta, 2010). Defiance and resentment, in particular, are cognitive-emotional states related to crime. Indicators of these cognitions include a negative attitude of the law and the justice system, the justification or rationalizations of crime and a belief that crime will produce rewards (Andrews \& Bonta, 2010). Complying with supervision conditions is an indication that an individual perceives rules and guidance as important. Maintaining negative attitudes towards the criminal justice system means that an individual may 
devalue these institutions, thereby making crime the more attractive and reasonable alternative. Therefore, change would be reflected in a more positive view of the criminal justice system.

\section{Engagement in Change}

Engagement in behavioural change is also an important factor in the process of change for an offender. SCT theory prescribes that a behavioural goal encourages motivation through engagement in a given activity, rather than directly (Bandura, 2001). Moreover, engagement in change processes has been investigated empirically through engagement in treatment. Drieschner \& Verschurr (2010) investigated the relationship between treatment engagement and treatment dropout as well as between treatment engagement and changes in risk status. Treatment engagement was found to be significantly correlated with reduced risk status $(\mathrm{Sr}=0.41, p<.01)$. Furthermore, in a logistic regression with the factors of age, gender, substance abuse, and cluster B personality disorder, the only variable that significantly predicted premature termination of treatment was treatment engagement $(\beta=1.33, p<.001)$, those who were less engaged were more likely to terminate (McMurran \& Ward, 2010). Specifically, when treatment engagement was one standard deviation below average, the odds of premature termination of treatment were four times more likely. Premature termination of treatment is a concern both for offenders and the public because it may hinder the benefits of treatment and diminish offenders' opportunities to lead more pro-social, fulfilling lives (McMurran \& Ward, 2010). Treatment engagement is thought to augment the process of offender change (Howells \& Day, 2003). Moreover, Yang and colleagues (2013) found that the relationship between criminal history and re-arrest 12 months post-release was partially mediated by treatment engagement and criminal thinking. Moreover, the relationship between criminal thinking and re-arrest was fully mediated by treatment 
engagement. The researchers believed that this meant engaging offenders in treatment could impact recidivism later, even for those offenders who were high on criminal thinking and past criminal behaviour.

\section{Effort in Change}

While motivation can stimulate change and potentially assist in maintaining it, behavioural change also requires effort. An individual desiring to desist from offending must recognize that behavioural change requires sustained effort. This is exemplified by the fact that persistent offenders have made many breaks from engagement in criminal activity, only to return to criminal behaviour (Maruna, 2001). In Drieschner \& Verschurr's (2010) research analyzing the relationships between treatment engagement and premature culmination of treatment and changes in risk status, the researchers used the Treatment Engagement Rating Scale (TER) which contains items measuring effort to change behaviour. Although the overall TER score predicted premature termination of treatment and was associated with reduced risk levels, effort in changing problem behaviour had a larger correlation with both outcomes than the total score (ability to predict outcome was not directly measured for the effort in change item). This indicates the importance of effort in change as it relates both to treatment completion and changes in risk status.

\section{Identity}

An individual's perception of their own roles and normative behaviours controls much of their daily behaviours. This is true not only for more regular roles, such as a 'sister' or 'aunt', but for the 'prisoner' role as well (Veysey, Christian, \& Matinez, 2013). Maruna (2001) describes 
desisting offenders as having cognitive distortions in terms of their roles in life. The desisting offender does not see their criminal past as a failure but instead as a necessary path to a newfound reality, whereas an active offender feels that they have no place in mainstream society, few chances at success, and are in the midst of a dire situation. A longitudinal examination of addicted offenders measured identity before being released from prison and at follow-up, the participants' level of help-seeking in substance abuse problems, and re-arrest statistics in terms of survival time. Patternoster, Bachman, Kerrison, O’Connell, \& Smith (2016) found that those who identified as addicts prior to leaving prison but identified as non-addicts upon follow-up had the longest survival rates. This group was also the most likely to seek assistance with substance abuse, indicating that these individuals were most involved in their desistance process. Hence, pro-social identity and engagement in pro-social behaviours (e.g. seeking help for substance abuse) are forecasters of crime desistance.

\section{Sense of Entitlement}

Additionally, both self-entitlement as well as antisocial peers are considered part of the central eight risk factors derived from PIC-R theory (Andrews \& Bonta, 2010). Self-entitlement is considered to be an antisocial cognition. While there is no official categorization of antisocial attitudes, these attitudes are generally known to be used to neutralize actions, identify with criminal associates, and reject convention in order to support criminal behaviour (Andrews \& Bonta, 2010). A sense of self-entitlement can be thought of as a neutralizing tactic wherein the offender believes that they are somehow more important, or special, than their potential victim. In this way the offender feels that their criminal actions are justified. 
In addition to being theoretically meaningful, empirical research has shown associations between self-entitlement and recidivism. For example, sense of entitlement has also been examined as a personality trait that may influence offending. Warren and South (2009) examined cluster B personality disorder criteria in 261 incarcerated female offenders and their relationship to offending behaviours within the prison. One of the personality disorders is narcissistic personality disorder, which includes as a criterion, expression of a sense of entitlement. The researchers found that both narcissistic and antisocial traits were associated with the perpetration of physical violence and threats. While this study focused primarily on the validation of a personality disorder scale, research examining links between antisocial attitudes, including selfentitlement, and recidivism have found similar results. Boduszek, Hyland, Pedziszczak, and Kielkiewicz (2012) postdictively examined criminal attitudes, including self-entitlement, antisocial associates, and recidivism in 133 incarcerated violent offenders. Sense of entitlement specifically had a correlation of .26 with recidivism. A mediating regression model also showed that entitlement had an indirect influence on recidivism through criminal friends. Therefore, sense of entitlement is a criminal attitude that can have an influence on recidivism as well as instances of aggression.

\section{Self-Efficacy}

Self-efficacy is another interpersonal factor identified as contributing to successful offender community re-integration and included in the model (Serin, Lloyd, \& Hanby, 2010; Serin \& Lloyd, 2009). Self-efficacy is defined as an individual's expectations of achievement regarding behaviour. Self-efficacy fluctuates and is developed through past experiences in both failure and success in achieving a desired goal as part of behaviour change (Bandura, 1977). 
Regarding change in offending behaviour, self-efficacy becomes important in the context of acquiring a pro-social identity. Bahr, Harris, Fisher, and Armstrong (2010) attempted to differentiate between those who successfully completed parole (being discharged from parole by three years) and those who were unsuccessful. Among other factors, the researchers found that successful parolees had more self-efficacy regarding change than those who were unsuccessful. However, a primary concern among increasing self-efficacy in offenders is creating offenders with higher criminal achievement rather than pro-social achievement (Lafferiere \& Morrselli, 2015). This is transposed with Maruna's (2001) idea that desisting offenders have many qualities that are also present in high achieving pro-social individuals. The challenge then is for an offender to both change their identity to one that is pro-social and increase their self-efficacy regarding their ability to initiate and maintain pro-social behaviours.

Lebel and colleagues (2008) studied multiple internal change factors in 126 offenders, including self-efficacy. The offenders were interviewed while incarcerated, again in the community four to six months after release, and finally ten years post-release. Self-efficacy and motivation (conceptualized as 'hope' here) were found to be negatively predictive of reconviction $(\beta=-.10, p<.05)$. Moreover, social problems upon readmittance to society $(\mathrm{OR}=$ 2.10) had a large effect for both re-conviction $(\mathrm{OR}=2.10)$ and re-imprisonment $(\mathrm{OR}=1.38)$ meaning that each added social problem would result in a 110 percent increase in likelihood of re-conviction and a 38 percent increase in re-imprisonment. The researchers reported that motivation and self-efficacy had an indirect effect on reconviction through action. These results also map well onto the TTM wherein actions involved in the stages of change are initiated and maintained by motivation (Velicer et al., 1998). 


\section{Explanatory Style}

The attributions that an individual has regarding the control they maintain over events in their life is another broadly applicable interpersonal change indicator (Serin, Lloyd, \& Hanby, 2010). Rotter (1966) explains that perceptions of behavioural outcome is person specific. One factor that influences how an individual might perceive a behavioural outcome is the extent to which an individual perceives the result as being internally or externally controlled. This tendency of an individual to think of outcomes as externally or internally controlled is both situationally dependant and a stable personality characteristic (Rotter, 1966). An internal locus of control suggests that an individual perceives an outcome as being contingent upon their actions, whereas an external locus of control implies that the person views events as being outside of their control, potentially due to the intervention of luck or fate (Rotter, 1966). Orientation of a person's locus of control has been shown to be related to outcomes in a variety of contexts. An internal locus of control has been associated with positive results concerning academic performance (Drago, Rheinheimer, \& Detweiler, 2018) and treatment outcome in alcoholics (Abbott, 1984). Moreover, an external locus of control has been associated with negative performance such as failure in the treatment for obesity (Cohen \& Albert, 1978). In the area of offender rehabilitation, an external locus of control has been associated with higher propensity of offending in sex-offenders. For example, Wood, Wilson, and Thorne (2015) used a combined quantitative and qualitative evaluation of 125 sex offenders and found that the offenders, specifically those who offended at higher rates, were motivated to commit crimes because of an external locus of control. Furthermore, qualitative analysis between a group of five desisting sex offenders and five active sex-offenders found that those in the active group were more likely to attribute outcomes externally whereas those in the desisting group reported a more internal sense 
of control (Farmer, Beech, \& Ward, 2012). Therefore, desisting offenders will be more likely to attribute positive events to their own effort and negative events to chance. Active offenders are more likely to attribute positive events to chance and negative events as the fault of others. This locus of control relates to outcome expectancies of change; an individual's perception of a reward as being contingent or non-contingent on their behaviour will influence their motivation to engage in the behaviour in the future (Bandura, 1977). An individual who believes that rewards for their behaviour are a result of fate rather than of their own intervention will be less likely to engage in a behaviour that produced the reward because they do not see a contingency between the two. In this way, an active offender who believes that rewards for pro-social behaviour are a result of luck rather than their own actions will be less likely to engage in prosocial behaviour again. In the context of the Client-Change Scale, locus of control is referred to as explanatory style in that it is a characteristic way of explaining the reasoning behind events.

\section{Expectations of Change}

Another internal change aspect of the model is change beliefs. Many offenders appear to take control of their change process by participating in treatment, but unfortunately, not all successfully apply what they learn to life outside of the correctional facility, or even complete treatment programs. Among successful completers, characteristics such as treatment engagement as well as effort in treatment and motivation for treatment can distinguish them (Drieschner \& Verschur, 2010). Motivation for change, engagement, effort in change and self-efficacy are similarly hypothesized to be broad internal factors involved in the change process leading to desistance (Serin \& Lloyd, 2009; Lebel, Burnett, Maruna, \& Bushway, 2008). Therefore, examining these aspects should inform correlates of success in treatment. 
While self-efficacy involves expectations about a person's ability to succeed in a task, outcome expectancies are classified as the individual's expectations that a particular behaviour will lead to a certain outcome (Bandura, 1977). In the context of expectations about change, outcome expectancies for a desisting offender would mean that the individual views both benefits to desisting and costs to continuing criminal activity (Lloyd \& Serin, 2009). As mentioned, an offender with a pro-social identity is more likely to have positive expectations for change, meaning that the individual perceives benefits to a pro-social lifestyle (Maruna, 2001). Moreover, positive expectations regarding change has been associated with better performance in terms of re-offending (Doekhie, Dirkzwager, \& Nieuwbeerta, 2017; Iselin, Mulvey, Loughran, Chung, \& Schubert, 2012; Mahler, Simmons, Frick, Steinberg, \& Cauffman, 2017). For example, Mahler and colleagues (2017) analysed 1,216 male juvenile offenders on IQ, expectations - using the Perceptions of Opportunities Measure - and impulse control relating to self-reported offending behaviour at three points after their first official encounter with the justice system. The results of the Ordinary Least Squares Regression indicated that expectations were a significant unique contributor to future self-reported offending behaviour with an Incident Risk Ratio (IRR) of .80 $(p<.001)$. This finding remained even after controlling for other potential confounding factors such as impulse control. Furthermore, Iselin and colleagues (2012) also measured expectations in 1,354 adolescent offenders using the Perceptions of Chances for Success Measure on offending behaviour and employment behaviour post-release. Positive expectations regarding pro-social work, refraining from obtaining money through illicit behaviours, and refraining from criminal activity at baseline predicted positive outcomes in these behaviours one year later even after controlling for factors such as gender, ethnicity, socioeconomic status, amount of time spent in the community, and baseline antisocial behaviour. 
Furthermore, positive expectations regarding desistance and negative expectations regarding crime have been associated with increased self-efficacious beliefs. Additionally, Serin \& Lloyd (2009) found that outcome expectancies associated with desistance were not related to static measurements of risk, which indicated measurement of this concept to be separate and complementary to risk measurement. These results indicate the importance of expectations regarding pro-social change (Mahler et al., 2017; Iselin et al., 2012), the desirability of which, as mentioned, is related to a pro-social identity (Maruna, 2001; Patternoster et al., 2016) and selfefficacy in achieving pro-social goals (Mahler et al., 2017).

\section{Social Support and Peers}

Generally, social support has been shown to be beneficial for a host of variables related to well-being, including post-traumatic growth (Prati \& Pietrantoni, 2009) as well as smoking cessation (Soulakova, Tang, Leonardo, \& Taliaferro, 2018). Social support and peers can have both a positive influence or a negative influence on the continuation of offending; association with pro-criminal associates and isolation from pro-social individuals are thought to be causal variables in criminal behaviour (Andrews \& Bonta, 2010). Moreover, fraternization with criminal associates is also negatively related to other desistance and change components, such as self-efficacy $(r=-0.37, p<.001)$ (Lloyd \& Serin, 2012). Wilson, Cortoni, \& McWhinnie, (2009) compared sexual offenders who had participated in Circles of Support and Accountability (COSA) program to matched sample who had not participated in the program. COSA is designed to have positive community members help the ex-offender successfully re-integrate by assisting them in making pro-social choices. This research project compared 44 high risk sexual offenders to offenders of matched risk level, time and location of the release, and treatment participation. 
Regarding re-offending after release, those who participated in COSA were less likely to sexually re-offend $\left(\chi^{2}(1)=3.89, p<.05\right)$, violently re-offend $\left(\chi^{2}(1)=8.12, p<.01\right)$, and generally re-offend $\left(\chi^{2}(1)=8.73, p<.01\right)$. While COSA shows the potential effectiveness of structured social support, research suggests that association with non-criminal peers in a less structured way also has benefits. Mitchell, Spooner, Jia, \& Zhang (2016) conducted a metaanalysis examining the potential relationship between prison visitation and reduced recidivism upon re-entry into the community. The researchers found that overall, average recidivism was significantly reduced due to prison visitation by $26 \%$. As the effect sizes were heterogenous across studies, potential moderators were examined finding that recidivism was reduced most for male offenders by 53\%. Mitchell and colleagues (2016) also found a higher effect for conjugal and furlough visitation compared to in-prison visitation. Finally, reduced recidivism was most strongly found in shorter follow-up periods. Therefore, when monitoring behaviour change leading to reduced recidivism, recording the quality and quantity of associations with criminal and non-criminal peers is important (Martinez, 2009).

Additionally, social controls such as marriage, accommodation, and work have been found to be related to desistance from crime. For example, Morizot \& LeBlanc (2007) attempted to empirically test the theories of cognitive transformation in desistance and the establishment/importance of informal social controls. In order to do this, the researchers used a longitudinal design first examining 470 youth at ages 13-17 on self-reported criminal behaviour. They were measured again at an average age of 23,31 , and finally 40 . The participants were also asked about behavioural, familial, peer, and personality factors. The researchers used structural equation modelling in which they analyzed both contemporaneous effects and a launch effect model. The launch effect model, which essentially looked at the influence of predictors of crime 
and desistance at age 15 and their influence at 40, found that late onset of offending and parental sanctions at 15 were related to desistance at age 40 . Interestingly, the contemporaneous effect model looked at factors associated with desistance between age groups. Here, substance abuse was a positive predictor of criminality at ages 15,31 , and 41 , work stability was a negative predictor at age 31 , and pro-social friends were negative predictors at ages 15 and 31 . This exemplifies the influence of peers at various times in the life cycle.

Laub, Nagin, \& Sampson (1998) used data from a previous prospective longitudinal study in which 500 delinquent and 500 non-delinquent children were compared using an exhaustive multimethod strategy at ages 14, 25, and 32. Laub and colleagues (1998) used only the delinquent sample as they were interested in understanding desistance from a social bond perspective, specifically analysing the influence of marriage on desistance behaviour. Although many of the delinquent youth followed the age crime curve in terms of offending behaviour, many did not. The researchers used a poisson mixture model to identify trajectories of offending and produced desisting groups from this analysis. Of those who continued offending or offended at higher rates until the age of 32 , the last assessment period, desisters were less likely to have had shotgun weddings, been divorced or separated, and had higher measurement of both marriage quality at age 32 and higher stability in employment from ages 25-32. This association between quality marriage and offending behaviour disappeared when group membership (groups were those who aged out of offending, chronic offenders, and desisters) was taken into account. This indicated to the researchers that it was not simply individual level differences between groups that produced the relationship between quality marriage and desistance. Additionally, the researchers looked at the difference between those offenders who had a good quality marriage and a bad quality marriage, according to the marriage index. Here, the researchers noticed that 
for those with a good quality marriage, the offense rate was $19 \%$ less. This difference between good and bad quality marriages was exacerbated as the relationship progressed, growing to $68 \%$ fewer offenses by the third time-period. Therefore, research shows a relationship between a quality marriage and offending behaviour. Moreover, in terms of parole release, Kusaj (2019) found that only $7 \%$ of California offenders who were granted parole had present and relevant difficulties with personal support, further exemplifying the influence that this factor has in parole and recidivism.

\section{Stable Accommodation}

While accommodation is not part of the most significant risk factors for crime (Andrews \& Bonta, 2010), its importance lies in its relationship to a more effective re-entry into the community. For example, Clark (2016) examined qualities of offender accommodation postrelease as well as characteristics of the neighbourhood and their impact on recidivism rates for 4, 357 individuals. Housing was categorized by type (e.g. private residential, shelter, work-release center) and recidivism was measured as either as re-arrest or the violation of a parole condition. A multi-level mixed effects logistic regression found that being released into a work-release accommodation versus a private residence significantly decreased the odds of re-arrest; moving from incarceration to an emergency shelter increased the odds. No other types of housing significantly increased or decreased odds of re-arrest. Furthermore, relationships between certain types of housing and re-arrest were significant, while measures of community disadvantage and re-arrest were not. This illustrated that housing is the key variable in recidivism rather than poverty. Moreover, Ullrich and Coid (2011) found that private accommodation increased the odds of a violent re-offense. These researchers theorized that a private accommodation takes 
away the social support that may come from a shared residency, such as the work-release accommodation in Clarke's (2016) research. Ullrich and Coid (2011) also found that having a place to stay was a significant protective factor against violent re-offence for one-year postrelease also suggesting that having housing is important, although potentially private housing may not be optimal for offenders who have recently re-entered into the community.

While type of housing was important in Clark's study, research has shown that the stability of an individual's accommodation is also an important factor on recidivism. For instance, Bahr et al (2005) interviewed parolees during three occurrences over three months after their release into the community and tracked 19 parolees for six months. Interviews contained both quantitative and qualitative aspects focusing on criminal history, family, accommodation, education, associates, recreation and work as well as participation in treatment and future plans. These aspects were compared against actual recidivism data as well as how parolees subjectively felt they were adjusting to parole and their ability to avoid being reincarcerated. The research found that who the individual might be living with, such as a family member or roommate, did not have an influence on recidivism rates but stability of the accommodation did. This was highlighted in the results wherein ten of the 39 parolees who planned on moving were reincarcerated, while none of the 12 who planned to stay put were later incarcerated. This exploratory research gives an understanding of the importance of the stability of accommodation, however it lacked inferential statistics.

\section{Stable Employment}

Employment is another of the central eight risk factors described by Andrews \& Bonta (2010). In measuring this criminogenic need, Andrews and Bonta stress the importance of an 
individual's performance and engagement in the work they're doing as well as the rewards and satisfaction that the person gets from stable employment. They describe employment as a dynamic risk factor as employment performance can be targeted by building employable skills as well as working to enhance the individual's rewards gained and satisfaction. Research has supported this connection between increased employment and reduced recidivism. For example, Duwe (2015) analyzed the influence of an employment-based re-entry program, EMPLOY, on recidivism rates in a sample of 464 offenders; 232 of which had participated and 232 who had not. The EMPLOY program worked by enhancing employee skills post-release and then providing community support in employment upon re-entry. Those who participated in EMPLOY were matched with non-EMPLOY offenders based on variables such as sex, race, age, risk level, time spent incarcerated, prior supervision failures, and prior convictions. Researchers used Cox regression models to analyze both differences in recidivism rates as well as time to recidivism for both groups. Overall, those offenders who completed EMPLOY had lower recidivism rates, higher rates of employment, earned more, and worked more hours than those who had not participated in the program. The influence of the EMPLOY program on recidivism remained even after controlling for factors such as age, race, sex, and risk level. Furthermore, those who participated in EMPLOY also stayed in the community longer before re-offending relative to the comparison group. The results demonstrated specifically the effectiveness of the EMPLOY program, but it also illustrated that building employment skills and attaining a job post-release can contribute to change towards desistance.

While employment is touted as a factor in reducing recidivism and contributing to change among offenders, there are some mixed results. For example, Cook, Kang, Braga, Ludwig, and O’Brien (2015) examined the combined influence of subsidized employment post-release and 
social services. The sample consisted of 236 high risk offenders with past violent or gang related convictions. These researchers found that while the reconviction rate for offenders in the treatment group were less so than for the comparison group, this difference was not statistically significant. However, the authors also found that the subsidized employment wages were low, indicating potentially low rewards, and the quality or individual engagement in those jobs was not measured. As Andrews and Bonta (2010) had predicted, engagement and rewards of a job are also important to reducing recidivism rates as well as contributing to offender change leading to desistance. Ramakers, Nieuwbeerta, Van Wilsem \& Dirkzwager, (2017) illustrated this through a longitudinal examination of employment characteristics and recidivism rates among 714 released offenders. After controlling for 36 independent variables that could differentiate employed and non-employed individuals, the researchers did not find a difference regarding recidivism between the groups. However, the type of job a released offender obtained and retained was significantly related to recidivism. This meant that if the individual held the same job for six months post release, they were less likely to be re-convicted. Yet, among salary workers this effect disappears and occupation becomes a more distinguishing difference between re-offenders and non reoffenders. Moreover, Tripodi, Kim, \& Bender (2010) analysed employment rates and recidivism for 250 released offenders. While rates of employment for these individuals were not related to reincarceration levels, employment was related to time to reincarceration, much like Duwe's (2015) research. This suggested to the authors that employment could be considered as an indicator of behavioural change towards desistance. 


\section{Substance Abuse}

Another well-known and well-documented risk factor for criminality is substance abuse. According to Andrews and Bonta (2010) substance abuse includes misuse of alcohol as well as illicit drug use and is one of the central eight risk factors for criminality. Additionally, if an offender has no evidence of substance abuse and ideation of substance abuse tends to be negative, it is considered a protective factor against offending (Andrews \& Bonta, 2010). Additionally, reducing or eliminating substance abuse is considered a viable and important dynamic variable that is a promising treatment target (Andrews \& Bonta, 2010). In a meta analysis, Dowden \& Brown (2002) found an overall effect size of .10 between substance abuse and general recidivism, the effect sizes for alcohol and drug problems (.22) and for just drug problems (.19) were found to be most significant in relationship to recidivism $\left(\chi^{2}(4)=678.56, p\right.$ $<.001)$.

A reason substance abuse has such a high relationship with recidivism is related to its use by offenders in the commission of crimes. Millson, Weekes, and Lightfoot (1995) found that $80 \%$ of 317 federal offenders analysed presented with alcohol, drug, or alcohol and drug problems severe enough to warrant intervention. Moreover, Pernanen, Cousineau, Brochu, \& Sun (2002) conducted primary research in Quebec and Ontario (called Federal Inmate Interviews [FII]) and a review of studies by CSC on the prevalence of substance abuse among federal inmates. The researchers found that in the six months prior to their arrest, $45 \%$ of federal inmates had used alcohol and an illicit drug. 30\% of those had used an illicit drug or alcohol at least a few times per week. Additionally, alcohol consumers were more likely to commit a violent offence as their most serious crime, whereas drug users were most likely to have committed an 
offence intended for personal gain. Furthermore, $21 \%$ of federal inmates in Ontario between 1992 and 2002 reported that they were under the influence of alcohol when they committed their most serious crime. A further $16 \%$ were under the influence of drugs and a further $11 \%$ were under the influence of drugs and alcohol.

Not only is drug use related to crime, but drug treatment that is directly related to reducing drug use is related to reduced recidivism (Aos et al., 2006). Relating to drug courts, Gallagher et al., (2015) analysed differences in recidivism for offenders who had been convicted of drug related offences and were eligible for drug court with those who actually participated in drug court. Recidivism rates were collected for 36 months post discharge from probation or drug court. The researchers found that probationers in drug court were less likely to be re-arrested than probationers not in drug court $\left(\chi^{2}=18.26, p<.05\right)$. Drug courts appear to be more effective when dealing with non-violent drug related offences than traditional probation. Furthermore, once under community supervision, preventing substance abuse relapses has been shown to be beneficial in reducing recidivism. For instance, Sutherland and colleagues (2015) compared selfreported recidivism 12 months post treatment for offenders who had both mental health disorders and substance abuse disorders in either treatment that was specifically designed to address both substance abuse and mental health or traditional treatment. Regression analyses found that substance use was a significant predictor of both criminal activity and reincarceration, while a change in mental health problems did not signify a change in recidivism. Overall, improvements in both criminality and reincarceration were greater when focusing on the prevention of substance abuse relapses. Therefore, the measurement of changes in behaviour and cognitions regarding problematic substance use relating to past criminality is important for examining offender change. 


\section{Problem Solving}

Problem-solving skills represent an important part of the GPCSL theoretical approach to deviant behaviour. Problem-solving skills are important to reducing criminal activity in two ways: 1) problem-solving skills help to shape the immediate situation, and 2) they assist the individual in efficiently and pro-socially solving problems in their lives (Andrews \& Bonta, 2010). If an individual has efficient and pro-social problem-solving abilities, when issues arise, such as being unable to obtain a desired goal, that person will be able to overcome that issue in a pro-social way, therefore circumventing a situation in which criminal activity is the easiest and most attractive alternative (Andrews \& Bonta, 2010). Furthermore, if an individual finds themselves in a situation where the prospect of criminal activity is both attractive and easy, strong pro-social problem-solving skills can help the individual to find a pro-social solution to the problem in spite of antisocial incentives. Problem solving skills is a key focus for various cognitive skills programs for offenders, including the National Institute of Corrections' "Thinking for a Change" program (National Institute of Corrections, n.d.).

McGuire \& Hatcher (2001) employed a problem-solving training program with probationers in the UK. The program focused on building positive problem-solving skills in analysing criminal events as well as in the negotiation of potentially criminogenic situations. The researchers hypothesized that these offenders would then be able to manage offence-related issues more positively. The researchers found that there were statistically significant differences in probationers' apprehension of future recidivism as well as their belief in change regarding events in their lives. 
Moreover, McGuire (2002) analyzed a problem-solving training and offence behaviour program. This program targets problem-solving skills both in general situations and situations specific to past offending behaviour. It then focuses on applying these skills to areas such as selfmanagement, social interaction, and attitude change. This program has been shown to secure reductions in various dynamic risk factors that are related to continued offending behaviour (McGuire, 2002) but its impact on outcome is unknown.

In terms of parole release, Kusaj (2019) found that an offenders' potential ability to manage future stressors differentiated between those offenders who obtained parole from the California Parole Board and those who did not. Specifically, only $24 \%$ of offenders granted parole without stipulations had present and relevant difficulties with managing stress. Moreover, $44 \%$ of offenders who were denied parole had present and relevant difficulties in managing stress. Overall, the ability to problem solve is not only related to re-offending, related to an offenders' belief in their ability to change, and reductions in dynamic risk factors, but it is also appears to be an important factor in parole decision making.

\section{Self-Regulation/Affect Management}

For decades researchers have highlighted self-regulation and negative affect as being important precursors of criminal conduct (Pithers, Kashima, Cummings, Beal, \& Buell, 1988). More recently, Garofalo \& Velotti (2017) examined the impact both emotion regulation and positive versus negative emotionality would have on propensity for trait aggression. Hierarchical regression analyses illustrated that even after removing shared variance between negative and positive emotionality, trait emotionality contributed to $10 \%$ of the variance in trait aggression and emotional dysregulation accounted for $17 \%$ of the variance in trait aggression. Additionally, 
Wolff and Baglivio (2017) analysed 27, 720 youth offenders regarding the influence of negative emotionality and adverse childhood experiences on recidivism. The researchers found that an adverse childhood, while predicting recidivism individually, also influenced recidivism through its effect on negative emotionality. Specifically, $50 \%$ of the influence of adverse childhood experiences on recidivism was through its influence on negative emotionality. Moreover, negative emotionality on its own significantly increased the likelihood of re-arrest. Overall, Wolff and Baglivio's (2017) findings suggest that emotionality, especially negative emotions, has an influence on the risk of recidivism. Additionally, the ability to regulate emotions is also related to variance in trait aggression. Therefore, treatment aimed at building emotional regulation would assist offenders' re-integration into pro-social society and would be a general indication of pro-social change. In terms of California parole release, Kusaj (2019) found that relevant and recent problems with emotional instability lead to more denials for parole or parole with stipulations, meaning that emotional regulation has an impact on parole decision making.

\section{California Parole}

In the California Prison System, there are generally two types of incarcerated offenders; those who have determinate sentences which have a pre-determined end date, and those who have indeterminate sentences. Those with indeterminate sentences are incarcerated for a term of life imprisonment with possibility of parole, "lifers". The Board of Parole Hearings usually schedules a suitability hearing about one year prior to the offender's minimum parole eligibility date (MPED) (California department of corrections and rehabilitation, 2019c). The Board of Parole Hearings takes many factors into account when coming to a decision regarding whether to release a "lifer". Title 15 of the California Code of Regulations stipulates that the board takes 
into account all relevant and reliable information when coming to a decision. This includes aspects of the offence including number of victims, if it was committed in a dispassionate manner, the motive for the offence, social history, sadistic sexual offences, psychological factors, age, criminal history, plans for the future, and institutional behaviour. When a negative decision is made, the board is required to articulate this decision with evidence to support it (California Office of Administrative Law, 2019). Additionally, the Forensic Assessment Division (FAD) provides the board with their professional judgement regarding the offenders' risk to reoffend using evidence-based risk assessments. They provide the board with Comprehensive Risk Assessments which may include but are not limited to an analysis of the offense committed, institutional programming, and an evaluation of stable and dynamic risk factors for the offender (California department of corrections and rehabilitation, 2019). Kusaj (2019) explained that if the risk variation within long-term offenders can be reliably measured then parole eligibility considerations can be enhanced.

The FAD takes into account the current relevance of risk factors for an offender including recent difficulties with mental disorder, recent problems with affective stability (i.e. emotional regulation, recent difficulties with supervision or treatment response, recent problems with insight formulated as an offender's ability to appreciate the factors that lead to that individual's heightened risk for violence, and the person's ability to cope with potential future stressors (Kusaj, 2019). Moreover, the FAD analyzes the offender's placement on risk assessments such as the HCR-20-V3 which assesses violence risk (Douglas et al., 2014), the Static-99R which assesses risk for male sexual offenders (Helmus, Thornton, Hanson, \& Babchichkin, 2011), and the PCL-R which assesses the presence of psychopathic traits (Hart, Forth, and Hare, 1991). 
According to Kusaj (2019) of the 3,100 long term offenders analyzed in California in 2016, parole grants varied by offender risk; $55 \%$ of low risk, $17 \%$ of moderate risk, and less than $1 \%$ of high-risk offenders were granted parole. Kusaj also found that dynamic risk factors such as insight, instability, and difficulties with treatment or supervision best differentiated parole decisions in that the higher the presence and relevance of these factors, the lower the probability was for a positive parole decision. Specifically, $63 \%$ of offenders who were granted parole were assessed to have difficulties with insight present but only $12 \%$ of offenders granted parole were determined to have difficulties with insight as a relevant risk factor. Importantly, the CCS takes into account these and various other elements of change processes which have been empirically shown to be related to offending behaviour. Moreover, once validated, the CCS could serve as an empirical test of overarching processes of change that can be used to supplement parole decisions.

Weisberg, Mukamal, \& Segall (2011) examined parole decisions in a random sample of indeterminately sentenced offenders in California whose hearings were conducted between October 1st, 2001 and January 28th, 2010. They found that age, criminal history, and the presence of substance abuse had no significant impact on granting parole. However, if substance abuse factors were present in the index crime, whether the offender was currently participating in a 12-step program for substance abuse did have a significant impact on parole decisions. Additionally, institutional behaviour and California's state-mandated risk assessment results did have a significant impact. This research further supports Kusaj's (2019) conclusion that dynamic risk factors and their current relevancy to offenders best differentiates the offenders who receive and are denied parole. In the current study, CBPH decisions are used as a proxy for direct recidivism rates. This is because of the low rate of re-offence for long-term offenders (Axford \& 
Young, 2014), the availability of relevant information in the parole portfolio provided by the $\mathrm{CBPH}$, and the goal of the research which is to illustrate the validity of client change.

\section{The Current Study}

When an offender is incarcerated and undergoes treatment, there is an assumption that this treatment initiates change processes which will effectively reduce (change) risk state, as measured by an empirical dynamic risk assessment and lead to lower rates of failure. However, at this point there is little research highlighting germane constructs nor reflecting a validated assessment with which to measure this change (Serin et al., 2013; Stewart, Usher, \& Vanderey, 2015). A measure of change will facilitate client success and provide more evidence-based assessments with which to examine a client's suitability for release. These processes are not only important for ensuring public safety but assist the offender in accessing the kind of treatment needed to support re-entry. Moreover, the CCS uses items which are derived from evidencebased change factors which should generalize across justice-involved individuals. Therefore, it is hypothesized to work similarly across offender populations.

The current study seeks to validate the CCS with a population of "lifers" in the California prison system. Lifers have an indeterminate sentence and will be released only upon determination that they are no longer a threat to public safety. The Board of Parole conducts hearings in order to determine lifers' suitability for parole (California department of corrections and rehabilitation, 2019). Ideally, the CCS would be completed using a prospective design, specifically measuring three points in time (e.g. before, during and after treatment) in order to measure change over time. However, the current research reflects more a proof of concept to determine if the CCS can differentiate individuals higher and lower in terms of offender change, and whether this will then be reflected in a positive or negative parole decision. 
The following questions will be considered:

1. Is the CCS internally consistent and can it be reliably scored? Using FAD reports from lifer parole hearings, it is expected that multiple coders would be able to score the CCS and come to similar conclusions.

2. Does the CCS relate to the PCL-R? It is expected that these instruments will have a small to moderate negative correlation.

3. Do scores on the CCS relate to client outcome? It is expected that higher scores on the CCS will be related to positive parole release decisions at the bivariate level.

4. Does the CCS predict client outcome? It is expected that not only will higher scores on the CCS be related to improved probability of positive parole suitability and release, but also that higher scores on the CCS will predict positive parole suitability decisions after controlling for gender, age, and risk level. Additionally, it is expected that the CCS will have moderate predictive validity (measured by AUC) similar to that of the DRAOR for two reasons: 1) it is similar in composition in that it uses acute, changeable factors that are meant to be assessed and reassessed to measure change, rather than a risk assessment that examines an individual in a snapshot of time. 2) Many of the items are derived from similar theory as the DRAOR and some are derived from the DRAOR itself.

Each of these research questions will address the relationship between client change and parole suitability decisions. The first research question addresses the functionality of the CCS. Research questions two and three can illustrate whether client change is related to and predicts recidivism. That is, whether it is likely that change eventually leads to positive parole suitability decisions. Finally, the fifth research question provides a measure of discrimination (e.g. AUC) 
that is easily comparable to the accuracy of risk assessments, although in this study the accuracy relates to parole decisions.

\section{Method}

\section{Participants}

The data used in this research was extracted from Comprehensive Risk Assessments (CRA's), also called, 'Parole Portfolios' obtained from the California Board of Parole Hearings. Although originally a random subsample of 120 was to be taken from a larger sample of 1,200 long-term offenders reviewed by the Board of parole, only 118 were obtained and 113 analysed, for reasons explained later. The participants were determinately and indeterminately sentenced offenders in the California Department of Corrections, all of whom were long term offenders.

The participants, on average, were 48.47 years old $(S D=9.7)$ with a grade level of 10.11 $(S D=2.74)$. Participants were primarily Mexican $(33.6 \%)$, and male $(92.9 \%)$ of low risk (51.3\%) whose 'life crime' had been second-degree murder (38.9\%). More demographic information for categorical variables in the sample can be seen in Table 1. Total PCL-R scores $(M=15.90, S D=6.41)$ were below the average level for American offenders and below the cutoff normally used to distinguish psychopathy (Hart, 1980). The average placement score for the offenders, with the lowest possible score being 19 , was $22.66(S D=15.49)$ and average CCS score was $24.01(S D=4.76)$. 
Table 1

Demographic Characteristics

\begin{tabular}{|c|c|}
\hline Variable & $n(\%)$ \\
\hline \multicolumn{2}{|l|}{ Race } \\
\hline Mexican & $38(33.6 \%)$ \\
\hline Hispanic & $6(5.3 \%)$ \\
\hline Black & $33(29.2 \%)$ \\
\hline White & $20(17.7 \%)$ \\
\hline Other & $15(13.3 \%)$ \\
\hline \multicolumn{2}{|l|}{ Gender } \\
\hline Male & $105(92.9 \%)$ \\
\hline Female & $8(7.1 \%)$ \\
\hline \multicolumn{2}{|l|}{ Parole Decision } \\
\hline Grant & $70(61.9 \%)$ \\
\hline Deny & $43(38.1 \%)$ \\
\hline \multicolumn{2}{|l|}{ CRA Risk Level } \\
\hline Low & $58(51.3 \%)$ \\
\hline Moderate & $55(48.7 \%)$ \\
\hline \multicolumn{2}{|l|}{ Offence Type } \\
\hline $1^{\text {st }}$ Degree Murder/ First Degree & $30(26.5 \%)$ \\
\hline \multicolumn{2}{|l|}{ Murder } \\
\hline $2^{\text {nd }}$ Degree Murder & $44(38.9 \%)$ \\
\hline Attempted $1^{\text {st }}$ Degree Murder & $8(7.1 \%)$ \\
\hline Aggravated Mayhem & $2(1.8 \%)$ \\
\hline Aggravated Sexual Assault of a Child & $2(1.8 \%)$ \\
\hline \multicolumn{2}{|l|}{ Under 14} \\
\hline Attempted Murder & $2(1.8 \%)$ \\
\hline Kidnap for Robbery & $3(2.7 \%)$ \\
\hline Kidnap/Robbery & $2(1.8 \%)$ \\
\hline Kidnapping & $2(1.8 \%)$ \\
\hline Other & $16(14.16 \%)$ \\
\hline Determinately Sentenced Offender & $61(54 \%)$ \\
\hline Indeterminately Sentenced Offender & $52(46 \%)$ \\
\hline Elderly Parole & $14(12.4 \%)$ \\
\hline Young Offender & $70(61.9 \%)$ \\
\hline
\end{tabular}

Note* CRA $=$ Comprehensive Risk Assessment 


\section{Measures}

\section{Client Change Scale (CCS).}

The CCS (see Appendix A) was the primary measure used in this study. As mentioned, it contains 16 items which assess general characteristic of inter/intrapersonal change derived from relevant theory. These characteristics are: motivation level, stage of change, compliance with supervision conditions, engagement in change, effort in change, identity, agency for positive change, explanatory style, expectations about change, social support and peers, stability of employment, stability of accommodation, substance use, problem-solving, self-regulation /affect management, and sense of entitlement. Each of these items is scored on a 0-2 scale. 0 generally indicating negative skills/attributes on the item, 1 representing some positive change, and 2 representing high positive skills/attributes. Each of the items has specific indicators for assessment on this rating scale. For example, when measuring compliance with supervision conditions a client who scores 0 will "reject authority and the merit to follow any rules or guidelines assigned to them. They very much view interaction with staff as an "us" versus "them" situation." A client who scores 1 will "not fully accept overall risk and need assessment and is ambivalent at best about following staff rules. Alternatively, verbalizes agreement but then rejects efforts for cooperation, often making up excuses for noncompliance." Finally, a client who scores 2 will, "be attentive and engaged to receive guidance about finding strategies and activities that will help them stay crime-free in the future. Client is compliant with rules and expresses a high motivation to complete supervision." 


\section{Psychopathy Checklist-Revised (PCL-R).}

The Psychopathy Checklist (PCL-R; Hare, 1980) and its revised version (Hart, Hare, \& Harpur, 1992) is a 20-item scale measuring the clinical construct of psychopathy in adults (Hare, 2016). Each item is scored from 0-2 based on its applicability to the individual. The PCL-R therefore produces scores that can range from $0-40$, generally with a score of 30 indicating the threshold for psychopathy. The items of the PCL-R fall into four factors: interpersonal, affective, lifestyle, and anti-social. Neuman, Hare, and Johansson (2013) assessed the four-factor model of the PCL-R with 1,016 offenders. They found that the four-factor model had good internal consistency and uni-dimensionality because for each factor all alphas exceeded .82 and mean inter-item correlations exceeded .48. The four-factor model overall was found to have excellent fit. These four factors can also be used to model a higher order two factor model of Interpersonal/Affective and Lifestyle/Anti-Social (Hare, 2016). While the two models are still debated, there is more empirical research regarding the two-factor model (Yang, Wong, \& Coid, 2010). The factors each express a conglomeration of personality traits (Hare, 2016). The interpersonal factor includes the characteristics of glibness/superficial charm, grandiose sense of self worth, pathological lying, and manipulative. The affective factor includes that characteristics of lack of remorse or guilt, shallow affect, callous/lack of empathy, and failure to accept responsibility. The lifestyle factor captures that characteristics of a need for stimulation, parasitic lifestyle, no realistic, long term goals, impulsivity, and irresponsibility. Finally, the antisocial factor incorporates the characteristics of poor behavioural controls, early behavioural problems, juvenile delinquency, revoke conditional release, and criminal versatility.

Although the PCL-R was originally produced to measure a personality disorder, it has become one the most proliferate instruments for the assessment of risk and prediction of violence 
(Yang et al., 2010). A meta-analysis of violence risk assessments found that the PCL-R was one of the most widely used in the 28 studies Yang and colleagues (2010) analysed. After controlling for individual study features (e.g. follow up time), these researchers found that only the effect size of the HCR-20 was significantly larger than the PCL-R; the seven other risk assessments represented comparable effect sizes. Yang and colleagues (2010) found that the PCL-R had an average AUC of .64, reflecting a moderate effect size in predicting risk.

\section{Historical Risk Management Version Three (HCR-20 $\left.{ }^{\mathrm{V} 3}\right)$.}

The Historical-Clinical Risk management assessment (HCR-20 ${ }^{\mathrm{V} 3}$; See Appendix B) is a risk assessment used in the decision-making process by the California Board of Parole. The information gleaned from an analysis of each factor in the assessment will be one of the materials used to score the CCS.

The HCR-20 ${ }^{\mathrm{V} 3}$ is a structured professional judgement risk assessment for general violence (Douglas et al., 2014) used across a range of decisions in correctional and forensic mental health settings. The measure contains three domains of risk items: the historical scale $(\mathrm{H} ; 10$ items $)$, the Clinical Scale (C;5 items), and the Risk Management scale (R;5 items) (Douglas et al., 2014). Historical factors indicate problematic past functioning in areas of living and adjustment, mental health, and anti-sociality. The clinical domain focuses on current psychological, social, and mental health, and behavioural functioning. The clinical section is designed to be re-evaluated periodically. The risk management domain concerns future psychological, social, mental health, and behavioural functioning (Douglas et al., 2014).

The HCR- $20^{\mathrm{V} 3}$ rates the presence of each of these risk factors on a scale from 0 (No), 1 (Possibly or Partially) to 2 (Yes). Some of the items of Version 3 also contain sub items for more 
complicated risk factors (e.g. Item: Relationships, sub-item: a. Intimate b. Non-Intimate). For each item, the assessor is also to measure the relevance of the risk factor for the individual on a three-point scale from low to high (Douglas et al., 2014).

The final designation of risk level from the HCR-20V3 is a narrative categorical designation, called a Summary Risk Rating (SRR) approach in which the assessor categorizes offenders as low, medium, or high risk (Douglas et al., 2014). For version 3, it is recommended that these summaries indicate risk for general violence, risk for serious physical violence specifically, and risk for imminent violence. Generally, as the number of relevant risk factors for an offender increase, so will the rating of risk.

Strubb, Douglas, and Nicholls (2014) found average ratings for the Historical Presence scale with offenders as 14.5 , the Clinical scale as 4.4 and the $\mathrm{R}$ scale as 6.3 . The average total for presence ratings was 25.2. In terms of relevance, the researchers found an average score of 9.2 for the Historical subdomain, 3.3 for the Clinical subdomain, and 4.2 for the Risk subdomain. The average total for the relevance scale was 16.6.

Strubb, and colleagues (2014) analysed the ability of the HCR-20V3 to predict short term violent re-offending as well as the validity of the relevance ratings with 56 offenders and 50 civil psychiatric patients. Each were assessed for violence at 4-6 weeks and 6-8 months release. AUC's for SRR's in the offender group were .91 and .68 for predicting violence at four to six weeks and six to eight months, respectively. AUC's for presence ratings ranged from .74 to .90 whereas AUC's for relevance ratings ranged from .56 to .84. However, power was somewhat reduced when dividing by the subgroups because of the small sample size. In combined analyses (civil psychiatric patients and offenders), AUC's for Presence subdomains averaged .74, and .68 
for the relevance subdomain. AUC's generally indicated moderate to large effect size in terms of predictive validity.

\section{Procedure}

The California Board of Parole Hearings provided access to 118 CRA's through a secure access website called "Workspaces”. The CRA's were conducted between 2016 and 2017. These parole portfolios were written from both an interview with the inmate and a review of their official records. The CRA's focused on relevant risk factors throughout the inmate's life span and included the inmate's perspective of their crimes, their life crime, and their time in prison. These narrative CRA's were scored according to the CCS (see Appendix A) using Excel version 16. Each item was scored individually, and an Excel SUM equation was used to sum the CCS for each participant. The scorer was blind to parole decision; however, risk levels and PCL-R scores were discussed within the CRA's. Within Workspaces, Excel spreadsheets were provided with relevant variables (e.g. race, hearing decision, etc.) regarding each of the participants that were not discussed within the narrative CRA. Upon the culmination of scoring the CCS, each of the relevant variables from these Excel sheets were amalgamated into one large spreadsheet and uploaded into SPSS version 25. Although individual scores for each item were provided for the $\mathrm{HCR}-20 \mathrm{~V}^{3}$, due to the nature of the aggregated narrative categorical summary risk rating approach to categorizing offenders as low, medium, or high risk, ultimate categorical ratings of $\mathrm{HCR} 20 \mathrm{~V}^{3}$ scores were unavailable. Arguably, the summary risk rating coming from the CRA is a more robust risk index as it holistically incorporates several risk instruments plus file and interview information with a focus on currently relevant risk factors.

In order to measure inter-rater reliability, a second rater was given access to workspaces and provided with the CCS. The second rater was also blind to hearing decision. The first and 
second rater met in order to go over the instrument and to answer any questions the second rater had regarding it's scoring. After this meeting, the second rater was given ten random participants to score on the CCS.

\section{Data Cleaning}

Before analysis began it became clear that five of the 118 participants provided by the California Board of Parole chose not to participate in their CRA. This meant that the assessor analysed relevant file information regarding criminal history, substance abuse, institutional behaviour, past analyses of clinical risk factors and parole plans. However, there was not enough information to code a variety of variables on the CCS including identity, self-entitlement, and explanatory style. As such, before preliminary analyses began, it was decided that there was not enough information to include these participants and they were excluded from the data set. This meant that only 113 participants were included in the analyses.

\section{Overview of Analyses}

The first research question examines the reliability of the CCS. SPSS was used to conduct Cronbach's Alpha in order to determine internal consistency and an intra-class correlation coefficient (ICC) was used to assess inter-rater reliability. Cronbach's alpha is based on the average inter-item correlation for a questionnaire, therefore a higher correlation between the items indicates that the items are measuring the same construct (Hinton, McMurray, Brownlow, 2014). Generally, alphas above .70 (Reynolds \& Livingstone, 2012) and .80 (Clark \& Watson, 1995) indicate adequate internal consistency for a measure. Corrected Item-Total Correlations and Cronbach's alpha if item were deleted were assessed for each item of the questionnaire. Corrected Item-Total Correlations represent the association between individual items and the total score on the measure, a reliable item should have a corrected item-total 
correlation above .3 (Hinton et al., 2014). Cronbach's Alpha if item were deleted indicates the influence that individual items have on the reliability of the scale (Hinton et al., 2014).

A two-way random effects intra-class correlation coefficient is a common instrument used to assess inter-rater reliability as the coefficient takes both the influence of the rater and the ratee into account and assumes that both are sampled from a larger population, meaning that the ICC can be generalized past the sample used (Shrout \& Fleiss, 1979). ICC values less than 0.5 indicate low reliability, values between 0.5 and 0.75 indicate moderate reliability, and values between 0.75 and 0.9 reflect good reliability (Koo \& Mae, 2016).

The second research question had to do with construct validity, in that the CCS should be conceptually related to similar instruments. As total scores for the HCR2 $20^{\mathrm{V} 3}$ were not provided, the CCS was examined in comparison to the PCL-R. As both of these variables were continuous, but the CCS was not normally distributed, a Spearman's correlation was used in order to examine this relationship. Spearman's correlation is a non-parametric correlation that is simply a special case of Pearson's $r$. Spearman's correlation artificially converts continuous variables into rank scores and therefore does not assume normality of the distribution (Chen \& Popovich, 2002). Due to a loss of information when converting these scores, Spearman's correlation decreases in size as compared to Pearson's $r$ (Chen \& Popovich, 2002) where .1 is a weak correlation, .4 is a moderate correlation, and .7 a strong correlation (Dancey \& Reidy, 2007).

The third research question examined the relationship between the CCS and hearing outcome. As hearing outcome was a dichotomous variable, a point-biserial correlation would normally be used. However, as total scores of the CCS were found to be non-normally distributed the Spearman's rank correlation was again used to assess the magnitude of this relationship. 
The fourth research question addressed the predictive relationship between CCS scores and hearing outcome after controlling for age, race, sex, and risk level. A logistic regression was used for this purpose as the logistic regression is a powerful way to analyze the influence of multiple independent variables on a binary outcome by calculating each variable's unique contribution to the prediction of the outcome. Logistic regression also permits controlling for confounding independent variables, which is the goal in the current research (Stoltzfus, 2011). In logistic regression, the influence of independent variables is typically reported using an Odds Ratio [OR] which provides the strength of the contribution made by a particular predictor variable to the outcome (Stolzfus, 2011). An OR of 1 indicates that there is no effect, whereas an OR different from one indicates some effect. Kleinbaum (1994) describes the OR as the probability that the event of interest (granted parole) will occur over the probability that that same event will not occur (denied parole). So, if you were to have an OR of 1.5 , this would mean that the probability of obtaining parole was 1.5 times that of the event not occurring, or a $50 \%$ chance of obtaining parole for a person exposed to the particular independent variable (Stoltzfus, 2011). Adjusted OR's represent the contribution of an independent variable while other independent variables remain constant. Adjusted OR's are often smaller than their unadjusted counterparts. Confidence intervals are also important for interpreting the influence of an OR. If the CI passes through one, this could signify that the OR may not be significant (Stolzfus, 2011). Generally, ORs of 1.68, 3.47, and 6.71 represent small, moderate, and large effect sizes because these values approximately correspond to Cohen's $d$ s of $.20, .50$, and .80 (Chen, Cohen, \& Chen, 2010).

The fifth research question addressed the predictive validity of the CCS which was assessed using a Receiver Operating Characteristic analysis (ROC). The ROC is created by 
plotting sensitivity by specificity, or the true positive rate by the false positive rate (Mossman, 2013). The Area Under the Curve (AUC) statistic, which is derived from the ROC, represents a summary statistic of the overall predictive accuracy of the ROC (Mossman, 2013). The AUC will essentially answer the question: if a client was randomly selected from the high CCS group, and another client randomly selected from the low CCS group, what would be the probability that the assessment would have assigned a higher probability of a positive parole suitability decision to the high CCS person? (Mossman, 2013). An AUC statistic can vary between 0 and 1, with .5 representing an effect that is due only to chance. An AUC above .5 indicates positive predictive accuracy. Essentially, higher scores on the assessment are related to higher probability of a positive parole decision and vice versa (Helmus \& Babchishin, 2017). Using a comparison to Cohen's (1998) heuristics for small, moderate, and large effect sizes, Rice and Harris (2005) denote a .56 AUC as small, a .64 as moderate, and a .71 as large. Generally, in predicting recidivism, AUC's are in the moderate range. Yesberg and Polaschek (2015) found AUC's for subscales and total scores of the DRAOR between .58 and .62 for re-imprisonment and AUC's between .55 and .62 for reconviction. As the CCS is based on dynamic risk factors, some of which were derived from the DRAOR and others derived from similar theoretical background, it is expected that the AUC for the CCS would be within this range.

\section{Results}

\section{Data Screening}

Preliminary analyses were conducted to test the assumptions of inferential statistics. Descriptive analyses indicated that there was no missing data for any variables of interest. Although the CCS ranges from 0 to 32, the range for this sample spanned from 11 to 32 , 
indicating some restricted range which may mean that this sample is not generalizable to other populations.

The presence of univariate outliers in the variables of interest were assessed using box plots for the continuous variables of the PCL-R and the CCS. Box plots indicated that there were no potential extreme values for either measure. $\mathrm{Z}$ scores were also calculated to assess the presence of univariate outliers, as none were above or below 3.29, it was concluded that there were no extreme outliers. The presence of multivariate outliers between variables of interest (PCL-R, hearing decision, and CCS) was assessed using scatterplots. A visual inspection of the scatterplots for these variables indicated no obvious multivariate outliers. Malahanobis distance was also used to inspect for multivariate outliers. None of the Malahanobis distance statistics were larger than 13.816 and therefore no multivariate outliers were discovered.

In order to test normality for continuous predictors, histograms and boxplots were analysed. A visual inspection indicated that the PCL-R appeared normally distributed but that the CCS was not and appeared to have a negative skew. A Shapiro-Wilk test for normality further indicated that the total score of the CCS was not normally distributed among the population $(W=$ 935, $p<.001)$. Descriptive statistics for the CCS and the PCL-R are in Table 2, where it can be seen that scores for the CCS reflect a negative skew whereas scores on the PCL-R range widely across the possible scores.

The logistic regression assumes a linear relationship between continuous dependent variables and the logit transformation of these variables (Meyers, Gamst, Guarino, 2006). In order to test this assumption, a constant of 13 was added to CCS total to make sure that no values fell below 1. Then, the natural log of the CCS was determined. The interaction between CCS total scores and its natural log for the dependent variable of hearing decision was assessed using 
a logistic regression. The interaction term was not significant and therefore this assumption was satisfied. This process was carried out for age and PCL-R total scores and was found to be satisfied for both.

Table 2

Descriptive Statistics of Continuous Independent Variables

\begin{tabular}{lcccc}
\hline Variable & Range & Min & Max & M(SD) \\
\hline CCS & 21 & 11 & 32 & $24.01(4.76)$ \\
PCL-R & 28.8 & 3.2 & 32 & $15.90(6.41)$ \\
\hline
\end{tabular}

Note* CCS $=$ Client Change Scale, PCL-R $=$ Psychopathy Checklist Revised

\section{Reliability and Validity of the CCS}

Internal consistency was determined to be adequate $(\alpha=.86)$ for the 16 items of the CCS. Table 2 reports the corrected item-total correlations and Cronbach's alpha if item were deleted for each of the items. The corrected item-total correlation for Compliance with Supervision Conditions was somewhat below .3, as was Identity, indicating that these items may be poor on reliability, however, Cronbach's Alpha did not increase if these items were to be omitted.

The first research question also addressed reliability of the CCS between multiple raters. Based on a mean rating, absolute effect, two-way random model, the ICC for ten participants with two raters indicated excellent inter-rater reliability $(\mathrm{ICC}=.96,0<.000,95 \% \mathrm{CI}=.78, .99)$. Further, the $95 \%$ confidence intervals indicated that ICC values would fall between 'good' and 'excellent' $95 \%$ of the time. 
Table 3

CCS Item-Total Correlations and Cronbach's Alphas if Item Deleted

\begin{tabular}{lcc}
\hline CCS Item & $\begin{array}{c}\text { Corrected item- } \\
\text { total correlation }\end{array}$ & $\alpha$ if item deleted \\
\hline Motivation & .72 & .84 \\
Stage of Change & .72 & .84 \\
Compliance with Supervision Conditions & .29 & .86 \\
Engagement & .69 & .84 \\
Effort & .44 & .86 \\
Identity & .26 & .86 \\
Agency & .58 & .85 \\
Explanatory Style & .51 & .85 \\
Expectations of Change & .65 & .85 \\
Support & .37 & .86 \\
Employment & .42 & .86 \\
Stability of Accommodations & .39 & .86 \\
Substance Use & .51 & .85 \\
Problem Solving & .50 & .85 \\
Self Regulation & .40 & .86 \\
Entitlement & .34 & .86 \\
\hline Note. CCS Clinn Change Scale & & \\
\hline
\end{tabular}

Note. CCS $=$ Client Change Scale

The second research question to be addressed was whether the CCS relates to the PCL-R, representing construct validity. It was expected that this relationship would be modest. A Spearman's correlation was undertaken in order to assess the relationship between the PCL-R and the CCS, as the CCS was found to be non-normally distributed. Results indicated a moderate association where as level of psychopathy decreased, client change increased $\left(\mathrm{r}_{s}=-.511, p<\right.$ $.0001)$. Figure 1 graphically represents the strength of this correlation with the raw scores of the measures. It should be noted, however, that Spearman's correlation is calculated using rank scores rather than raw scores.

The CRA's provided an overall assessment of risk derived from the totality of the interview, file review, and validated risk instruments (PCL-R, HCR20V ${ }^{3)}$. A Spearman's correlation was therefore calculated between the CCS and this risk categorization, which was found to be significant $\left(\mathrm{r}_{s}=-.727, p<.0001\right)$. The nature of the relationship indicated that as risk 
level increased, client change decreased. The CCS was therefore related to other assessments of risk in expected directions.

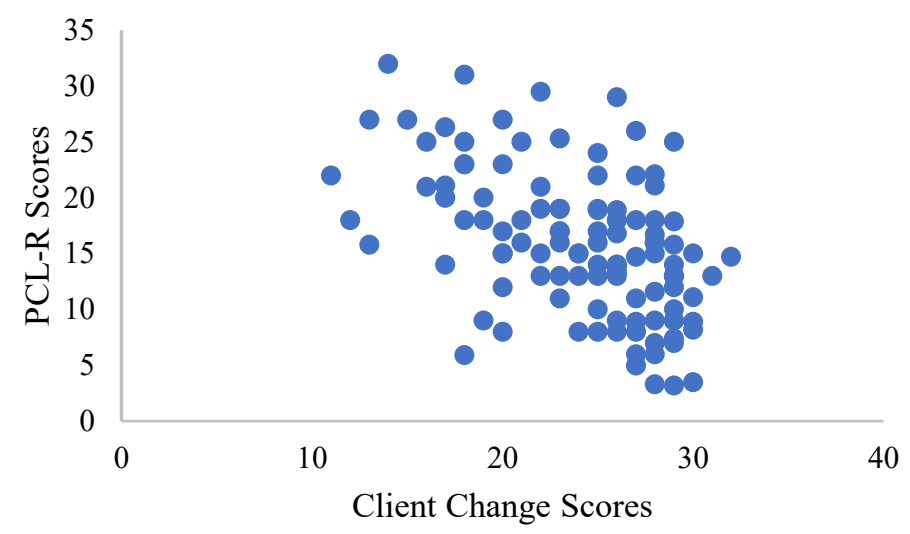

Figure 2. Relationship Between Client Change Scale and PCL-R

\section{Relationship Between the CCS and Parole Decision}

The third research question addressed whether there was an association between CCS scores and hearing outcome. Spearman's correlation indicated that there was no significant relationship between Client Change, as measured by the CCS, and hearing decision $\left(r_{s}=.069, p\right.$ $=.470$ ). This relationship is graphically represented in Figure 2, which confirms that there is little relationship between CCS scores and hearing decision. Interestingly, there was also no significant association between PCL-R scores and hearing decision $\left(r_{p b s}=-.111, p=.242\right)$, 


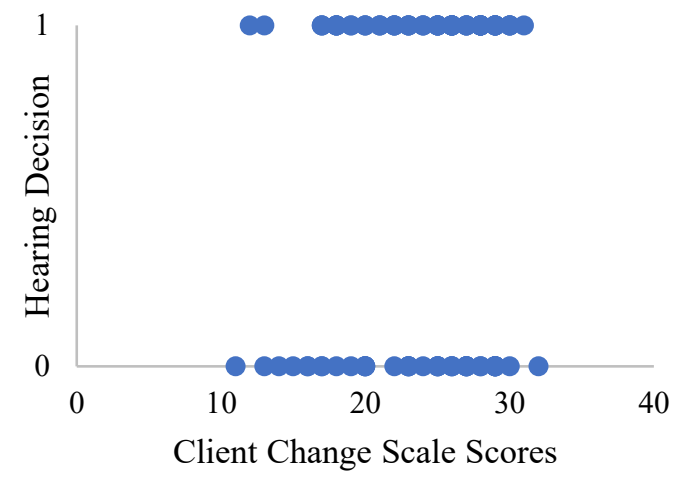

Figure 3. Relationship between Client Change Scores and Hearing Decision.

A logistic regression was conducted in order to asses the ability of the CCS to independently predict parole decision. First, a logistic regression was conducted with hearing decision as the outcome and the CCS as the only predictor variable (results can be seen in Table 1). The omnibus test indicated that the model did not significantly predict parole decision $\left(\chi^{2}(1)\right.$ $=.99, p=.321)$ whereas the Hosmer and Lemeshow test indicated good fit between the predicted and actual outcome $\left(\chi^{2}(8)=8.53, p=.38\right)$.

Overall, the model with only the CCS as a predictor accounted for only between .09 and $1.2 \%$ of the variance in the dependent variable with $100 \%$ of the parole grants being successfully predicted, but only $2.3 \%$ of parole denials. Overall, $62.8 \%$ of parole decisions were successfully predicted. The OR indicated that for every one-unit increase in CCS scores, the odds of an inmate being granted parole increased by a factor of $1.04(95 \% \mathrm{CI}=.961,1.128)$. According to Chen and colleagues (2010) this OR is quite small, as it is below the 1.68 level for a small OR. Additionally, the confidence intervals of the OR crossed one, indicating that CCS may not be a significant contributor to the prediction of hearing decision in this sample. 
Table 4

Logistic Regression for CCS

\begin{tabular}{cccccccccc}
\hline & & & & & & & \multicolumn{2}{c}{$95 \%$ CI for OR } \\
\cline { 6 - 9 } Outcome & $B$ & $S E$ & Wald & $d f$ & $p$ & OR & Lower & Upper \\
\hline CCS Scores & .040 & .041 & .98 & 1 & .32 & 1.04 & .96 & 1.128 \\
\hline
\end{tabular}

Note* $^{*} \mathrm{CCS}=$ Client Change Scale

The fourth research question specifically focused on whether CCS scores would predict hearing decision after controlling for the influence of age, race, sex, and risk level. It was unlikely that the CCS would predict parole decision after controlling for these factors, given that it did not predict risk without taking the influence of these factors into account. However, a hierarchical binary logistic regression was undertaken regardless to examine this relationship as per the fourth research question. For the sake of ease of interpretation in these results, the six Hispanic participants and one American Indian participant were re-coded into the "other" race category, as they represented the smallest group membership in an already small sample size. The covariate of risk level was assessed using PCL-R scores in the absence of HCR $20^{\mathrm{V} 3}$ risk categories. The categorical variables of sex and race were dummy coded so that the respective reference categories were "Other" and "Females". At step one of the logistic regression race, sex, age, and PCL-R scores were entered, and CCS scores were entered at step two.

At step one of the logistic regression which included only the covariates, the Omnibus Chi Square test indicated that the model did not significantly predict parole decision $\left(\chi^{2}(6)=\right.$ $6.63, p=.36$ ), Although the omnibus Chi square test indicated a poor model fit for this sample, the Hosmer Lemeshow test indicated good agreement between the observed and predicted outcomes $\left(\chi^{2}(8)=6.17, p=.63\right)$. Overall, the model accounted for between 5.7 and $7.8 \%$ of the variance in parole decision with $64.6 \%$ of hearing decisions being correctly predicted $(88.6 \%$ of grants were correctly predicted while only $25.6 \%$ of denials). 
The results of the overall logistic regression can be found in Table 3 . The $B$ coefficients indicated that the odds of being granted parole decline for Mexican and White persons but increase for Black participants. Additionally, the odds of obtaining a positive parole determination decrease for male participants. The odds of being granted parole increased with age and decreased with a higher PCL-R scores. None of the Wald statistics for any of the covariates were significant and all OR's passed through one, indicating that none of the covariates significantly contributed to the variance in hearing decision.

Specifically, the odds ratios indicated that the odds of obtaining parole were increased by a function of $1.031(\mathrm{CI} 95 \%=.298,3.565)$ for Black participants, but decreased by a function of $.976(\mathrm{CI} 95 \%=.307,3.1)$ and $.319(\mathrm{CI} 95 \%=0.080,1.26)$ for Mexican and White participants, respectively. Further, for males, the odds of obtaining parole decreased by a function of .621 (CI $95 \%=.109,3.528)$.

As mentioned, CCS scores were entered into block two. An Omnibus test indicated that the full model did not significantly predict hearing decision $\left(\chi^{2}(7)=6.643, p=.467\right)$, neither did the step in which the CCS was entered $\left(\chi^{2}(1)=.01, p=.92\right)$. While the omnibus chi square test indicated poor fit, again, the Hosmer Lemeshow test indicated agreement between the predicted and actual outcomes form the model $\left(\chi^{2}(8)=.6 .17, p=.63\right)$. Overall, the model continued to explain between 5.7 and $7.8 \%$ of the variance in parole decision with $64.6 \%$ of hearing decisions being correctly predicted, which suggested that no additional variance was accounted for when entering CCS scores into the model. Additionally, the -2 Log likelihood for the model decreased in step one from 143.56 to 143.49 in step two. The fact that the likelihood decreased very little further indicated poor model fit. As can be seen in Table 4, the direction of the relationship of the covariates with the odds of obtaining a positive hearing decision remained the same. However, 
the Beta coefficients and the OR for CCS total score indicated that independently, CCS scores decreased the odds of obtaining a positive parole determination, although the opposite relationship was noted in a model including only CCS scores (see Table 3). Moreover, the 95\% confidence intervals for each individual variable at each step of the logistic regression passed through one, suggesting that the variables may not independently be significant contributors to the variance in hearing decision.

Some diagnostic tests were run in order to examine the logistic regression for potential problems that may distort the results. Cook's influence statistics were calculated in order to assess whether any one participant was having undue influence on the results, however, none of Cook's statistics reached one. Additionally, a correlation matrix was created to examine whether multicollinearity had any influence on the model but none of the correlations exceeded .5. As mentioned in the data screening section, all other assumptions of the logistic regression were met. 
Table 5

Logistic Regression for CCS after Controlling for Age, Race, Sex, and Risk Level

\begin{tabular}{|c|c|c|c|c|c|c|c|c|}
\hline \multirow[b]{2}{*}{ Outcome } & \multirow[b]{2}{*}{$B$} & \multirow[b]{2}{*}{$S E$} & \multirow[b]{2}{*}{ Wald } & \multirow[b]{2}{*}{$d f$} & \multirow[b]{2}{*}{$p$} & \multirow[b]{2}{*}{ OR } & \multicolumn{2}{|c|}{$95 \% \mathrm{CI}$ for $\mathrm{OR}$} \\
\hline & & & & & & & Lower & Upper \\
\hline \multicolumn{9}{|l|}{ Step 1} \\
\hline Mexican & -.03 & .59 & .002 & 1 & .20 & .98 & .31 & 3.1 \\
\hline Black & .03 & .63 & .002 & 1 & .97 & 1.03 & .30 & 3.57 \\
\hline White & -1.14 & .70 & 2.65 & 1 & .96 & .32 & .08 & 1.26 \\
\hline Males & -.48 & .89 & .29 & 1 & .59 & .62 & .11 & 3.53 \\
\hline PCL-R Score & -.04 & .03 & 1.23 & 1 & .27 & .96 & .90 & 1.03 \\
\hline Age & .007 & .02 & .08 & 1 & .77 & 1.007 & .96 & 1.05 \\
\hline \multicolumn{9}{|l|}{ Step 2} \\
\hline Mexican & -.02 & .59 & .001 & 1 & .97 & .98 & .31 & 3.12 \\
\hline Black & .03 & .63 & .002 & 1 & .97 & 1.03 & .30 & 3.56 \\
\hline White & -1.16 & .71 & 2.63 & 1 & .11 & .32 & .08 & 1.27 \\
\hline Males & -.49 & .90 & .30 & 1 & .58 & .61 & .11 & 3.55 \\
\hline PCL-R Score & -.04 & .04 & 1.04 & 1 & .31 & .96 & .90 & 1.04 \\
\hline Age & .007 & .02 & .08 & 1 & .77 & 1.01 & .96 & 1.05 \\
\hline $\mathrm{CCS}$ & -.005 & .05 & .01 & 1 & .92 & 1.00 & .90 & 1.10 \\
\hline
\end{tabular}

Note. PCL-R = Psychopathy Checklist Revised, CCS = Client Change Scale

In order to answer the final research question, a ROC curve was created. Saved probabilities from the logistic regression using only CCS scores were used as the independent variable in predicting positive parole decision. The resulting AUC statistic indicated that the CCS did not significantly predict hearing decision above chance (AUC $=.541[.428, .653], p=$ .469), and the resulting ROC curve can be seen in Figure 3. In order to investigate the predictive validity of the other variables in the model, age, race, sex, PCL-R scores, and CCS scores were entered as individual variables into an ROC curve. As can be seen in Figure 4, and in Table 5 indicating the AUC results, none of the variables individually predicted parole decision above chance levels (AUC's below the .5 level indicate prediction of a denial rather than a grant in parole decision). However, a ROC curve was created using the predicted probabilities from the logistic regression including all of the variables: age, sex, race, PCL-R scores, and CCS scores, which suggested moderate cumulative accuracy. 
As can clearly be seen in Figure 5 and Table 5, this model significantly predicted hearing decision above chance levels.

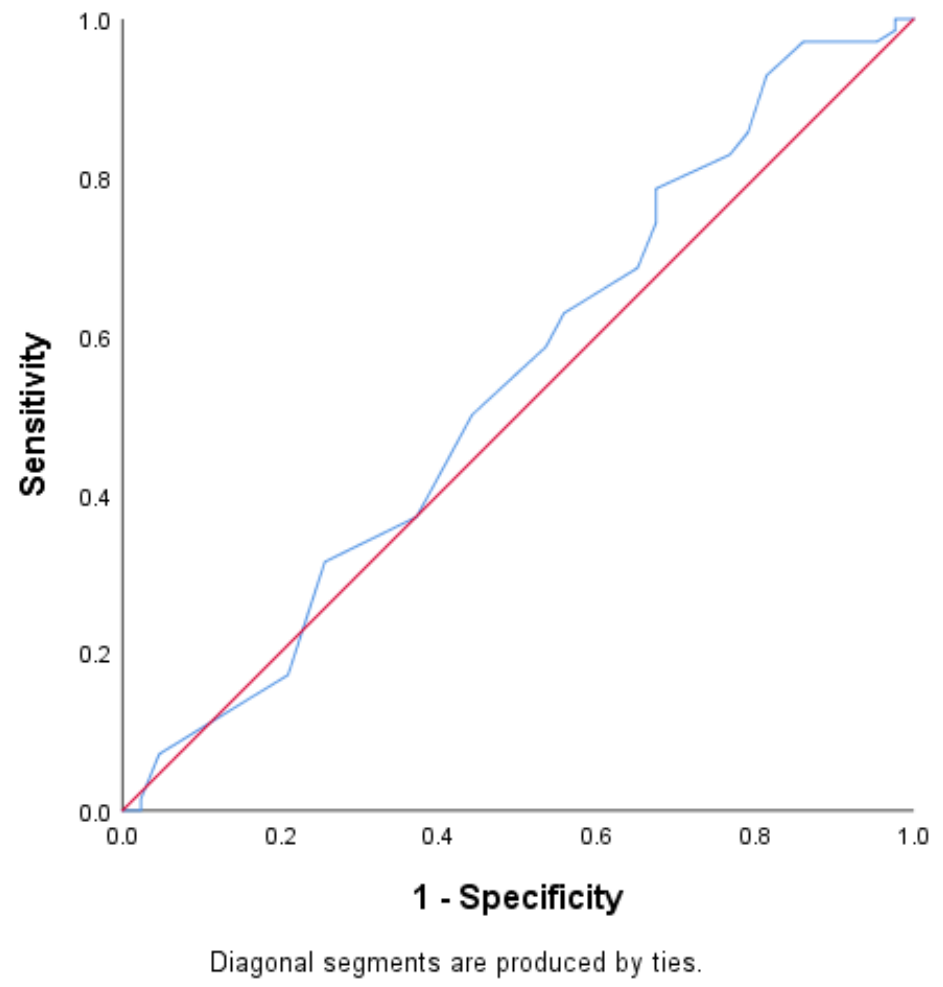

Figure 4. ROC curve for CCS in predicting parole decision. 


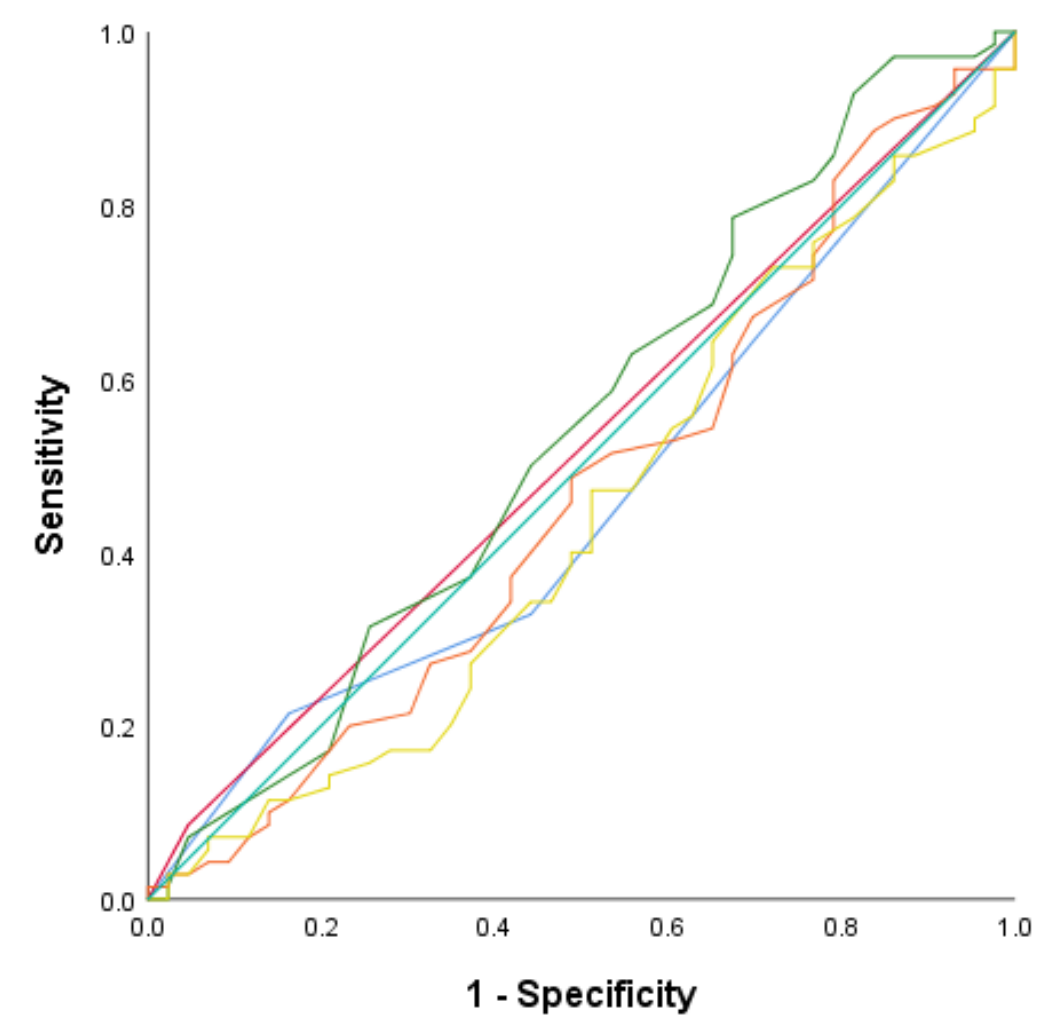

\section{Source of the Curve}

Race Numeric with Other

Combined

- Gender_Num

- CSC_TŌTAL

AGE

PCL_R_TOTAL_SCORE

- Reference Line

Diagonal segments are produced by ties.

Figure 5. ROC curves for individual variables of age, race, sex, PCL-R scores, and CCS in predicting hearing decision. 
Table 6

Individual AUC statistics for age, race, sex, PCL-R scores, and CCS scores

\begin{tabular}{lcl}
\hline \multicolumn{1}{c}{ Variable } & AUC $[95 \% \mathrm{CI}]$ & $p$ \\
\hline CCS & $.54[.43, .65]$ & .47 \\
Gender & $.52[.41, .63]$ & .73 \\
Race & $.47[.36, .58]$ & .54 \\
Age & $.47[.36, .58]$ & .55 \\
PCL-R & $.44[.33, .55]$ & .30 \\
Model & $.64[.53, .74]$ & .02 \\
\hline
\end{tabular}

Note* CCS = Client Change Scale, PCL-R = Psychopathy Checklist Revised, AUC = Area Under the Curve

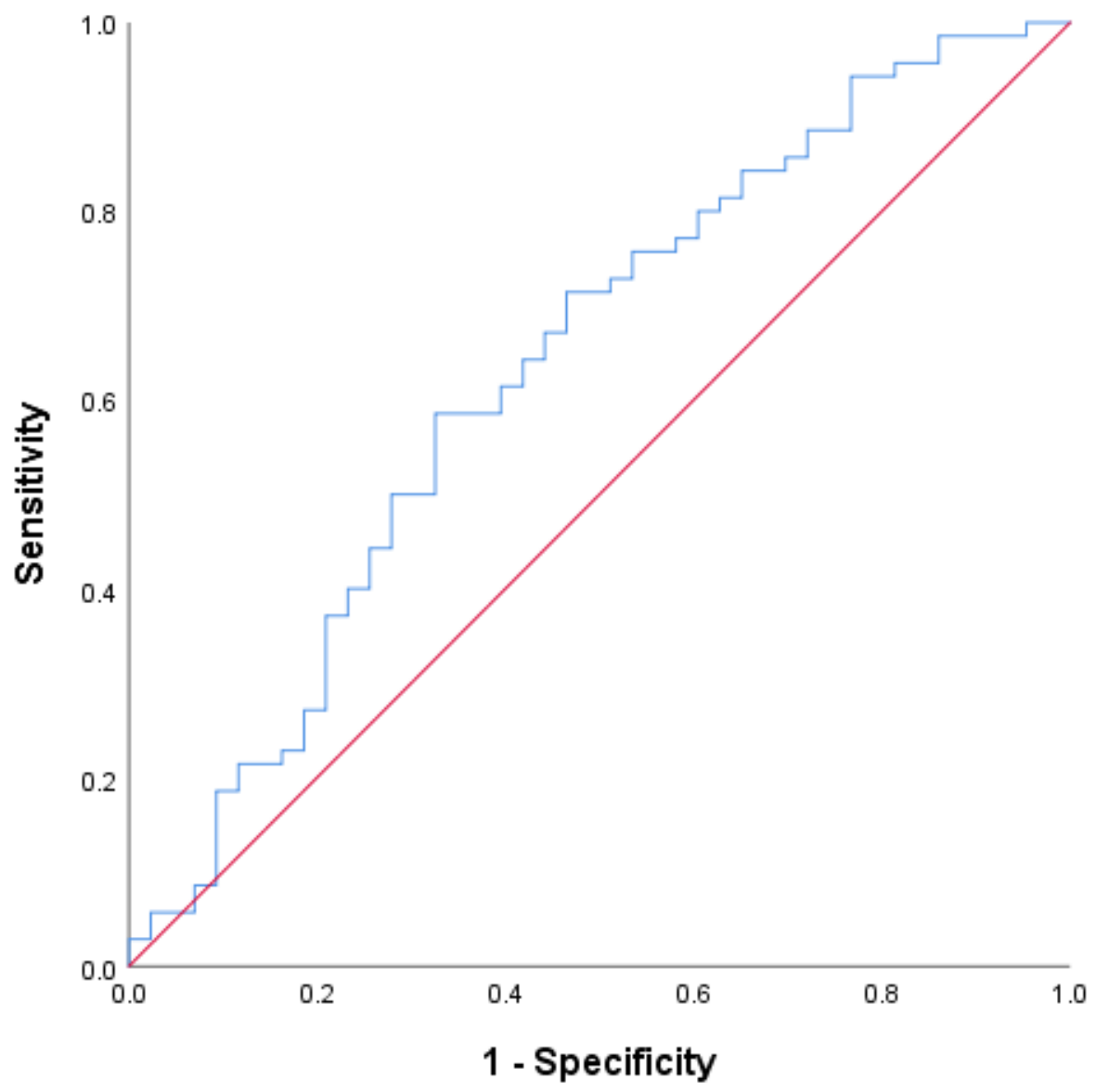

Figure 6. ROC curve for the additive predictive accuracy of age, sex, race, PCL-R scores, and CCS scores 


\section{Exploratory Analyses}

Given the surprising nature of some of the results, it was decided that some analyses would be undertaken in order to better understand the relationship between risk categories as determined by the comprehensive risk assessments (CRA's), client change, and the final parole decision made by the California Board of Parole Hearing (CBPH). These analyses were undertaken to understand whether client change was related to the risk assessment provided to parole decision makers, and whether these risk assessments were in fact, related to the final parole decision.

First, the mean difference was assessed between the low CRA risk group and the moderate CRA risk group. Levene's test for homogeneity of variance indicated that the assumption was violated, and therefore homogenous variances were not assumed in the results. It was discovered that the groups were significantly different $(t(82.18)=10.29, p<.000[5.39$, 7.97]), in that those of low risk $(M=27.26, S D=2.31)$ were higher on the CCS than those of moderate risk $(M=20.58, S D=4.26)$.

In order to explore the CCS' relationship with the CRA designations of risk and hearing decision, and how these scores related to parole decision it was decided to examine mean differences between groups. In order to do this, four groups were created: those low on risk who were granted parole, those low on risk denied parole, those moderate risk who were granted parole, and those moderate risk who were denied parole. As the continuous variable of interest was skewed (CCS), a Kruskall Wallis test was used to assess mean differences between the four groups. The Kruskall-Wallis test assumes the homogeneity of ranked data (Ruxton \& Beauchamp, 2008). In order to test homogeneity of variance for the non-parametric Kruskall Wallis test, rank scores and mean rank scores were created for the CCS values. A one-way 
ANOVA was performed in which the difference between rank scores and mean rank scores between the above-mentioned groups were found to be significantly different, meaning that the ranked data was heteroscedastistic. In cases such as this, the Kruskal Wallis test is found to be unreliable, particularly in cases with unequal $n$ 's, it is recommended (Declare, Leys, Mora, \& Lakens, 2019; Lix, Keselman, \& Keselman, 1996) to use the Welch's test, however, the Welch's test assumes normality of the distribution, which was violated for CCS scores. It was therefore decided to conduct a non-parametric Kruskal Wallis test, but to compare to Welch's test and the Brown-Forsythe so that any differences could be noted. The Kruskal Wallis test indicated that the distribution of the CCS was not the same across the four categories. Pairwise comparisons between the groups were conducted using the Dunnett test with a Bonferroni correction for multiple tests. Statistics for the pairwise comparisons can be found in Table 7. Essentially, those who were moderate risk were lower in terms of CCS scores than those of lower risk, regardless of final hearing decision. Additionally, those of low risk who were granted parole were lower in terms of CCS scores than those of moderate risk who were granted parole. These results further highlighted an expected relationship between offender change as measured by the CCS and CRA determinations of risk. However, as can be seen in Table 7, CCS scores were not significantly different between those who were granted and denied parole for either low risk or moderate risk. This highlights that parole decision is unrelated to client change. 
Table 7

Mean Comparisons and Kruskal Wallis Results Between Groups

\begin{tabular}{lcccc}
\hline Group Comparison & M1 (SD1) & M2 (SD2) & $\chi^{2}$ & $p$ \\
\hline MR, Deny; MR Grant & $19.55(4.41)$ & $21.27(4.1)$ & 8.79 & 1.0 \\
MR Deny; LR Grant & $19.55(4.41)$ & $27.11(2.4)$ & 51.37 & $<.000^{*}$ \\
MR Deny; LR Deny & $19.55(4.41)$ & $27.52(2.16)$ & 54.67 & $<.000^{*}$ \\
MR Grant; LR Grant & $21.27(4.1)$ & $27.11(2.4)$ & 42.59 & $<.000^{*}$ \\
MR Grant; LR Deny & $21.27(4.1)$ & $27.52(2.16)$ & 45.88 & $<.000^{*}$ \\
LR Grant; LR Deny & $27.11(4.1)$ & $27.52(2.16)$ & -3.23 & 1.00 \\
\hline
\end{tabular}

Note*: MR = Moderate Risk, LR = Low Risk, M1 = Mean of Group One, M2 = Mean of Group two

Both the Welch's test and Brown-Forsythe were significant, indicating that regardless of non-parametric test chosen, a significant difference between the groups was discovered. Tukey's test indicated the same pattern of significant pairwise comparisons.

In order to further assess the relationship between risk as measured by the CRA, client change, and parole outcome, it was decided that four artificial groups would be created based on expected parole outcome from combinations of low and moderate risk and low and high CCS derived from a median split. These four groups were: low risk, low CCS with the expected parole outcome being denial; low risk, high CCS with the expected parole outcome being grant; moderate risk, low CCS with the expected parole outcome being denial; and moderate risk, high CCS with the expected parole outcome being grant. These groups were then compared to the observed parole decision using a Chi square which indicated that the groups were not significantly different from one another $\left(\chi^{2}(3)=.985, p=.81\right)$. This means that the purported 
grant and denials based on client change and CRA risk were not significantly different from the actual observed grant and denial rates made by the CBPH.

Finally, in order to assess whether CRA risk independently contributed to parole decision, a logistic regression was conducted with hearing decision as an independent variable. The overall model accounted for only $.002 \%$ of the variance in parole decision. Further, risk independently was not a significant predictor of parole decision $(W=.17, p=.68)$. The $\log$ odds indicated that for those of low risk there was an increase in the odds of a positive parole determination by $1.18(95 \% \mathrm{CI}=.55,2.51)$ which was not significant. This result further showed that the CRA was not contributing significantly to denials and grants made by the CBPH.

\section{Discussion}

Positive client change is perceived to reduce risk for re-offence and is alleged to be an important factor considered in early release decisions (Serin et al., 2016). A valid and reliable measure of client change would permit for more transparent and reliable decisions regarding parole release. The current research empirically investigated a theoretically grounded measure of client change with lifers in the California Parole system. Although the CCS did not appear to predict hearing decision, it proved to be a reliable measure which could potentially be useful with other populations. A summary of the results is provided below.

\section{Reliability of the CCS}

The first three research questions focused on the reliability of the Client Change Scale (CCS). Overall, the CCS showed good internal consistency and excellent inter-rater reliability. Furthermore, as predicted, the CCS was moderately correlated with the PCL-R indicating that client change as measured by the CCS is related to risk. 
A limitation in this area was the necessary use of PCL-R scores instead of summary risk ratings for the $\mathrm{HCR}-20^{\mathrm{V} 3}$. As noted, risk ratings for the HCR $-20^{\mathrm{V} 3}$ were not calculated and it was simply used as a tool to assess various risk factors for each participant within the parole portfolios. While the PCL-R is commonly used to assess risk and has large effect sizes in terms of predicting recidivism, it was originally formulated to assess a personality construct. Additionally, in a meta-analysis, the HCR-20 $0^{\mathrm{V} 3}$ outperformed the PCL-R in terms of measuring risk and was specifically created as a risk assessment (Yang et al., 2010). The results of the ICC measuring interrater reliability with 10 percent of the sample were encouraging but Koo and BPS (2016) suggest that the ideal sample size for the ICC is three raters and 30 participants for an accurate ICC estimate.

\section{Relationship Between the CCS and Parole Decision}

Contrary to what was predicted, there were no significant associations between scores on the CCS and parole determinations. One possible explanation for this unexpected correlation is that correlations are sensitive to base rates in the dichotomous outcome variable (Babchishin \& Helmus, 2016). Babchishin and Helmus (2016) indicate that deviations in the dichotomous outcome variable over $50 \%$ can reduce the size of a correlation coefficient because if there is a low base rate in a dichotomous variable, false positives become more likely. The current sample had a base rate of $61 \%$ which is some deviation from a base rate of $50 \%$. Additionally, restricted range is also a problem for correlation coefficients. This is a problem because a correlation is attempting to reflect the amount of variance in one variable which can be predicted from the other variable. If there is little variability in one variable, it becomes more difficult to predict (Babchishin \& Helmus, 2016). In the current sample, the CCS had a restricted range in that while 
the CCS could range from 0 to 32, observed scores ranged only from 11 to 32. Interestingly, no significant relationship was found between parole decision and PCL-R scores or the CRA.

The restricted range of the CCS in this sample could potentially be due to the nature of the population studied. The lifers in this parole process generally had significant access to treatment and limited access to substances, and less access to more vulnerable victims without constant supervision. As the CCS was originally intended for use with populations on community supervision, this could have artificially inflated CCS scores.

\section{Predictive Ability of the CCS}

The results of the logistic regression indicated that the CCS did not predict parole decision, nor did it predict parole decision after controlling for age, race, sex, and risk level. Interestingly, none of the other variables significantly individually contributed to the variance in hearing decision.

These unexpected results could be due to low power resulting from a small sample size $(N=113)$. Although suggested sample sizes for logistic regression vary, Vergouwe, Steyerberg, Eijkemans, and Habbema, (2005) suggest that in order to have adequate power for a predictive logistic regression model, it is necessary to have 100 events for each outcome, meaning that 200 participants would have been necessary to achieve adequate power. Specifically, regarding the contention between the omnibus Chi square and Hosmer-Lemeshow goodness of fit tests, Kuss (2002) suggests that the Hosmer-Lemeshow test is the better test when assessing sparse data. This is because the Chi Square test relies on larger cell counts, meaning that more participants are needed for each covariate, whereas the Hosmer-Lemeshow test does not. 
Theoretically speaking, parole hearing decision was used as a proxy for actual recidivism rates. While literature suggests that lifers who attain parole have low recidivism rates (Axford \& Young, 2012), only 46\% of the current sample qualified as 'lifers' in the California parole process. Moreover, while $100 \%$ of parole grants were successfully predicted with CCS scores, only $2.3 \%$ of denials were successfully predicted. As it is not possible to assess recidivism for those who were not granted parole, it is not possible to know whether CCS would accurately have predicted recidivism for these participants. Further, the logistic regression with all variables (age, race, sex, risk level, and CCS) indicated that this model was correctly predicting $88.6 \%$ of parole grants and $25.6 \%$ of parole denials. This pattern wherein a large portion of grants are predicted, but a much smaller portion of denials are predicted, could indicate that while risk and offender change may be incorporated into the decision regarding parole grants, other factors appear to be taken into account when assessing parole denials. This theory is further supported by Serin and Gobeil's (2014) research which suggested that parole decision makers (in Ohio, Connecticut, and Kansas) took a variety of factors into account that were not included in the evidence-based parole decision making framework, including the nature of the offence, the potential presence of unsubstantiated criminal activity, opposition by victims or by the prosecution, and characteristics of the individual. The results suggested that these factors were most often rated as aggravating on behalf of the person, less often as having no impact, and least often as being mitigating.

Wardrop and colleagues (2019) assessed the seven domains of the Structured Parole Decision Making Framework (SPDMF) in terms of their ability both to predict reconviction after release and the initial parole decision. The researchers found that offender change, responsivity, and release plans were all significantly predictive of reconviction, and for participants whom 
parole boards had rated offender change as an aggravating factor, these were $1.5 \%$ more likely to be reconvicted after parole release, and 6\% less likely to attain parole release. This suggests a predictive relationship between client change, parole decision, and reconviction for that population. It also suggests that offender change has some relationship both with reconviction and parole decision when assessed using the SPDMF.

The two AUC's indicated that CCS alone did not predict parole decision above chance levels, nor did each of the variables individually; however, while none of the variables had independently predicted parole decision in a logistic regression, the combined variables offered significant discriminatory ability through the AUC. Additionally, the Hosmer-Lemeshow test of model fit indicated that this model was a good fit for the data, whereas the Chi square test indicated it was not. The potential disconnection between the AUC results and negative goodness of fit tests could be due to the fact that the AUC measures discriminative ability (the likelihood that an individual falling higher on client change, lower on psychopathy, lower on age) will have a positive parole decision, while ignoring the ability of the model to fit the data. This means that a well-fitting model may have poor discriminative ability, or that a badly fitting model could have adequate discriminative ability (Lobo, Valverde, and Real, 2007). However, Seshan, Gone, and Begg (2012) suggest that using an AUC measure with known directionality of variables of interest can reduce the power of the AUC. A confounding variable problem could also be at play, where the influence of confounding variables associated with the outcome of interest, which would have been partialed out in a logistic regression, may be inflating the likelihood of incorrect conclusions (Sibai, 2005). Therefore, the significant AUC combining the insignificant independent predictors (age, race, sex, client change, risk level) should be examined with caution. 


\section{Exploratory Analyses}

In light of the fact that none of the variables hypothesized to predict parole decision independently did so, some further analyses to explore the relationship between parole decision, risk of recidivism as quantified by the CRA, and client change were undertaken. It was discovered that participants designated as low risk by the CRA were significantly higher on the CCS than those of moderate risk. Additionally, there was no mean difference between either low or moderate risk offenders who were granted or denied parole on the CCS. However, there were significant mean differences in CCS scores between those moderate risk and low risk participants who were granted or denied parole. The pattern of relationship wherein those of low risk were significantly lower in terms of CCS scores suggests that the CRA may be attending to client change.

Based on this assessment of a potential relationship between CRA risk and CCS, a further analysis was conducted wherein four artificial groups were created: low risk, low CCS with the expected parole outcome being denial; low risk, high CCS with the expected parole outcome being grant; moderate risk, low CCS with the expected parole outcome being denial; and moderate risk, high CCS with the expected parole outcome being grant. These four groups were statistically compared to the actual parole decisions made using a Chi square goodness of fit test, which was not found to be statistically different. Finally, it was also determined that CRA risk was not a significant predictor of parole decision.

Overall, the CRA and the CCS were found to have a strong relationship, however, there was little relationship between parole decision and any factor (age, race, sex, risk level). This indicates that the CRA may be attending to both risk and offender change, but that the CBPH may not be attending to either the CRA or offender change. This is at odds with Title 15 of the 
California Code of Regulations which outlines a variety of factors that are to be taken into account when coming to decision regarding parole, including: psychological factors, age, criminal history, plans for the future, and institutional behaviour (California department of corrections and rehabilitation, 2019). The CCS and CRA both explicitly take many of these factors into account, however, neither had a significant association or predictive relationship to parole decision. This is somewhat in line with Weisberg's (2011) research which found that age, criminal history, and substance abuse had no significant impact on parole decisions for a sample of indeterminately offenders in California. Although, for that sample, institutional behaviour and the state-mandated risk assessments (Axis-V GAF and Clinician Generic Risk) did impact the decision. Scores on the HCR-20V3 and LC/CMI were not available for this study, but PCL-R scores were not found to be individually contributive or significantly associated with parole decisions. This is potentially contrary to Kusaj's (2019) research that indicated that those who were denied parole had an average PCL-R score of 18.7 while those who were denied had an average score of 15.5, though this research did not address whether this relationship was significant. Weisburg and colleagues (2011) further found that external factors could also influence grant rates for offenders in California. For example, when a victim was present during a parole hearing, the grant rate was half that of a hearing where no victim was present. Moreover, CDC 115 infractions and violent infractions (regardless of temporality to the hearing) were significantly associated with denials. The conflicting research with parolees and parole decision in California may indicate that more transparent and consistent parole procedures are needed.

\section{Limitations}

There are several limitations in this research, foremost of which was the small sample size, which, as discussed, limited power for finding legitimate effects. This was particularly so 
for a logistic regression with five covariates. Additionally, using parole decision as a proxy measure of recidivism means that we remain unaware of how the CCS performs in predicting recidivism and in assisting community supervisors with addressing the needs of their charges. Additionally, the CCS was designed as a measure of change and was constructed to quantify where an individual falls on the downward slope of the curve into desistance from crime (see Figure 1 The Transitional Model of Offender Change). Although this research attempted to associate differences between individuals in terms of client change with expectedly related outcomes (parole decision, risk), due to the lack of multiple assessments, this research was unable to examine change within a participant over time that could lead to fluctuating scores on the CCS.

\section{Summary}

The CCS has been developed on theoretical and empirical literature of offender change factors and has now been shown to be reliable. Additionally, recent literature has suggested that client change predicts both parole decision and recidivism in other U.S. states (Wardrop, Serin, \& Rentler, 2019). Therefore, if the CCS is theoretically accepted to be predictive of parole decision and reconviction, the lack of difference between the artificial groups (which highlight the expected grant and denial rates if CRA and client change were assessed) and the observed grant and denial groups indicates that board members may not be attending to client change and may be using other factors to influence their decisions. Encouragingly race, age and gender did not appear to be related to parole decisions.

The presence of a significant relationship between CRA risk and client change, both in terms of a correlation and in mean differences between groups, would suggest that the CRA is incorporating client change into their overall assessment of risk, albeit in an unstructured 
manner; this could not be done with an actuarial assessment of risk. However, the lack of relationship between parole decision and either CCS scores or CRA risk, both in terms of correlation, mean differences, and a logistic regression, is potentially indicative that the CBPH may not be taking either the CRA or client change into account when coming to a decision regarding parole.

This research was conducted on random subsample of 113 offenders in the California parole system which were taken from a larger sample of 1,200 long term offenders. It is possible that this particular subsample was not representative of the larger population of parole decisions made in California. Moreover, for both the logistic regression with just CCS scores, and the logistic regression with CCS, age, sex, race, risk, and CCS, a larger proportion of grants were accurately predicted than were denials. Therefore, these factors may influence when an individual is granted parole, however, other factors not captured in this research may be influencing the CBPH in denying parole. This theory is further supported by Serin and Gobeil's (2014) research which suggested that parole decision makers (in Ohio, Connecticut, and Kansas) took a variety of factors into account that were not included in the evidence-based parole decision making framework, including the nature of the offence, the potential presence of unsubstantiated criminal activity, opposition by victims or by the prosecution, and characteristics of the individual. The results suggested that these factors were most often rated as aggravating on behalf of the person, less often as having no impact, and least often as being mitigating.

\section{Conclusions and Directions for Future Research}

There are several avenues for future research in offender change highlighted by this research. First, the items of the CCS should be thoroughly and prospectively examined for their effectiveness in predicting parole decision and eventual recidivism. While all of the items of the 
CCS showed internal consistency, it could be that certain change items are more related to prosocial outcome than others. Empirically supporting these items will assist in furthering research regarding the factors involved in offender change. Second, the factor structure of the CCS should be analysed to see how variables group together and how this may relate to offender change theory. As mentioned, future research should also seek to investigate the CCS's ability to predict recidivism for offenders in the community, independent of the nature of release. Finally, it would be prudent to examine how offenders change in over time. For example, examining offenders before, during, and after treatment to examine whether change variables (e.g. identity, commitment, sense of entitlement) change and build in relation to external prosocial sources.

In conclusion, this research sought to validate the CCS in order to further change theory and to provide an empirically supported and standardized way to measure offender change. In order to do this, parole hearing decision was used as a proxy for actual recidivism outcome because past research has suggested that lifers who attain parole have low recidivism rates (Axford \& Young, 2012) and that client change predicts both recidivism and parole decision (Wardrop et al., 2019). In the current study, offender change as measured by the CCS was not associated with and did not predict parole decision, nor did any of the other covariates individually predict parole decision; however, the combination of all covariates did significantly predict parole decision. Furthermore, reliability analyses showed that the CCS is internally consistent and is moderately associated to a validated measure of risk (PCL-R), which suggests a level of concept validity. Exploratory analyses also indicated that client change was captured in the CRA but that the CRA did not predict parole decision either. Overall, while research suggests that offender change is an important factor in recidivism and has previously predicted parole decision, based on the current research, the CBPH may not have been attending to offender 
change in their decisions. Future research should focus on empirically investigating the individual items of the CCS and the factor structure of the CCS in order to examine which items are most closely related to outcome, as well as examining offender change over time and in relation to recidivism directly. 


\section{References}

Abbott, M. W. (1984). Locus of control and treatment outcome in alcoholics. Journal of Studies on Alcohol. http://dx.doi.org.proxy.library.carleton.ca/10.15288/jsa.1984.45.46 Andrews, D. A., \& Bonta, J. (2010). The psychology of criminal conduct (5th ed.). New York: Routledge, Taylor and Francis Group.

Andrews, D.A., \& Bonta, J. (2007). Risk-Need-Responsivity model for offender assessment and rehabilitation. Retrieved from Public Safety Canada website: https://www.publicsafety.gc.ca/cnt/rsrcs/pblctns/rsk-nd-rspnsvty/index-en.aspx

Andrews, D., Bonta, L., \& Hoge D. (1990) Classification for effective rehabilitation: Rediscovering psychology. Criminal Justice \& Behaviour, 17(1), 19-52.

Andrews, D. A., Bonta, J., \& Wormith, J. S. (2011). The risk-need-responsivity (RNR) model: Does adding the good lives model contribute to effective crime prevention? Criminal Justice and Behavior. https://doi.org/10.1177/0093854811406356

Andrews, D., Bonta, J., \& Wormith. (2006). The recent past and near future of risk and/or need assessment. Crime \& Delinquency, 52(1), 7-27. https://doi.org/10.1177/0011128705281756

Andrews, D. A., Zinger, I., Hoge, R. D., Bonta, J., Gendreau, P., \& Cullen, F. T. (1990). Does correctional treatment work? A clinically relevant and psychologically informed metaanalysis. Criminology, 28(3), 369-404. https://doi.org/10.1111/j.1745-

9125.1990.tb01330.x 
Anstiss, B., Polaschek, D. L. L., \& Wilson, M. (2011). A brief motivational interviewing intervention with prisoners: When you lead a horse to water, can it drink for itself? Psychology, Crime and Law, 17(8), 689-710. https://doi.org/10.1080/10683160903524325

Aos, S., Miller, M., \& Drake, E. (2006) Evidence-based public policy options to reduce future prison construction, criminal justice costs and crime rates. Olympia: Washington State Institute for Public Policy.

Assailly, J., \& Cestac, J. (2014). Alcohol interlocks and prevention of drunk-driving recidivism. European Review of Applied Psychology / Revue Européenne De Psychologie Appliquée, 64(3), 141-149.

doi:http://dx.doi.org.proxy.library.carleton.ca/10.1016/j.erap.2014.03.002

Axford, M., \& Young, M. (2012). Community outcomes for offenders serving a life sentence. Ottawa, Ontario: Correctional Services of Canada. https://books.scholarsportal.info/uri/ebooks/ebooks0/gibson_cppc/2014-06-25/1/10863640

Babchihin, K.M., \& Helmus, L.M. (2015). The influence of base rates on correlations: An evaluation of proposed alternative effect sizes with real-world data. Behavior Research Methods, 48(3), 1021-1031. DOI: 10.3758/s13428-015-0627-7.

Bandura, A. (2001). Social Cognitive: An agentic perspective. Annual Review of Psychology, 52, 1-26. https://doi.org/10.1146/annurev.psych.52.1.1

Bandura, A. (1977). Toward a unifying theory of behavioral change. Psychological Review, 84(2), 191-215. https://doi.org/10.1037/0033-295X.84.2.191

Bahr, S. J., Harris, L., Fisher, J. K., \& Armstrong, A. H. (2010). Successful re-entry: What Differentiates successful and unsuccessful parolees? International Journal of Offender 
Therapy and Comparative Criminology, 54(5), 667692.

https://doi.org/10.1177/0306624X09342435

Blumstein, A., \& Cohen, J. (1987). Characterizing criminal careers. Science, 237(4818), 985991. https://doi.org/10.1126/science.237.4818.985

Boduszek, D., Hyland, P., Pedziszczak, J., \& Kielkiewicz, K. (2012). Criminal attitudes, recidivistic behaviour, and the mediating role of associations with criminal friends: An empirical investigation within a prison sample of violent offenders. Europe's Journal of Psychology, 8(1), 18-31. https://doi.org/10.5964/ejop.v8i1.296

Bourgon, G., Bonta, J., Rugge, T., Scott, T.-L., \& Yessine, A. K. (2010). The role of program design, implementation, and evaluation in evidence-based "Real World" community supervision. Federal Probation, 74(1), 2-15. https://doi.org/10.1525/sp.2007.54.1.23.

Bourgon, G., Leticia, G., \& Ashton, J. (2011). The evolution of community supervision practice: The transformation from case manager to change agent. Irish Probation Journal.

Bonta, J., \& Andrews, D. (2007). Risk-need-responsivity model for offender assessment and rehabilitation. Rehabilitation, 22. https://doi.org/10.1002/jclp.20317

Bonta, J., Bourgon, G., Rugge, T., Scott, T., Yessine, A. K. Gutierrez, L., Li, J. (2010). The Strategic Training Initiative in Community Supervision: Risk-Need-Responsivity in the real world. Retrieved from: https://www.publicsafety.gc.ca/cnt/rsrcs/pblctns/2010-01$\underline{\text { rnr/2010-01-rnr-eng.pdf }}$ 
Brown, S. L., St. Amand, M. D., \& Zamble, E. (2009). The dynamic prediction of criminal recidivism: A three-wave prospective study. Law and Human Behavior, 33(1), 25-45. https://doi.org/10.1007/s10979-008-9139-7

Bush, H.M. (2012). Biostatistics: An applied introduction for the public health practitioner. Delmar, NY: Cengage Learning

California department of corrections and rehabilitation. (2019a). The rehabilitative process. Retrieved from: https://www.cdcr.ca.gov/Rehabilitation/Process.html

California Department of Corrections and Rehabilitation. (2019b). Board of parole hearings: Lifer parole process. Retrieved from: https://www.cdcr.ca.gov/BOPH/lifer_parole_process.html

California Office of Administrative Law (2019). California Code of Regulations. Retrieved February 5th, 2019, from https://govt.westlaw.com/calregs/Document/I5E3918F0078211E3A8E0B021DF1F7DCE?v $\underline{\text { iew Type }}=$ FullText\&originationContext $=$ documenttoc $\&$ transitionType $=$ CategoryPageItem $\&$ $\underline{\text { contextData }=(\text { sc.Default })}$

Campbell, M. A., French, S., \& Gendreau, P. (2009). The prediction of violence in adult offenders: A meta-analytic comparison of instruments and methods of assessment. Criminal Justice and Behavior, 36(6), 567-590. https://doi.org/10.1177/0093854809333610

Caplan, J. (2007). What factors affect parole: A review of empirical research. Federal Probation, 71(1), 16-19. Retrieved from: https://heinonline- 
org.proxy.library.carleton.ca/HOL/Page?collection=journals\&handle=hein.journals/fedpro7 $\underline{1 \& \mathrm{id}=117 \& \text { men } \mathrm{tab}=\text { srchresults\# }}$

Casey, S. (In press). Offender rehabilitation and theories of behaviour change. In The Wiley International Handbook of Correctional Psychology.

Chadwick, N. Dewolf, A., Serin, R. (2015) Effectively training community supervision officers: A meta-analytic review of the impact on offender outcome. Criminal Justice and Behavior, 42, 977-989.

Chen, H., Cohen, P., Chen, S. (2010). How big is a big odds ratio? Interpreting the magnitude of odds ratios in epidemiological studies. Communications in Statistics-Simulation and Computation, 39, 860-864. doi:10.1080/03610911003650383

Chen, P. Y. \& Popovich, P.M. (2002). Correlation: Parametric and non-parametric measures. California: SAGE Publications Inc. https://dx.doi.org/10.4135/9781412983808

Clark, V. A. (2016). Predicting two types of recidivism among newly released prisoners: First addresses as "Launch Pads" for recidivism or re-entry success. Crime and Delinquency, 62(10), 1364-1400. https://doi.org/10.1177/0011128714555760

Clark, L. A., \& Watson, D. (1995). Constructing validity: Basic issues in objective scale development. Psychological Assessment, 7, 309-319. doi:10.1037/1040-3590.7.3.309

Cohen, N. L., \& Albert, M. (1978). Locus of control as a predictor of outcome in treatment of obesity. Psychological Reports, 42(3, Pt 1), 805-806. https://doi.org/10.2466/pr0.1978.42.3.805 
Cook, P. J., Kang, S., Braga, A. A., Ludwig, J., \& O’Brien, M. E. (2015). An experimental evaluation of a comprehensive employment-oriented prisoner re-entry program. Journal of Quantitative Criminology, 31(3), 355-382. https://doi.org/10.1007/s10940-014-9242-5

Corrections and Conditional Release Regulations. (1992). Retrieved from Justice Laws Website: https://www.lib.sfu.ca/help/cite-write/citation-style-guides/apa/gov-docs-apa\#actsstatutesa704-pp-219-221

Correctional Services of Canada (2009). Evaluation Report: Correctional Service Canada's Correctional Programs. Evaluation Branch, Performance Assurance Sector.

Cronbach, L.J. (1951). Coefficient alpha and the internal structure of tests. Psychometrika, 16(3), 297-333.

Cullen, F.T. (2012). Taking rehabilitation seriously: Creativity, science, and the challenge of offender change. Punishment \& Society, 14(1), 94-114. doi: 10.1177/1462474510385973

Cullen, F.T., \& Gendreau, P. (2001). From nothing works to what works: Changing professional ideology in the $21^{\text {st }}$ century. The Prison Journal, 81(3), 313-338. https://doi.org/10.1177/0032885501081003002

Dancey, C. P., \& Reidy, J. (2007). Statistics without maths for psychology. Pearson Education.

Day, A., Bryan, J., Davey, L., \& Casey, S. (2006). The process of change in offender rehabilitation programmes. Psychology, Crime and Law, 12(5), 473-487. https://doi.org/10.1080/10683160500151209 
Delacre, M., Leys, C., Mora, Y. L., Lakens, D. (2019). Taking parametric assumptions seriously: Arguments for the use of Welch's $F$-test instead of the classical $F$-test in One-Way ANOVA. International Review of Social Psychology, 32(1), 1-12. DOI : https://doi.org/10.5334/irsp.198

de Vries Robbé, M., de Vogel, V., \& de Spa, E. (2011). Protective factors for violence risk in forensic psychiatric patients: A retrospective validation study of the SAPROF. International Journal of Forensic Mental Health, 10, 178-186. doi:10.1080/14999013.2011.600232

de Vries Robbé, M., de Vogel, V., \& Douglas, K. S. (2013). Risk factors and protective factors: A two-sided dynamic approach to violence risk assessment. The Journal of Forensic Psychiatry \& Psychology, 24(4), 440-457. https://doi.org/10.1080/14789949.2013.818162

DiClemente, C. C., Prochaska, J. O., \& Gibertini, M. (1985). Self-efficacy and the stages of selfchange of smoking. Cognitive Therapy and Research, 9(2), 181-200. https://doi.org/10.1007/BF01204849

Doekhie, J., Ginneken, E. V., Dirkzqager, A., Noeuwbeerta, P. (2018). Managing risk or supporting desistance? A longitufinal study on the nature and perceptions of parole supervision in the Netherlands. Journal of Developmental and Life-Course Criminology. https://doi.org/10.1007/s40865-018-0097-6

Douglas, K. S., Hart, S. D., Webster, C. D., Belfrage, H., Guy, L. S., \& Wilson, C. M. (2014). Historical-Clinical-Risk Management-20, Version 3 (HCR-20V3): Development and Overview. International Journal of Forensic Mental Health. https://doi.org/10.1080/14999013.2014.906519 
Dowden, C., \& Brown, S. L. (2002). The role of substance abuse factors in predicting recidivism: A meta-analysis. Psychology, Crime and Law, 8(3), 243-264. https://doi.org/10.1080/10683160208401818

Drago, A., Rheinheimer, D. C., \& Detweiler, T. N. (2018). Effects of locus of control, academic self-efficacy, and tutoring on academic performance. Journal of College Student Retention: Research, Theory and Practice, 19(4), 433-451. https://doi.org/10.1177/1521025116645602

Drake, E. (2012). Chemical Dependency Treatment for Offenders: A Review of the Evidence and Benefit-Cost Findings (Document No. 12-21-1201). Olympia: Washington State Institute for Public Policy.

Drieschner, K. H., \& Verschuur, J. (2010). Treatment engagement as a predictor of premature treatment termination and treatment outcome in a correctional outpatient sample. Criminal Behaviour and Mental Health, 20(2), 86-99. https://doi.org/10.1002/cbm.757

Duwe, G. (2015). The benefits of keeping idle hands busy: An outcome evaluation of a prisoner re-entry employment program. Crime and Delinquency, 61(4), 559-586. https://doi.org/10.1177/0011128711421653

Ægisdóttir, S., White, M. J., Spengler, P. M., Maugherman, A. S., Anderson, L. A., Cook, R. S., ... \& Rush, J. D. (2006). The meta-analysis of clinical judgment project: Fifty-six years of accumulated research on clinical versus statistical prediction. The Counseling Psychologist, 34, 341-382. doi: 10.1177/0011000005285875 
Efta-Breitbach, J., \& Freeman, K. A. (2004). Recidivism and resilience in juvenile sexual offenders: An analysis of the literature. Journal of Child Sexual Abuse, 13(3-4), 257-279. https://doi.org/10.1300/J070v13n03 13

Farmer, M., Beech, A. R., \& Ward, T. (2012). Assessing desistance in child molesters: A qualitative analysis. Journal of Interpersonal Violence, 27(5), 930-950. https://doi.org/10.1177/0886260511423255

Fougere, A., \& Daffern, M. (2011). Resilience in young offenders. International Journal of Forensic Mental Health, 10(3), 244-253. https://doi.org/10.1080/14999013.2011.598602

Fougere, A., Daffern, M., \& Thomas, S. (2015). Does resilience predict recidivism in young offenders? Psychiatry, Psychology and Law, 22(2), 198-212. https://doi.org/10.1080/13218719.2014.936333

Gallagher, J. R., Nordberg, A., Deranek, M. S., Ivory, E., Carlton, J., \& Miller, J. W. (2015). Predicting termination from drug court and comparing recidivism patterns: Treating substance use disorders in criminal justice settings. Alcoholism Treatment Quarterly, 33(1), 28-43. https://doi.org/10.1080/07347324.2015.982451

Garofalo, C., \& Velotti, P. (2017). Negative emotionality and aggression in violent offenders: The moderating role of emotion dysregulation. Journal of Criminal Justice, 51, 9-16. https://doi.org/10.1016/j.jcrimjus.2017.05.015

Grove, W. M., Zald, D. H., Lebow, B. S., Snitz, B. E., \& Nelson, C. (2000). Clinical versus mechanical prediction: A meta-analysis. Psychological Assessment, 12, 19-30. 
Guy, L.S., Kusaj, C., Packer, I.K., \& Douglas, K.S. (2015). Influence of the HCR-20, LS/CMI, and PCL-R on decisions about parole suitability among lifers. Law and Human Behavior, 39(3), 232-243. Doi: http://dx.doi.org/10.1037/lhb0000111

Hanson, K. R. (2009). The psychological assessment of risk for crime and violence. Canadian Psychology, 50(3), 172-182. https://doi.org/10.1037/a0015726

Hanson, R. K., Harris, A. J. R., Scott, T.-L., \& Helmus, L. (2007). Assessing the risk of sexual offenders on community supervision: The Dynamic Supervision Project (User report, Corrections research). Ottawa, ON, Canada: Public Safety Canada. Retrieved from http://www.publicsafety.gc.ca/cnt/rsrcs/pblctns/ssssng-rsk-sxl-ffndrs/index-eng.aspx

Hare, R.D. (2016). Psychopathy, the PCL-R, and criminal justice: Some new findings and current issues. Canadian Psychology, 57(1), 21-34. http://dx.doi.org/10.1037/cap0000041

Hart, S. D., Forth, A. E., \& Hare, R. D. (1991). The MCMI-II and psychopathy. Journal of Personality Disorders, 5(4), 318-327. http://dx.doi.org.proxy.library.carleton.ca/10.1521/pedi.1991.5.4.318

Hart, S. D., Hare, R. D., \& Harpur, T. J. (1992). The psychopathy Checklist—Revised (PCL-R): An overview for researchers and clinicians. In J. C. Rosen, \& P. McReynolds (Eds.), Advances in psychological assessment, vol. 8; advances in psychological assessment, vol. 8 (pp. 103-130, Chapter xv, 266 Pages) Plenum Press, New York, NY. doi: http://dx.doi.org.proxy.library.carleton.ca/10.1007/978-1-4757-9101-3 4 
Harris, G. T., \& Rice, M. E. (2015). Progress in violence risk assessment and communication: Hypothesis versus evidence. Behavioral Sciences and the Law, 33, 128-145. https://doi.org/10.1002/bs1.2157

Havlicek, L. L., Peterson, N.L. (1977). Effect of the violation of assumptions upon significance levels of the Pearson $r$. Psychological Bulletin, 84(2), 373-377. DOI:10.1037/00332909.84.2.373

Heather, N., \& Stockwell, T. (2004). The Essential Handbook of Treatment and Prevention of Alcohol Problems. John Wiley \& Sons: England.

Helmus, L. M., \& Babchishin, K. M. (2017). Primer on risk assessment and the statistics used to evaluate its accuracy. Criminal Justice and Behavior, 44(1), 8-25. https://doi.org/10.1177/0093854816678898

Helmus, L., Thornton, D., Hanson, R.K., Babchishin, K.M. (2011). Assessing the risk of older sex offenders: Developing the Static-99R and the Static 2000R. Public Safety Canada. Retrieved from: https://www.publicsafety.gc.ca/cnt/rsrcs/pblctns/2011-01-rsd/indexen.aspx

Hinton, P.R., McMurray, I., Brownlow, C. (2014). SPSS Explained. New York, NY: Routledge.

Hirschi, T., \& Gottfredson, M. (1983). Age and explanation of crime. The American Journal of Sociology, 89(3), 552-584. https://doi.org/10.1007/s10964-013-9926-4 
Hosmer, D.W., Hosmer, T., Le Cessie, S., \& Lemeshow, S. (1997). A comparison of goodnessof-fit tests for the logistic regression model. Statistics in medicine, 16, 965-980. file://C:/Users/taylo/Downloads/HOSMER_et_al-1997-Statistics_in_Medicine.pdf

Howard, P.D. (2017) The effect of sample heterogeneity and risk categorization on area under the curve predictive validity metrics. Criminal Justice and Behaviour, 44(1). DOI: 10.1177/0093854816678899.

Howells, K., \& Day, A. (2003). Readiness for anger management: Clinical and theoretical issues. Clinical Psychology Review. https://doi.org/10.1016/S0272-7358(02)00228-3

Hsieh, F. Y., \& Lavori, P. W. (2000). Sample-size calculations for the cox proportional hazards regression model with nonbinary covariates. Controlled Clinical Trials. https://doi.org/10.1016/S0197-2456(00)00104-5

Jones, N. J., Brown, S. L., Robinson, D., \&Frey, D. (2016). Validity of the youth assessment and screening instrument: A juvenile justice tool incorporating risks, needs, and strengths. Law and Human Behavior, 40(2), 182-194. https://doi.org/10.1037/1hb0000170

Jung, H., Spjeldnes, S., Yamatani, H. (2010). Recidivism and survival time: racial disparity among jail ex-inmates. Social Work Research, 34(3). Retrieved from: https://go-galecom.proxy.library.carleton.ca/ps/i.do? $\mathrm{p}=\mathrm{AONE} \& \mathrm{u}=\mathrm{ocul}$ carleton\&id=GALE $\%$ 7CA236162 $\underline{755 \& \mathrm{v}=2.1 \& \mathrm{it}=\mathrm{r} \& \mathrm{sid}=\text { summon }}$

Iselin, A. M. R., Mulvey, E. P., Loughran, T. A., Chung, H. L., \& Schubert, C. A. (2012). A longitudinal examination of serious adolescent offenders' perceptions of chances for 
success and engagement in behaviors accomplishing goals. Journal of Abnormal Child Psychology, 40(2), 237-249. https://doi.org/10.1007/s10802-011-9561-z

Kazemian, L., LeBlanc, M., Farrington, D.P., \& Pease, K. (2007). Patterns of residual criminal careers among a sample of adjudicated French Canadian males. Canadian Journal of Criminology and Criminal Justice, 49, 307-340. Doi: 10.3138/cjecj.49.3.307

Kleinbaum, D.G. (1994). Logistic regression: A self-learning text. New York: Springer.

Koo, T.K., \& Li, M. Y. (2016). A guideline of selecting and reporting intraclass correlation coefficients for reliability research. Journal of Chiropractic Medicine, 15, 155-163. http://dx.doi.org/10.1016/j.jcm.2016.02.012

Kusaj, C. (2019). Analysis of comprehensive risk assessments administered in 2017. Poster session presented at the meeting of Organization Name, California.

Kuss, O. (2002). Global goodness-of-fit tests in logistic regression with sparse data. Statistics in Medicine, 21(24) 3789-3801. DOI: 10.1002/sim.1421

Laferrière, D., \& Morselli, C. (2015). Criminal achievement and self-efficacy. Journal of Research in Crime and Delinquency, 52(6), 856-889. https://doi.org/10.1177/0022427815579513

Laub, J. H., Nagin, D. S., \& Sampson, R. J. (1998). Trajectories of change in criminal offending: Good marriages and the desistance process. American Sociological Review, 63(2), 225238. https://doi.org/10.2307/2657324 
Laub, J. H., \& Sampson, R. J. (1993). Turning points in the life course: Why change matters to the study of crime. Criminology, 31(3), pp. 301-325. https://doi.org/10.1111/j.17459125.1993.tb01132.x

LeBel, T. P., Burnett, R., Maruna, S., \& Bushway, S. (2008). The “chicken and egg” of subjective and social factors in desistance from crime. European Journal of Criminology, 5(2), 131-159. https://doi.org/10.1177/1477370807087640

Levesque, D. A., Driskell, M., Prochaska, J. M., \& Prochaska, J. O. (2008). Acceptability of stage-matched expert system intervention for domestic violence offenders. Violence and Victims, 23(4), 432-445. doi: http://dx.doi.org.proxy.library.carleton.ca/10.1891/0886$\underline{6708.23 .4 .432}$

Lloyd, C.D. \& Serin, R. (2012). Agency and outcome expectancies for crime desistance: Measuring offenders' personal beliefs about change. Psychology, Crime, \& Law, 18(6), $543-565$.

Loeber, R., Menting, B., Lynam, D. R., Moffitt, T. E., Stouthamer-Loeber, M., Stallings, R., ... Pardini, D. (2012). Findings from the Pittsburgh youth study: Cognitive impulsivity and intelligence as predictors of the age-crime curve. Journal of the American Academy of Child and Adolescent Psychiatry. https://doi.org/10.1016/j.jaac.2012.08.019

Lösel, F., \& Farrington, D. P. (2012). Direct protective and buffering protective factors in the development of youth violence. American Journal of Preventive Medicine, 43(2), 8-23. https://doi.org/10.1016/j.amepre.2012.04.029 
Lowenkamp, C.T., Johnson, J.L., Trevino, P., \& Serin, R.C. (2016). Enhancing community supervision through the application of dynamic risk assessment. Federal Probation, 80(2), 16-20.

Mahler, A., Simmons, C., Frick, P. J., Steinberg, L., \& Cauffman, E. (2017). Aspirations, expectations and delinquency: The moderating effect of impulse control. Journal of Youth and Adolescence, 46(7), 1503-1514. https://doi.org/10.1007/s10964-017-0661-0

Martinez, D.J. (2009). Former prisoners, their family members, and the transformative potential of social support. In Veysey, B.M. Christian, J., and Martinez, D.J. (Eds.), How offenders transform their lives (56-71). Canada: Wilson Publishing.

Martinson, R. (1974). What works? questions and answers about prison reform. The Public Interest, 35(c), 1-33.

Maruna, S. (2001). Making good: How ex-convicts reform and rebuild their lives. American Psychological Association. http://dx.doi.org/10.1037/10430-000

Maruna, S. (2010). Understanding desistance from crime. Ministry of Justice: National Offender Management Service. Retrieved from http://www.safeground.org.uk/wpcontent/uploads/Desistance-Fact-Sheet.pdf.

Maruna, S. \& Mann, R. (2019). Reconciling 'desistance' and 'what works'. HM Inspectorate of Probation. Retrieved from: https://www.justiceinspectorates.gov.uk/hmiprobation/wpcontent/uploads/sites/5/2019/02/Academic-Insights-Maruna-and-Mann-Feb-19-final.pdf 
Masten, A. S., \& Coatsworth, J. D. (1998). The development of competence in favorable and unfavorable environments: Lessons from research on successful children. American Psychologist, 53(2), 205-220. https://doi.org/10.1037/0003-066X.53.2.205

McGuire, J. (2002). Motivation for what? Effective programs for motivated offenders. In Hollin, C. R. \& McMurran, M. (Eds.), Motivating offenders to change: A guide to enhancing engagement in therapy (157-168). England: John Wiley \& Sons Ltd.

McGuire, J., \& Hatcher, R. (2001). Offense-focused problem solving: Preliminary evaluation of a cognitive skills program. Criminal Justice and Behavior, 28(5), 564-587. https://doi.org/10.1177/009385480102800502

McMurran, M. (2009). Motivational interviewing with offenders: A systematic review. Legal and Criminological Psychology 14, 83-101. https://doi.org/10.1348/135532508X278326

McMurran, M. (2002). Motivation to change: Selection criterion or treatment need? In McMurran, M. (Eds.), Motivating offenders to change: A guide to enhancing engagement in therapy (3-14). England: John Wiley \& Sons Ltd.

McMurran, M., \& Ward, T. (2010). Treatment readiness, treatment engagement and behaviour change. Criminal Behaviour and Mental Health, 20, 75-85. https://doi.org/10.1002/cbm.762

Meyers, L.S., Gamst, G., Guarino, A.J. (2006). Applied multivariate research: Design and interpretation. California, US: Sage Publications. 
Millson, W.A., Weekes, J.R., Lightfoot, L.O. (1995). The offender substance abuse pre-release program: Analysis of intermediate and post-release outcomes. Retrieved from: http://www.csc-scc.gc.ca/research/r40e-eng.shtml\#res

Mitchell, M. M., Spooner, K., Jia, D., \& Zhang, Y. (2016). The effect of prison visitation on reentry success: A meta-analysis. Journal of Criminal Justice, 47, 74-83. https://doi.org/10.1016/i.jcrimjus.2016.07.006

Morizot, J., \& Le Blanc, M. (2007). Behavioral, self, and social control predictors of desistance from crime: A test of launch and contemporaneous effect models. Journal of Contemporary Criminal Justice, 23(1), 50-71. https://doi.org/10.1177/1043986206298945

Mossière, A., \& Serin, R. (2014). A critique of models and measures of treatment readiness in offenders. Aggression and Violent Behavior, 19(4), 383-389. https://doi.org/10.1016/j.avb.2014.06.004

Mossman, D. (2013). Evaluating risk assessments using receiver operating characteristic analysis: Rationale, advantages, insights, and limitations. Behavioral Sciences \& the Law, 31, 23-29. https://doi.org/10.1002/bs1.2050

National Institute of Corrections (n.d.) Thinking for a change. Retrieved from: https://nicic.gov/thinking-for-a-change

Neumann, C.S., Hare, R.D., Johansson, P.T. (2013). The Psychopathy Checklist-Revised (PCLR), low anxiety, and fearlessness: A structural equation modeling analysis. Personality Disorders: Theory, Research, and Treatment, 4(2), 129-137. Doi: 10.1037/a0027886 
O'Brien, K., \& Daffern, M. (2017). Treatment gain in violent offenders: The relationship between proximal outcomes, risk reduction and violent recidivism. Psychiatry, Psychology and Law, 24(2), 244-258. http://dx.doi.org/10.1080/13218719.2016.1209804

Olver, M. E., \& Wong, S. C. P. (2009). Therapeutic responses of psychopathic sexual offenders: Treatment attrition, therapeutic change, and long-term recidivism. Journal of Consulting and Clinical Psychology, 77(2), 328-336. https://doi.org/10.1037/a0015001

Patternoster, R., Bachman, R., Kerrison, E., O’connell, D., \& Smith, L. (2016). Desistance from crime and identity: An empirical test with survival time. Criminal Justice and Behavior, 43(9), 1204-1224. https://doi.org/10.1177/0093854816651905

Pearson, F. S., Lipton, D. S., Cleland, C. M., \& Yee, D. S. (2002). The effects of behavioral/cognitive-behavioral programs on recidivism. Crime and Delinquency, 48(3), 476-496. https://doi.org/10.1177/001112870204800306

Pernanen, K., Cousineau, M., Brochu, S., \& Sun, F. (2002). Proportions of crimes associated with alcohol and other drugs in Canada. Canadian Centre on Substance Abuse. Retrieved from: http://www.ccsa.ca/Resource\%20Library/ccsa-009105-2002.pdf

Petras, H., Nieuwbeerta, P., \& Piquero, A. R. (2010). Participation and frequency during criminal careers across the life span. Criminology, 48(2), 607-637. https://doi.org/10.1111/j.1745-9125.2010.00197.x

Pithers, W.D., Kashima, K.M., Cummings, G.F., Beal, L.S., \& Buell, M.M. (1988). Relapse prevention in sexual aggression. In R.A. Prentky \& V.L. Quinsey (Eds.), Human sexual 
aggression; Current perspectives (pp. 244-260). New York: Annals of the New York Academy of Sciences.

Polaschek, D. L. L. (2012). An appraisal of the Risk-Need-Responsivity (RNR) model of offender rehabilitation and its application in correctional treatment. Legal and Criminological Psychology, 17(1), 171-189. https://doi.org/10.1111/j.20448333.2011.02038.x

Polaschek, D.L. (2016) Desistance and dynamic risk factors belong together, Psychology, Crime \& Law, 22:1-2, 171-189,DOI: 10.1080/1068316X.2015.1114114

Prati, G., \& Pietrantoni, L. (2009). Optimism, social support, and coping strategies as factors contributing to posttraumatic growth: A meta-analysis. Journal of Loss and Trauma. https://doi.org/10.1080/15325020902724271

Porter, S., Birt, A. R., \& Boer, D. P. (2001). Investigation of the criminal and conditional release profiles of Canadian federal offenders as a function of psychopathy and age. Law and Human Behavior, 25(6), 647-661. https://doi.org/10.1023/A:1012710424821

Prochaska, J.O., DiClemente, C.C. (1983). Stages and processes of self-change of smoking: Toward an integrative model of change. Journal of Consulting and Clinical Psychology, 51(3), 390-395.

Public Safety Canada. (2016). Correctional and conditional release statistical overview. Retrieved from Public Safety Canada website: http://www.publicsafety.gc.ca 
Public Safety Canada (2010). The same risk factors predict most types of recidivism. Keeping Canadians Safe, 15(4). Retrieved from: https://www.publicsafety.gc.ca/cnt/rsrcs/pblctns/smrsk-fctrs/index-en.aspx

Qiu, W., Chavarro, J., Lazarus, R., and Ma, J. (2018). Package 'powerSurvEpi'. Retrieved from: https://cran.r-project.org/web/packages/powerSurvEpi/powerSurvEpi.pdf.

Ramakers, A., Nieuwbeerta, P., Van Wilsem, J., \& Dirkzwager, A. (2017). Not just any job will do: A study on employment characteristics and recidivism risks after release. International Journal of Offender Therapy and Comparative Criminology, 61(16), 1795-1818. https://doi.org/10.1177/0306624X16636141

Reynolds, C. R., \& Livingstone, R. B. (2012). Mastering modern psychological testing: Theory and methods. Harlow, UK: Pearson Education Limited.

Rice, M. E., \& Harris, G. T. (2005). Comparing effect sizes in follow-up studies: ROC area, Cohen's d, and r. Law and Human Behavior. https://doi.org/10.1007/s10979-005-6832-7

Rotter, J. B. (1966). Generalized expectancies for internal versus external control of reinforcement. Psychological Monographs, 80(1), 1-28. Retrieved from: https://pdfs.semanticscholar.org/161c/b7ac92d7571042bb11ebdaaa1175be8079f8.pdf

Ruxton, G.D., Beauchamp, G. (2008). Some suggestions about appropriate use of Kruskal-Wallis test. Animal Behaviour, 76, 1083-1087. doi:10.1016/j.anbehav.2008.04.011 
Ryan, R. M., \& Deci, E. L. (2000). Self-determination theory and the facilitation of intrinsic motivation, social development, and well-being. American Psychologist, 55(1), 68-78. https://doi.org/10.1037/0003-066X.55.1.68

Serin, R. (2018). Client change scale: Community version. [Measurement Instrument]. Unpublished instrument.

Serin, R. (2017). The Dynamic Risk Assessment Scale for Offender Re-entry (DRAOR): Guidelines for case planning and risk management using structured assessment of dynamic risk and protective factors. Unpublished user-manual.

Serin, R. (2007). The dynamic risk assessment scale for offender re-entry (DRAOR). Unpublished scale. Carleton University, Ottawa Ontario.

Serin, R. C., Chadwick, N., \& Lloyd, C. D. (2016). Dynamic risk and protective factors. Psychology, Crime \& Law, 22(1-2), 151-170. https://doi.org/10.1080/1068316X.2015.1112013

Serin, R., \& Gobeil, R. (2014). An analysis of the use of the structured decisionmaking framework in three states. National Institute of Corrections: US Department of Justice. Retrieved from: https://info.nicic.gov/nicrp/system/files/028408.pdf

Serin, R., \& Gobeil, R. (2010). Parole decision making. In Brown, J. M., \& Campbell, E. A. (Eds.). (2010). The cambridge handbook of forensic psychology (251-256) Retrieved from http://ebookcentral.proquest.com 
Serin, R. C., \& Lloyd, C. D. (2009). Examining the process of offender change: The transition to crime desistance. Psychology, Crime and Law, 15(4), 347-364. https://doi.org/10.1080/10683160802261078

Serin, R.C., Lloyd, C.D., \& Hanby, L.J. (2010). Enhancing offender re-entry: An integrated model for enhancing offender re-entry. European Journal of Probation, 2 (2), 53-75.

Serin, R. C., Lloyd, C. D., Helmus, L., Derkzen, D. M., \& Luong, D. (2013). Does intraindividual change predict offender recidivism? Searching for the Holy Grail in assessing offender change. Aggression and Violent Behavior, 86. https://doi.org/10.1016/j.avb.2012.09.002

Serin, R. C., \& Lowenkamp, C. T. (2015). Drug court practioners fact sheet: Selecting and using risk and need assessments. A report provided to the National Association of Drug Court Professionals. https://www.bexar.org/DocumentCenter/View/11790/Selecting-and-Using$\underline{\text { Risk-and-Need-Assessments }}$

Seshan, V.E., Gonen, M., \& Begg, C.B. (2012). Comparing ROC curves derive from regression models. Statistics in Medicine, 32(9). DOI: https://doi.org/10.1002/sim.5648

Shah, R. (2017). The meaning of rehabilitation and its impact on parole: There and back again in California. New York: Routledge.

Shrout, P. E., \& Fleiss, J. L. (1979). Intraclass correlations: Uses in assessing rater reliability. Psychological Bulletin 86(2), 420-428. https://doi.org/10.1037/0033-2909.86.2.420 4 Sibai, A.M. (2005). A positive or a negative confounding variable? A simply teaching guide for clinicians and students. Annals of Epidemiology, 15(6), DOI:10.1016/j.annepidem.2004.10.004 
Smith, P., Gendreau, P., \& Swartz, K. (2009). Validating the principles of effective intervention: A systematic review of the contributions of meta-analysis in the field of corrections. Victims and Offenders, 4(2), 148-169. https://doi.org/10.1080/15564880802612581

Soulakova, J. N., Tang, C.-Y., Leonardo, S. A., \& Taliaferro, L. A. (2018). Motivational benefits of social support and behavioural interventions for smoking cessation. Journal of Smoking Cessation, 1-11. https://doi.org/10.1017/jsc.2017.26

Stewart, L.A., Usher, A., \& Vandermey, K. (2015). Validation of the generic program performance measure for correctional programs. Criminal Justice and Behavior, 42, 856871.

Stoltzfus, J. C. (2011). Logistic regression: A brief primer. Academic Emergency Medicine, 18, 1099-1104. https://doi.org/10.1111/j.1553-2712.2011.01185.x

Stouthamer-Loeber, M., Wei, E., Loeber, R., \& Masten, A. S. (2004). Desistance from persistent serious delinquency in the transition to adulthood. Development and Psychopathology, 16(4), 897-918. https://doi.org/10.1017/S0954579404040064

Strubb, D.S., Douglas, K.S., Nicholls, T.L. (2014). The validity of version 3 of the HCR-20 Violence Risk Assessment scheme amongst offenders and civil psychiatric patients. International Journal of Forensic Mental Health, 13(2), 148-159. DOI: $10.1080 / 14999013.2014 .911785$

Sutherland, R., Sindicich, N., Barrett, E., Whittaker, E., Peacock, A., Hickey, S., \& Burns, L. (2015). Motivations, substance use and other correlates amongst property and violent 
offenders who regularly inject drugs. Addictive Behaviors, 45, 207-213. https://doi.org/10.1016/j.addbeh.2015.01.034

Tierney, D. W., \& McCabe, M. P. (2005). The utility of the Trans-theoretical Model of Behavior Change in the treatment of sex offenders. Sexual Abuse: A Journal of Research and Treatment, 17(2), 153-170. https://doi.org/10.1007/sl

Tripodi, S. J., Kim, J. S., \& Bender, K. (2010). Is employment associated with reduced recidivism? The complex relationship between employment and crime. International Journal of Offender Therapy and Comparative Criminology, 54(5), 706-720. https://doi.org/10.1177/0306624X09342980

Turner, S., \& Fain, T. (2006). Validation of the risk and resiliency assessment tool for juveniles in the Los Angeles County probation system. Federal Probation, 70(2), 49-57. Retrieved from

http://search.ebscohost.com/login.aspx?direct=true\&db=cja\&AN=24036751\&site=ehostlive

Ullrich, S., \& Coid, J. (2011). Protective factors for violence among released prisoners-- Effects over time and interactions with static risk. Journal of Consulting and Clinical Psychology, 79(3), 381-390. https://doi.org/10.1037/a0023613

Velicer, W. F., DiClemente, C. C., Prochaska, J. O., \& Brandenburg, N. (1985). Decisional balance measure for assessing and predicting smoking status. Journal of Personality and Social Psychology, 48(5), 1279-1289. https://doi.org/10.1037/0022-3514.48.5.1279 
Velicer, W. F., Prochaska, J. O., Fava, J. L., Norman, G. J., \& Redding, C. A. (1998). Smoking cessation and stress management: Applications of the transtheoretical model of behavior change. Homeostasis in Health and Disease, 38(5-6), 216-233.

Vergouwe, Y., Steyerberg, E. W., Eijkemans, M. J. C., \& Habbema, J. D. F. (2005). Substantial effective sample sizes were required for external validation studies of predictive logistic regression models. Journal of Clinical Epidemiology, 58, 475-483. doi:10.1016/j.jclinepi.2004.06.017

Veysey, B. M., Christian, J., \& Martinez, D. J. (2009). Identity transformation and offender change. In Veysey, B. M., Christian, J., \& Martinez, D. J (Eds.), 1-11. How offenders transform their lives. Canada: Willan Publishing.

Viets, V. L., Walker, D.D., \& Miller, W. R. (2002). What is motivation to change? A scientific analysis. In McMurran, M. (Eds.), Motivating offenders to change: A guide to enhancing engagement in therapy (15-30). England: John Wiley \& Sons Ltd.

Ward, T., Yates, P. M., \& Willis, G. M. (2012). The good lives model and the risk need responsivity model. Criminal Justice and Behavior, 39(1), 94-110. https://doi.org/10.1177/0093854811426085

Ward, T., Melser, J., \& Yates, P. M. (2007). Reconstructing the Risk-Need-Responsivity model: A theoretical elaboration and evaluation. Aggression and Violent Behavior, 12, 208-228. https://doi.org/10.1016/j.avb.2006.07.001

Wardrop, K., Serin, R., \& Rentler, D. (2019). Evaluating the Structured Parole Decision Making Framework in three U.S. States. The American Journal of Forensic Psychology, 37, 5-30. 
Warren, J. I., \& South, S. C. (2009). A symptom level examination of the relationship between Cluster B personality disorders and patterns of criminality and violence in women. International Journal of Law and Psychiatry, 32(1), 10-17. https://doi.org/10.1016/j.ijlp.2008.11.005

Weisberg, R., Mukamal, D. A., Segall, J. D. (2011). Life in limbo: Parole release for prisoners serving life sentences with the possibility of parole in Claifornia. Retrieved from: https://law.stanford.edu/wpcontent/uploads/sites/default/files/publication/259833/doc/slspublic/SCJC\%20Lifer\%20Par ole \%20Release $\% 20$ Sept $\% 202011 . p d f$

Williamson, P., Day, A., Howells, K., Bubner, S., \& Jauncey, S. (2003). Assessing offender readiness to change problems with anger. Psychology, Crime \& Law, 9(4), 295-307. doi: http://dx.doi.org.proxy.library.carleton.ca/10.1080/1068316031000073371

Wilson, N. J. (2014). Review of PhD research by Laura Hanby on the ability of the Dynamic Risk Assessment for Offender Re-entry (DRAOR) to identify risk and desistance for NZ parolees (2010-2012). The New Zealand Corrections Journal, 2(1), 9-12.

Williamson, P., Day, A., Howells, K., Bubner, S., \& Jauncey, S. (2003). Assessing offender readiness to change problems with anger. Psychology, Crime, and Law, 9(4), 295-307, DOI: $10.1080 / 1068316031000073371$

Wilson, R. J., Cortoni, F., \& McWhinnie, A. J. (2009). Circles of support \& accountability: A Canadian national replication of outcome findings. Sexual Abuse: Journal of Research and Treatment, 21(4), 412-430. https://doi.org/10.1177/1079063209347724 
Woldgabreal, Y., Day, A., \& Ward, T. (2015). Linking positive psychology to offender supervision outcomes: The mediating role of psychological flexibility, general self-efficacy, optimism, and hope. Criminal Justice and Behavior, 43(6), 697-721. https://doi.org/10.1177/0093854815620816

Wolff, K. T., \& Baglivio, M. T. (2017). Adverse childhood experiences, negative emotionality, and pathways to juvenile recidivism. Crime and Delinquency, 63(12), 1495-1521. https://doi.org/10.1177/0011128715627469

Wood, P.B., Wilson, J.A., and Thorne, D. P. (2015). Offending patterns, control balance, and affective rewards among convicted sex offenders. Deviant Behavior, 36(5), 368-387. doi:10.1080/ 01639625.2012.707550

Yang, M., Guo, B., Olver, M. E., Polaschek, D. L. L., \& Wong, S. C. P. (2017). Assessing associations between changes in risk and subsequent reoffending: An introduction to relevant statistical models. Criminal Justice and Behavior, 44(1), 59-84. https://doi.org/10.1177/0093854816678648

Yang, Y., Knight, K., Joe, G. W., Rowan-Szal, G. A., Lehman, W. E. K., \& Flynn, P. M. (2013). The influence of client risks and treatment engagement on recidivism. Journal of Offender Rehabilitation, 52(8), 544-564. https://doi.org/10.1080/10509674.2013.840353

Yang, M., Wong, S. C. P., \& Coid, J. (2010). The efficacy of violence prediction: A metaanalytic comparison of nine risk assessment tools. Psychological Bulletin, 136(5), 740-767. https://doi.org/10.1037/a0020473 
Yesberg, J. A., \& Polaschek, D. L. L. (2015). Assessing dynamic risk and protective factors in the community: examining the validity of the Dynamic Risk Assessment for Offender Reentry. Psychology, Crime and Law, 21(1), 80-99. https://doi.org/10.1080/10683

Yesberg, J. A., \& Polaschek, D. L. L. (2014). What can the DRAOR tell us about high risk offenders? A preliminary examination. Practice, 2(1), 13-19. Retrieved from http://www.corrections.govt.nz/ data/assets/pdf file/0011/736265/COR-Practice-JournalVol2-Iss1-April14-v4lowres.pdf

Yoder, J., \& Caserta, D. A. (2018). Associations between substance use in commission of sexual crimes and offense characteristics among youth: Mitigating effects of substance use treatment. International Journal of Offender Therapy and Comparative Criminology, 62(3), 655-675. https://doi.org/10.1177/0306624X16651903

Youssef, C., Casey, S., \& Day, A. (2016). Desistance: The "other side" of change and implications for maintenance programs. Journal of Offender Rehabilitation, 55(7), 443465. https://doi.org/10.1080/10509674.2016.1216913 


\section{Appendix A}

\section{DOB:} Gender:

\section{Ralph C. Serin, Carleton University \\ Client Change Scale (CCS) - Community Version} Ethnicity:

Risk score/risk bin/risk group:

The purpose of the CCS is to systematically assess and re-assess constructs and indicators relating to client change. It is deliberately not organized according to program content, instead is items are designed to generalize across program types and tap into foundational change processes relevant to all justice involved client types. Further, it emphasizes both internal and external aspects of change that are highlighted in crime desistance research (Maruna, 2010). It is expected that higher scores will relate to more successful client outcome, whether that is program completion versus dropout or success on release versus technical violations or recidivism. Hence, the CCS is intended to be used to gauge success on supervision as well as progress in treatment. Ideally, it is completed during regular (monthly) supervision sessions and pre, middle and post-programming for either individual or group-based intervention.

Tracking such change and providing feedback to clients is intended to encourage and support those making progress, while simultaneously challenging those whose progress is less than desired. Utilization of the CCS in post-program reports can provide a systematic explanation of client effort and change. Moreover, classification staff could use client change as reflected in the CCS as an important rationale for transfer to reduced security.

\section{Motivation level}

Motivation has been operationally defined as "the probability that a person will enter into, continue, and adhere to a specific strategy". As such it is a dynamic variable reflecting both internal and external factors (Ward, et al., 2004). Importantly, higher risk clients with low motivation have poorer correctional outcomes. Increased motivation should reflect stated intentions to change with consistent behavioral exemplars.

2 Client is self-motivated, verbally expresses a commitment to change, citing internal and external reasons for change.

1 Client may not fully accept overall assessment and is ambivalent about the need for change, but can provide a reason for changing

0 Client rejects the need for change.

\section{Stage of Change}

The Transtheoretical Model asserts that client change is cyclical, interspersed with periods of challenge and progress. It has been applied to correctional samples with some success and is intuitively appealing to staff and clients. Research indicates change measured by stages incrementally predicts client outcome even when controlling for pre-program risk (Olver et al., 2017). While less fluid than ratings of motivation, consistency of intentions, planning and behavior are required. It is not uncommon for clients to move up and down, especially early in the change process. Desisting justice involved clients recognize that change is not immediate.

2 Client is in Action or Maintenance phase - The action stage involves having made a commitment to change and engaging in actions to bring about change. Lastly, the maintenance stage works to sustain the significant changes made and individuals actively work to prevent relapse. 
1 Client is in Contemplation or Determination stage - The contemplation stage is characterized by ambivalence, whereby individuals may simultaneously consider and reject reasons to change, or alternate between the two. The determination stage involves intention and planning behavior.

0 Client is in precontemplation stage - rejects the need for change and is unwilling to participate in recommended programs or other interventions.

\section{Compliance with supervision conditions}

This item is intended to identify clients who recognize and express the understanding that rules and guidelines are intended to help them be successful as they progress through the Criminal Justice System. High scorers will meet expectations regarding conditions; they will not reject or debate the merits of meeting staff expectations to follow certain conditions of community supervision. Low scorers will consistently fail to follow rules (i.e., be late or miss appointments, fail to complete assigned work, fail urinalysis testing).

2 Client is attentive and engaged to receive guidance about finding strategies and activities that will help them stay crime-free in the future. Client is compliant with rules and expresses a high motivation to complete supervision.

1 Client does not fully accept overall risk and need assessment and is ambivalent at best about following staff rules. Alternatively, verbalizes agreement but then rejects efforts for cooperation, often making up excuses for noncompliance.

(0 Client rejects authority and the merit to follow any rules or guidelines assigned to them. Very much views interaction with staff as an "us" versus "them" situation.

\section{Engagement in changing}

Related to compliance with rules and conditions, this item refers to how well the client is engaged or invested in the change process. Engagement could be driven by either internal or external factors; alone or in combination, they have been demonstrated to influence client change (LeBel, Burnett, Maruna \& Bushway, 2008).

This item refers to the client expressing openness to receive and take guidance for making lifestyle changes that will lead toward a long-term, crime-free lifestyle. This is the "Do I care, do I listen, and do I act?" component of the beliefs that support a process of desisting from crime.

2 Client accepts overall assessment and Correctional Plan and demonstrates behavior consistent with this (attends group, is not late for meetings/work, completes homework).

1 Client may not fully accept overall assessment and is ambivalent about participating in Correctional Plan or states interest in participation but behavior is weak or inconsistent with stated intentions (late for meetings/work, doesn't follow through on things).

( Client is unwilling to participate in recommended programs or other interventions. 


\section{Effort in changing}

Change requires motivation but also effort. More skilled clients may achieve change with less effort and some clients may work very hard at change but fall short of competency for a crimefree life. This item only considers how much effort the client demonstrates while engaged in the change process. Desisting justice involved clients recognize that change requires sustained effort. This is rated over the past 60 days.

2 Client demonstrates considerable effort in the change process. This need not be restricted to only group-based intervention. Clients who score 2 will work outside of formal programming or supervision sessions. Clients will complete tasks on time, with reflection, and feedback will be sought to ensure they achieve competency.

1 Client makes somewhat limited or minimal effort. Homework will be completed but only in a haphazard manner. Group interaction will be minimal, but not disruptive. Essentially, a client who scores 1 will not go the extra steps to change, presuming simple participation will result in change. Client does the basic minimum.

0 Client shows up but is often late and may miss sessions with no satisfactory reason. Homework is rarely done or done superficially. Client does less than the basic minimum or rejects the need to try, believing no effort is required. "I can stop doing crime whenever I choose.

\section{Identity}

A crucial aspect of desistance from crime is a change in the client's identity from being an active criminal to someone committed to a crime-free life (Maruna, 2010). This shift is not swift and may involve setbacks, but the key point is the client's self-perception. This item refers to the client's internal self-image. This is the "Who am I?" component of the beliefs that support a process of desisting from crime. The purpose of this item is to assess whether the client can imagine and articulate a "future self" that feels comfortable, fulfilled, and satisfied in a fully noncriminal lifestyle.

2 Client can articulate a non-criminal self-image that feels satisfying and fulfilling to them. Client currently discusses their personal identity in a purely prosocial fashion, i.e., "family man", "role model for troubled kids", "diligent worker", with evidence that they behave consistently with this identity.

1 Client articulates a desire to be viewed by others as a non-criminal, but there is evidence of ambivalence regarding putting in effort to make that identity consistent with their behavior. Client can only describe a weak or superficial non-criminal self-image they desire to attain for themselves. This self-image is not fully formed, or client appears to be dissatisfied by the idea of attaining that identify for themselves.

(0 Client expresses pleasure or enjoyment at the thought of being viewed and interacting with others as "criminal". Client is dismissive of individuals who consider themselves conventional, prosocial, or contributing members of society, viewing them as losers. 


\section{Agency for positive change}

Sometime referred to as self-efficacy, agency is the realistic belief and expectation by the client that change is not only possible but also likely. This is not a naïve, unrealistic expectation but more a sober reflection by the client that change is possible, with effort and support. Simple statement by the client that they can change is not agency, without demonstrated elements of efficacy.

2 Client expresses or demonstrates confidence in their ability to effect change in their life that leads to a completely crime-free life.

1 Client expresses or demonstrates some clear hesitancy about their ability to face the challenges involved in attaining a crime-free life

( Client expresses or demonstrates a belief that effecting change in their life or attaining a crime-free life is beyond their ability or control or are uninterested in change.

\section{Explanatory style}

This item considers a client's views regarding explanations for positive and negative events occurring in their lives. Active justice involved clients are more inclined to explain negative events as due to the influence of others (i.e., beyond their control) and positive prosocial events as due to chance (i.e., "I got lucky"). In contrast, desisting justice involved clients consider that positive events are due to their own efforts (i.e., "I worked for this and deserve it") while negative events are due to chance (i.e., "things happen but this does not define me") and therefore beyond their direct control. These perceptions are consistent with agentic explanations of behaviour and are thought to influence client' propensity for persistence in or desistance from crime.

2 Client is accountable for their behavior. They report and understand the consistency between stated intentions and behavior. Client accepts personal accountability and ownership of their criminal behavior.

1 Client is somewhat accountable for their behavior. They remain likely to blame others for negative events but somewhat recognizes the need for personal accountability and ownership of their criminal behavior.

(0 Client reflects no appreciation that they are authors of their own destiny. They deflect blame for negative events and feel powerless to influence positive events. Client fully rejects personal accountability and ownership of their criminal behavior.

\section{Expectations about change}

Expectations about change combines positive benefits for desisting from crime (stability, improved prosocial supports, prosocial respect) and negative costs (always fearing police, prison sentence) for continuing a criminal lifestyle. In contrast, chronic, active justice involved clients can only see benefits for continued criminality (easy money, hedonistic lifestyle, status, recreational drugs) and negative costs for ceasing crime (lack of status, poor paying jobs, boredom). 
2 Client clearly views attempts to give up crime as a worthwhile and valuable goal for their life.

1 Client recognizes that some positive consequences may result from attempts to give up crime.

0 Client expresses no positive benefits for attempting to give up crime.

\section{Social supports and peers}

This item refers to whether clients have any meaningful relationships with non-criminal individuals, especially individuals who assist the client by offering relational (and/or material) support to the client. It also refers to the nature and frequency of associations with prosocial individuals. Social supports could be volunteers, church groups, mentors, employers, or anyone that espouses prosocial views and to whom the client looks for support and guidance to sustain a prosocial life.

2 Client only has contact with prosocial, non-criminal others. Client's close, most meaningful relationships are with supportive, non-criminal individuals. Client is embedded in social groups that do not engage in situations that would put the client at risk for future crime.

1 Client has some, but limited contact with prosocial, non-criminal others, but appears to be engaged and influenced by these relationships when there is contact. Client receives some relational or material support from non-criminal family members, but it is unclear if contact with them is meaningful to client.

0 Client reports no relationships with prosocial, non-criminal others. Client has only minor contact with prosocial relationships, and this contact does not seem relevant, substantial, or meaningful to the client.

\section{Stability of employment}

The goal of this item is to assess the client's current employment status, and their perceptions of their employment status. Other considerations surrounding employment have additional relevance. Specifically, (a) employability (i.e., does the client have the necessary skills to join the workforce?), (b) engagement (i.e., is the client currently satisfied with existing employment?), and (c) effort (i.e., is the client motivated to gain or maintain employment?).

2 Prior to incarceration, client was employed in a job they enjoyed, seek to maintain, and caused no problems for the client. Client currently employed in a job they enjoy and seek to maintain

1 Prior to incarceration, client was unemployed due to reasons that might be outside their control, but the client was spending daytime hours in productive, prosocial ways. Client is currently unemployed, but was actively seeking a job or skill-training.

0 Prior to incarceration, client was unemployed without relevant reason. Client is/was unemployed, reports wanting employment in the future, but there is no evidence of effort to do so, or efforts are unrealistic. Client is/was working at a job that likely exposed them to high-risk situations for future crime, and client intends to return to the same occupation after release. Client 
is/was employed in a job that was not a good fit, was short-term, or was otherwise problematic in some way.

\section{Stability of accommodation}

This item primarily assesses whether or not the client is currently living in stable, long-term housing. Stable housing can be considered on a continuum from lack of any suitable housing, or homelessness (a definite problem), temporary or possibly problematic housing situations, such as residence at a halfway house, or "couch surfing" (a possible problem), to safe, suitable, longterm housing (not a problem).

2 Client is living in a stable, long-term, non-criminal environment. Client is living in supported housing (e.g., a halfway house), but has made firm plans for more suitable, stable housing for a later date. No change is required.

1 Client has a current fixed address, but it is short-term or otherwise unsuitable for the longterm future. Client is living in supported housing (e.g., a halfway house), and has not made plans to find more suitable, stable housing for a later date. Some change is required.

0 Client is homeless, without a fixed address. Client is living in the same environment that appeared to trigger their previous criminal behavior. Changes are required.

\section{Substance use}

This item refers to use of unauthorized substances, including illegal drugs, and the misuse of other substances, including prescription drugs and alcohol. It is important to consider how past substance use was related to previous and current crime. Did substance use trigger the client to commit crime? Similarly, what is the client's typical level of substance use? Also, what is the client's current relationship with their substance use?

The goal of this item is to assess recent problematic use and misuse of substances, especially to identify recent uncontrolled changes in typical substance use.

2 Client is abstinent from substance use (supported by urinalysis, if need be). Client is active user of recovery support services, with no lapse. Client uses legal substances at normative levels in ways that appear to be under the client's control, even if patterns of use are unhealthy or not recommended (i.e., regular weekend alcohol binges that do not lead to criminal behavior). Prior to incarceration, client maintained non-problematic substance use (i.e., using substances that are not associated with past criminal activity, or legal substance use that appears to be under the client's control).

1 Client has experienced a lapse from substance recovery in the community or custodial setting, which is generally uncharacteristic given recent abstinence efforts. Client has shown active attempts at recovery from substance use, but expresses some ambivalence with their recovery attempts. Client has recent history of substance misuse, but is currently extending strong effort to seek recovery services and attain abstinence.

0 Client was engaged in illegal or clearly problematic substance use prior to incarceration. Client has more than 1 lapse within the past 3 months while on community supervision. Leading up to 
incarceration, client has exhibited a substantial change in the amount of substances used, or returned to using a substance that is particularly problematic within their criminal history. Client has engaged in substance use in the custodial setting, and demonstrates no interest or effort in reducing their substance use.

\section{Problem-solving}

This item refers to the client's ability to find solutions to their life problems in a way that takes them away from risk situations and criminal behavior. Good problem solvers consider short and long-term consequences of their behaviour.

2 Client has no recent examples of poor problem-solving, and demonstrates the ability to generate multiple non-criminal solutions to problems in multiple life domains. Client expresses motivation to solve problems with non-criminal solutions, and seeks and follows advice when encountering difficulties with generating solutions. Client considers short and long-term consequences.

1 Examples of poor problem-solving are occasional and / or problematic, but not devastating. Client can generate only shallow or unrealistic solutions for solving life problems in a noncriminal way, but also demonstrates some openness to hearing and taking advice about how to solve the problem. Client expresses motivation to solve problems through non-criminal solutions, but needs assistance when breaking down the problem into pieces, choosing courses of action, or maintaining motivation in the face of setbacks. Client demonstrates effort to enact non-criminal solutions to problems, but gets off-track quickly when chosen solutions do not straightforwardly lead to their desired outcome.

0 Examples of poor problem-solving are frequent and / or severe. Client expresses no interest in finding non-criminal solutions to life problems. Client does not believe that it is problematic to ignore an unsolved life difficulty, even though inaction or ignoring the problem will place the client at risk for future crime, or will result in an unfulfilled task that is required by his or her supervision order. Client is undisciplined in attempts to solve life problems, meaning there is either poor ability to think through options and their consequences, or courses of action are chosen impulsively, without thinking. Client is half-hearted in attempts to solve problems or fulfil responsibilities, and shows little or no serious attempt to follow-through or persist with noncriminal solutions when setbacks appear.

\section{Self-regulation/affect management}

Clients may be aware they want to avoid harmful behaviors, but consistently fail when "negatively influenced by emotions. In addition, this item refers to the presence of unpleasant emotions, especially agitation, distress, anxiety, stress, or sadness.

The goal of this item is to assess current negative feelings and how effectively the client can manage them. Negative moods may be self-reported by the client, or the client may present as depressed or distressed within session (for example, displaying crestfallen facial expressions, crying, or moving their body nervously).

2 Client presents as adjusted, calm, or neutral. Client shows a pattern of thoughtful decision making. Client does not report any negative moods in the past two weeks. Client may report 
anticipating future distressing events that may involve feeling negative moods, but is preparing to cope effectively with these feelings.

1 Client self-reports some negative mood, but evidence and collateral information suggests disruptions in mood are mild, not severe, or the client is coping effectively with them. Examples of poor impulse control are occasional, may be problematic, but not devastating.

0 Client is experiencing strong negative moods, without successful effort to cope with them. Client presents as distressed, sad, stressed, restless, or hopeless. Client self-reports feeling strong negative moods in the past two weeks. Client appears to be experiencing some negative moods, and negative mood was previously a precursor prior to their past offending. Examples of poor impulse control are frequent and/or severe.

\section{Sense of entitlement}

This item considers a client's accountability towards others. Low accountability refers to an attitude of self-centeredness, at the expense of regard for other's rights. At its extreme, this refers to a high sense of entitlement by the client. This is often expressed as the client being narcissistic, grandiose, with over-inflated beliefs that they are better, more special, and more deserving than others. Less extreme, but also problematic, limited personal accountability may express itself as narrow focus on one's own needs while failing to consider the impact of personal behaviour on others.

2 Client does not justify past criminal behavior by expressing that they had good reasons to do what they did. Client accepts that he or she may sometimes "lose out" in life, and there are legitimate paths to follow successfully reach one's goals, even if it takes time and / or effort. Client accepts personal accountability.

1 Client has a general "me-first" attitude, but can articulate some limits to their right to have everything they want. Client is preoccupied with beliefs that it is unfair that they have not gotten everything they want out of life, but can be redirected to agree that many aspects of life are out of their control. Client deflects personal accountability.

0 Client expresses preoccupation with being treated with due respect from others, getting what they feel is deserved, and making it known that they have superiority over others. Client shows strong disregard for the rights of others, especially when others' rights would interfere with their goals. Client expresses disdain for or condescension toward victims. Client rejects personal accountability. 


\section{Appendix B}

Douglas, K.S., Hart, S.D., Webster, C.D., Belfrage, H. (2016, October 16). Rating sheet for version 3 of the HCR-20. Retrieved from: http:/hcr-20.com/materials/

\begin{tabular}{|c|c|c|}
\hline Name & \multicolumn{2}{|l|}{ Record Number } \\
\hline DOB & \multicolumn{2}{|l|}{ Gender } \\
\hline \multicolumn{3}{|l|}{ Nature/Purpose of the Evaluation } \\
\hline \multirow[t]{2}{*}{ HCR-20V3 Items } & Presence & Relevance \\
\hline & Omit $\mathrm{N} \quad \mathrm{P} \quad \mathrm{Y}$ & Omit $\mathrm{N} \quad \mathrm{P} \quad \mathrm{Y}$ \\
\hline \multicolumn{3}{|l|}{ Historical Scale (History of problems with...) } \\
\hline \multicolumn{3}{|l|}{ H1. Violence } \\
\hline \multicolumn{3}{|l|}{ H2. Other Antisocial Behaviour } \\
\hline \multicolumn{3}{|l|}{ H3. Relationships } \\
\hline \multicolumn{3}{|l|}{ H4. Employment } \\
\hline \multicolumn{3}{|l|}{ H5. Substance Use } \\
\hline \multicolumn{3}{|l|}{ H6. Major Mental Disorder } \\
\hline \multicolumn{3}{|l|}{ H7. Personality Disorder } \\
\hline \multicolumn{3}{|l|}{ H8. Traumatic Experiences } \\
\hline \multicolumn{3}{|l|}{ H9. Violent Attitudes } \\
\hline \multicolumn{3}{|l|}{ H10. Treatment or Supervision Response } \\
\hline \multicolumn{3}{|l|}{ OC-H Other Considerations } \\
\hline \multicolumn{3}{|c|}{ Clinical Scale (Recent Problems with...) Rating Period: } \\
\hline \multicolumn{3}{|l|}{ C1. Insight } \\
\hline \multicolumn{3}{|l|}{ C2. Violent Ideation or Intent } \\
\hline \multicolumn{3}{|l|}{ C3. Symptoms of Major Mental Disorder } \\
\hline \multicolumn{3}{|l|}{ C4. Instability } \\
\hline \multicolumn{3}{|l|}{ C5. Treatment of Supervision Response } \\
\hline OC-C Other Considerations & & \\
\hline
\end{tabular}




\begin{tabular}{|c|c|c|c|}
\hline \multicolumn{2}{|c|}{$\begin{array}{l}\text { R1. Professional Services and Plans } \\
\text { R2. Living Situation } \\
\text { R3. Personal Support } \\
\text { R4. Treatment or Supervision Response } \\
\text { R5. Stress or Coping } \\
\text { OC-R Other Considerations }\end{array}$} & & \\
\hline $\begin{array}{c}\text { Future Violence/Case } \\
\text { Prioritization }\end{array}$ & $\begin{array}{c}\text { Serious Physical } \\
\text { Harm }\end{array}$ & Imminent Violence & $\begin{array}{c}\text { Recommended } \\
\text { Reassessment Date }\end{array}$ \\
\hline Low Mod High & Low Mod High & Low Mod High & YY/MM/DD: \\
\hline Evaluator & & Signature & Date: \\
\hline
\end{tabular}




\section{Appendix C}

Hare, R.D. (2016). Psychopathy, the PCL-R, and criminal justice: Some new findings and current issues. Canadian Psychology, 57(1), 21-34. http://dx.doi.org/10.1037/cap0000041

\section{PCL-R}

\begin{tabular}{l}
\hline Factor $\mathbf{1}$ (F1) \\
\hline Interpersonal \\
1. Glibness/suprficial charm \\
2. Grandiose sense of self worth \\
3. Pathological lying \\
4. Conning/manipulative \\
Affective \\
5. Lack of remorse or guilt \\
6. Shallow affect \\
7. Callous/Lack of empathy \\
8. Failure to accept responsibility \\
\hline Factor 2 (F2) \\
\hline Lifestyle \\
1. Need for stimulation \\
2. Parasitic lifestyle \\
3. No realistic, long term goals \\
4. Impulsivity \\
5. Irresponsibility \\
Antisocial \\
1. Poor behavioural controls \\
2. Early behavioural problems \\
3. Juvenile delinquency \\
4. Revoke conditional release \\
5. Criminal versatility
\end{tabular}

